\title{
ANDREA GLEZER
}

Estudo da atividade biológica da macroprolactina

humana em células $\mathrm{Nb2}$ e em células $\mathrm{Ba} / \mathrm{F}-03$ transfectadas

com o receptor de prolactina humano forma longa

Tese apresentada à Faculdade de Medicina da Universidade de São Paulo para obtenção do título de Doutor em Ciências

Área de concentração: Endocrinologia

Orientador: Prof. Dr. Marcello Delano Bronstein

São Paulo

2005 


\section{FICHA CATALOGRÁFICA}

Preparada pela Biblioteca da

Faculdade de Medicina da Universidade de São Paulo

Creprodução autorizada pelo autor

Glezer, Andrea

Estudo da atividade biológica da macroprolactina humana em células $\mathrm{Nb2}$ e em células Ba/F-03 transfectadas com o receptor de prolactina humano forma longa / Andrea Glezer. -- São Paulo, 2005.

Tese(doutorado)--Faculdade de Medicina da Universidade de São Paulo.

Departamento de Clínica Médica.

Área de concentração: Endocrinologia e Metabologia.

Orientador: Marcello Delano Bronstein.

Descritores: 1.HIPERPROLACTINEMIA 2.PROLACTINA 3.ISOFORMAS DE PROTEÍNAS 4.BIOENSAIOS/métodos 5.RECEPTORES DA PROLACTINA 6.PROLACTINOMA

USP/FM/SBD-292/05 
A minha avó Fany Hirsch. Aos meus queridos pais, Itamar e Vera Lucia. Aos meus irmãos, Isaias e Rubens. 


\section{AGRADECIMENTOS}

Agradeço a Deus pela oportunidade de desenvolver este trabalho e por permitir que em meu caminho houvesse tantos amigos e colaboradores. $\mathrm{O}$ aprendizado profissional e pessoal foram profundos e extensos nestes quatro anos de Doutoramento. Agradeço a todos que estiveram ao meu lado, colaborando de alguma maneira para a conclusão deste projeto; infelizmente é impossível citar a todos nominalmente.

À minha família, pelo apoio incondicional. Ao meus avós Frederico Hirsch e Sarah Glezer, em memória. À minha querida avó Fany Hirsch e ao meu avô Owsiej Glezer. Aos meus pais, Itamar e Vera, pela minha existência, claro, por seu amor, pelo ensino da ética e integridade e por garantirem todas as condições ao meu aprendizado técnico. Aos meus irmãos, Isaias e Rubens, por seu companheirismo e pela visão divertida e masculina da vida. Ao meu tio Dr. Roberto Hirsch, por seu exemplo, como brilhante médico e por seu auxílio e incentivo na minha carreira.

Aos meus amigos, especialmente Vanessa Quintas Passos e Adriana Laudanna, por sua companhia constante nos momentos alegres ou difíceis.

A todos os colegas das Unidades de Neuroendocrinologia do Hospital das Clínicas, Diane P. Belchior, Márcio C. Machado, Raquel Jallad, Luis Roberto Salgado, Nina Rosa Musolino e Malebranche Berardo Cunha neto. Em especial, ao Prof. Dr. Marcello Delano Bronstein, orientador desta tese de Doutorado, professor Livre Docente da Disciplina de Endocrinologia do HC-FMUSP e responsável pela Unidade de Neuroendocrinologia do

mesmo serviço, por seu incentivo e apoio desde o início de minha formação em Endocrinologia, abrindo-me as portas do ambiente acadêmico e científico. Agradeço o apoio profissional e pessoal nesta jornada e seu grande exemplo como médico clínico. 
Aos estudantes e profissionais do Laboratório de Investigação Médica LIM-25, da FMUSP. Em especial, ao Prof. Dr. Daniel Giannella Neto, meu co-orientador de fato, professor Livre Docente da Disciplina de Endocrinologia do HC-FMUSP e responsável pelo Laboratório de Endocrinologia Celular e Molecular - LIM-25 da FMUSP. Ao auxílio no início da caminhada ao desconhecido mundo da ciência básica, por seus contatos e incentivo à minha independência como pesquisadora, e pelo seu inestimável auxílio na análise dos resultados.

Ao Departamento de Biotecnologia do IPEN-CNEN, em particular, Dr. Carlos Roberto Soares, por me iniciar nas práticas de bancada e por seu apoio nos momentos de crise, com seu insuperável bom-humor e otimismo. Agradeço ao Dr. Paolo Bartolini, que permitiu a colaboração entre nossos serviços.

Aos profissionais do setor de Endocrinologia do Laboratório Fleury, em especial a Leda Obara, por seu interesse em me auxiliar e seu companheirismo. Agradeço ao Prof. Dr. José Gilberto Vieira, por permitir a colaboração entre nossos serviços e pelo incentivo em meu projeto.

Aos integrantes do Departamento de Endocrinologia e Metabologia do HCFMUSP, como o corpo de enfermagem da Enfermaria e Ambulatório, os secretários Maria Aparecida da Silva, Rosana Zamboni, Rubens José da Silva e Márcia Helena Monteiro. Ao Prof. Dr. Éder C. Rocha Quintão, Profa. Dra Dalva Marreiro Rocha e Profa Dra Berenice Bilharinho de Mendonça, atual Professora titular da Disciplina de Endocrinologia e Metabologia do Departamento de Clínica Médica do Hospital das Clínicas de São Paulo, pelo incentivo no projeto e na participação de diversos congressos importantes na minha área de interesse. 
À equipe do U584 INSERM, da Faculté de Necker, em Paris, em especial ao Dr. Paul Kelly por permitir meu estágio no laboratório sob sua chefia e ao $\mathrm{PhD}$ Vincent Goffin por me receber tão amigavelmente e pelo auxílio em meu trabalho, com críticas construtivas. A todos os estudantes e funcionários que tornaram minha estadia em Paris um período muito agradável.

Aos pacientes do estudo, por sua compreensão e participação desinteressados.

Agradeço ao apoio financeiro da FAPESP (Fundação de Amparo à Pesquisa do Estado se São Paulo), através da bolsa de Doutorado no país, processo 02/00761-7, e auxílio pesquisa, processo 02/02688-5, bem como a CAPES (Coordenação de Aperfeiçoamento de Pessoal de Nível Superior) pelo financiamento do estágio no exterior de doutorando, processo BEX 2381/02-8. 
"La meilleure école de la modestie est la recherche scientifique. L'experience nous montre si souvent que les conceptions que nous estimons les meilleurs sont erronées qu'elle nous guérit de la vanité. "

Dr. Emile Roux

Médico pesquisador do Instituto Pasteur, Paris 
Esta tese está de acordo com:

Referências: adaptado de International Committee of Medical Journals Editors (Vancouver).

Universidade de São Paulo. Faculdade de Medicina. Serviço de Biblioteca e Documentação. Guia de apresentação de dissertações, teses e monografias. Elaborado por Anneliese Carneiro da Cunha, Maria Julia de A. L. Freddi, Maria F. Crestana, Marinalva de Souza Aragão, Suely Campos Cardoso, Valéria Vilhena. São Paulo: Serviço de Biblioteca e Documentação; 2004.

Abreviaturas dos títulos dos periódicos de acordo com List of Journals Indexed in Index Medicus. 


\section{SUMÁRIO}

Lista de Abreviaturas e Siglas

Lista de Símbolos

Lista de Fórmulas

Lista de Figuras

Lista de Tabelas

Resumo

Summary

1. Introdução

1.1 Prolactina: estrutura e funções ..................................................................... 2

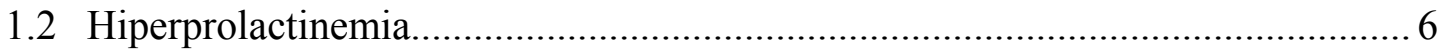

1.3 Isoformas de prolactina e implicações clínicas .................................................... 7

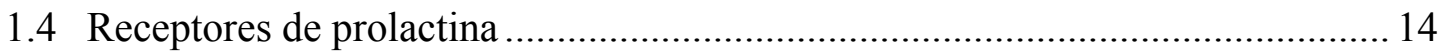

1.5 Bioensaios para prolactina e bioatividade da macroprolactina in vitro .............. 15

2. Objetivos ................................................................................................................................................. 17

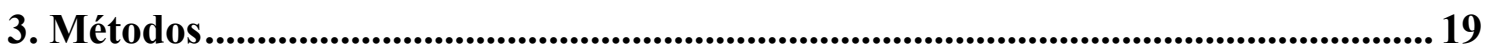

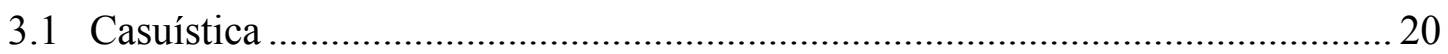

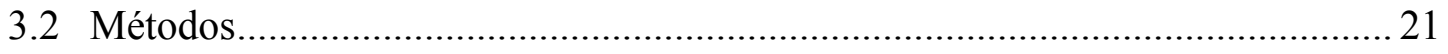

3.2.1 Avaliação clínica ............................................................................. 21

3.2.2. Avaliação laboratorial ...................................................................... 22

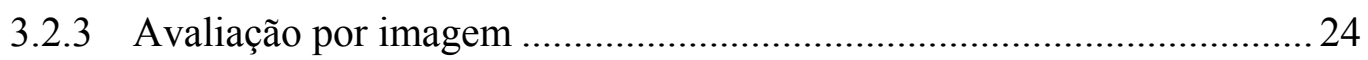

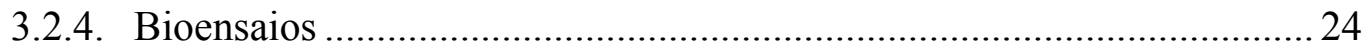

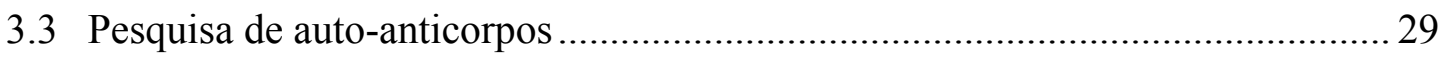

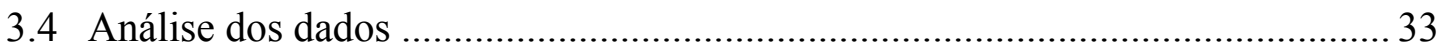

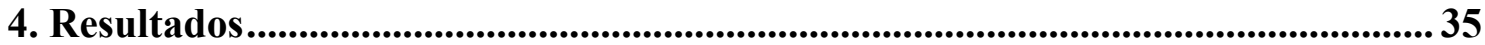

4.1 Características clínicas e laboratoriais dos Grupos I e II .................................... 36

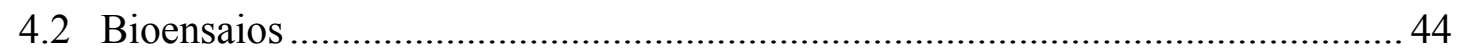

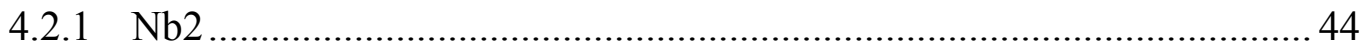

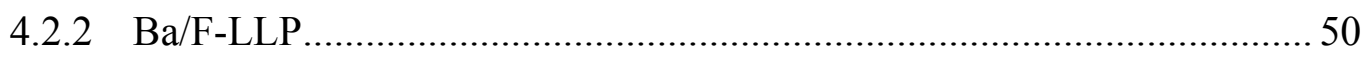

4.2.3 Análise estatística dos dados obtidos nos bioensaios............................ 56

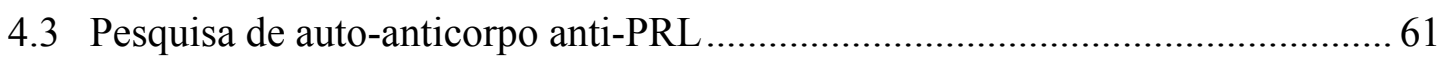

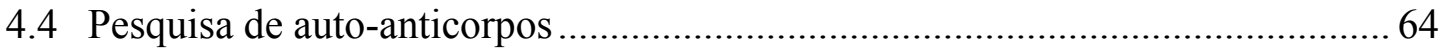

5. Discussã

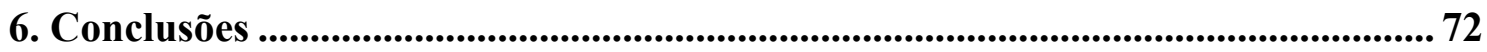

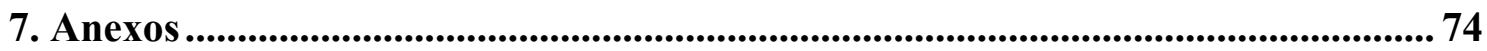

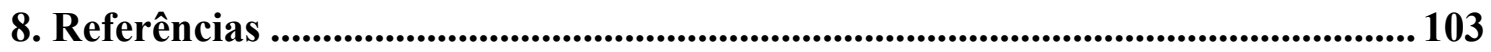




\section{LISTA DE ABREVIATURAS E SIGLAS}

\begin{tabular}{|c|c|}
\hline Ac & anticorpo \\
\hline $\mathrm{ACTH}$ & hormônio estimulante da córtex adrenal \\
\hline DMEM & meio de cultura "Dulbecco's Modified Eagle Médium" \\
\hline DNA & ácido desoxirribonucléico \\
\hline DO & densidade óptica \\
\hline DP & desvio padrão \\
\hline Dr. & doutor \\
\hline E. coli & Escherichia coli \\
\hline $\mathrm{ED}_{50}$ & 50 por cento da dose efetiva \\
\hline Et al. & e colaboradores \\
\hline $\mathrm{F}$ & feminino \\
\hline FSH & hormônio folículo estimulante \\
\hline FPLC & "fast protein liquid chromatography" \\
\hline g & força de gravidade, utilizada em centrifugação \\
\hline GH & hormônio de crescimento \\
\hline $\mathrm{h}$ & humano (a) \\
\hline $\mathrm{h}$ & horas \\
\hline HEPES & M-2-hidroxietilpiperazina-N'-2-ácido etano sulfônico \\
\hline $\operatorname{Ig}$ & imunoglobulina \\
\hline IGF-I & fator de crescimento insulina-símile tipo I \\
\hline IL- 3 & interleucina 3 \\
\hline Jak & janus quinase \\
\hline
\end{tabular}




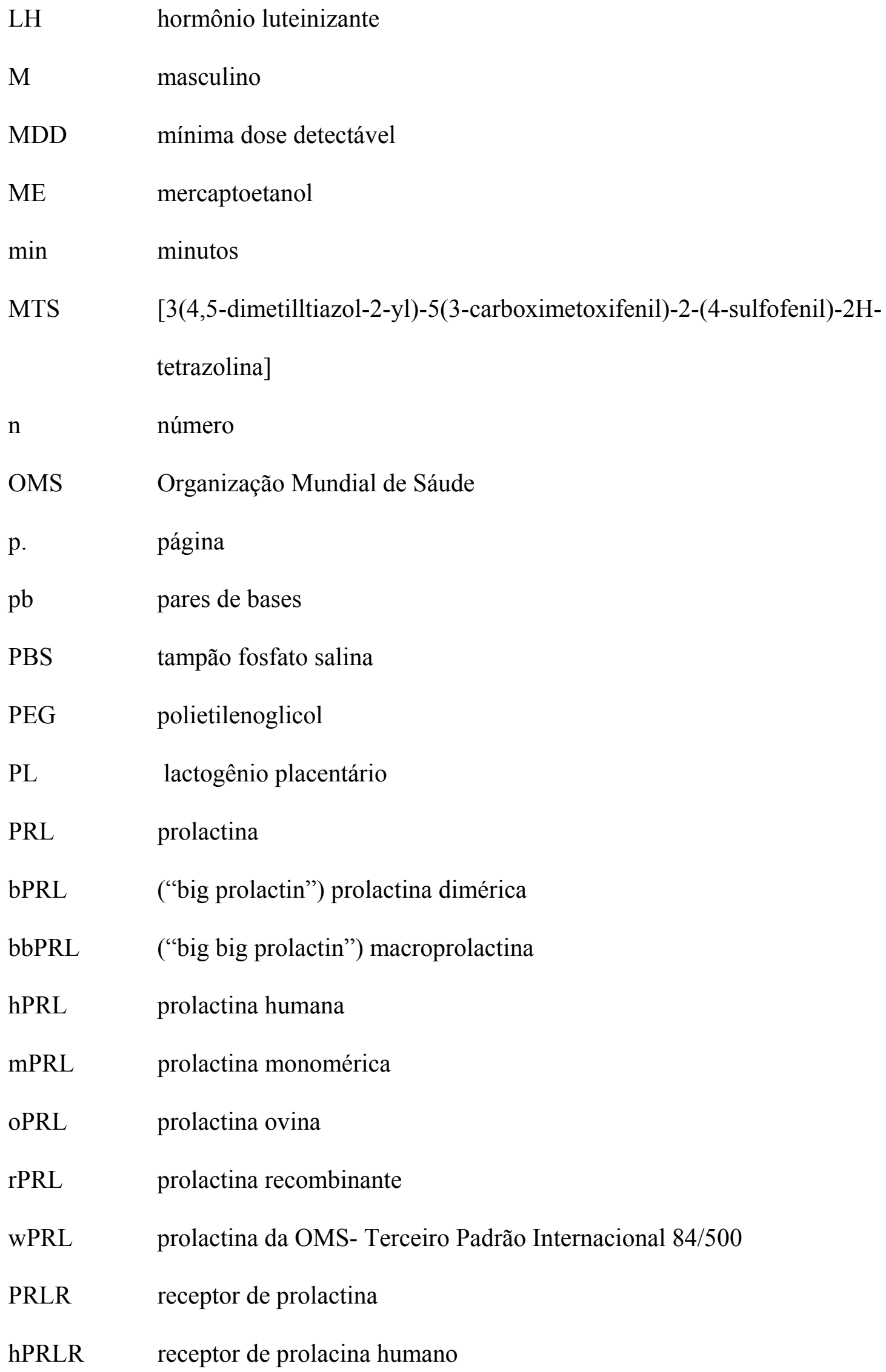




$\begin{array}{ll}\text { Prof. } & \text { Professor } \\ \text { RM } & \text { ressonância magnética } \\ \text { RNA } & \text { ácido ribonucléico } \\ \text { RNAm } & \text { ácido ribonucléico mensageiro } \\ \text { RPMI } & \text { meio de cultura cellular "Roswell Park Memorial Institute" } \\ \text { rpm } & \text { rotações por minuto } \\ \text { S } & \text { segundos } \\ \text { SC } & \text { soro de cavalo } \\ \text { SFB } & \text { soro fetal bovino } \\ \text { T41 } & \text { tiroxina livre } \\ \text { TC } & \text { tomografia computadorizada } \\ \text { TRH } & \text { hormônio liberador de TSH } \\ \text { TSH } & \text { hormônio tireo-estimulante } \\ \text { UA } & \text { unidades arbitrárias } \\ \text { UI } & \text { unidades internacionais } \\ \text { Vol } & \text { volume }\end{array}$




\section{LISTA DE SÍMBOLOS}

\begin{tabular}{|c|c|}
\hline$\beta$ & beta \\
\hline$\gamma$ & gama \\
\hline$=$ & igual a \\
\hline \pm & mais ou menos que \\
\hline$>$ & maior que \\
\hline$<$ & menor que \\
\hline $\mathrm{p}$ & significância estatística \\
\hline${ }^{0} \mathrm{C}$ & graus Celsius \\
\hline $\mathrm{kDa}$ & quiloDalton \\
\hline $\mathrm{kg}$ & quilograma \\
\hline $\mathrm{L}$ & litro \\
\hline$\mu$ & micro \\
\hline $\mathrm{mL}$ & mililitro \\
\hline $\mathrm{mg}$ & miligrama \\
\hline M & molar \\
\hline ng & nanograma \\
\hline$\%$ & por cento \\
\hline
\end{tabular}




\section{LISTA DE FÓRMULAS}

$\mathrm{CO}_{2}$

gás carbônico

$\mathrm{NaCl}$

cloreto de sódio

$\mathrm{Na}_{2} \mathrm{HPO}_{4} / \mathrm{NaH}_{2} \mathrm{PO}_{4}$

fosfato de sódio 


\section{LISTA DE FIGURAS}

Figura 1. Representação gráfica da tradução do gene da PRL a partir de dois

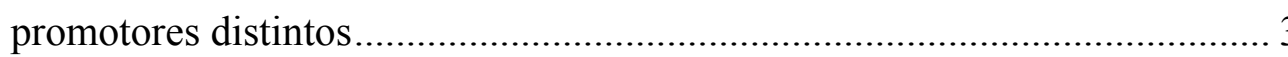

Figura 2. Estrutura terciária da prolactina humana .................................................. 4

Figura 3. Perfil cromatográfico das isoformas de prolactina ..................................... 5

Figura 4. Precipitação com PEG (polietilenoglicol) para diagnóstico de macroprolactinemia 10

Figura 5. Ilustração do processo de dimerização entre a prolactina e seus receptores, com representação dos sítios de ligação 1 e 2

Figura 6. Comparação entre os receptores de PRL de Nb2 e a forma nativa longa de rato

Figura 7. Relação inversa entre bbPRL/PRL(\%) e recuperação da PRL após precipitação com PEG, no Grupo I

Figura 8. Gráficos obtidos após cromatografia do soro de indivíduos do Grupo I: caso de número $1(\mathrm{~A})$ e caso de número 14 (B)

Figura 9. Gráficos obtidos após cromatografia do soro de indivíduos do Grupo II caso de número 19 (A) e caso de número 23 (B)

Figura 10. Microfotografia óptica com aumento de 100x das células Nb2 44

Figura 11. Comparação entre os meios de Fischer e RPMI em Nb2 45

Figura 12. Densidade óptica versus número de células $\mathrm{Nb} 2$ por $\mathrm{mL}$

Figura 13. Comparação entre as respostas biológicas das amostras wPRL (84/500, OMS) e rPRL (prolactina recombinante).

Figura 14. Gráfico obtido cromatografia por gel-filtração de wPRL 46

Figura 15. Curva dose-resposta do padrão wPRL, em octoplicatas, em Nb2

Figura 16. Atividade biológica de bbPRL dos casos de número 2 (A) e 14 (B) comparadas à wPRL, no bioensaio $\mathrm{Nb} 2$ 
Figura 17. Atividade biológica de mPRL dos casos de número 21 (A) e 22 (B) comparadas à wPRL, no bioensaio $\mathrm{Nb2}$

Figura 18. Microfotografia com aumento de 10x das células Ba/F-LP ....................... 50

Figura 19. Comparação entre wPRL e rPRL no ensaio Ba/F-LLP .............................. 51

Figura 20. Ensaio de proliferação celular com células Ba/F LLP em resposta à rPRL, em octoplicatas

Figura 21. Exemplos de resposta das amostras de bbPRL do Grupo I em Ba/F-LLP ... 53

Figura 22. Exemplos de resposta das amostras de mPRL do Grupo II em Ba/F- LLP.. 54

Figura 23. Valores individuais e médias de BA/IA, em Nb2, nos Grupos I e II 59

Figura 24. Valores individuais e as médias das inclinações, de cada caso dos Grupos I e II, nos bioensaios Nb2 e Ba/F-LLP. 60

Figura 25. Relação B/T (\%) das amostras de bbPRL do Grupo I com o grupo de controle negativo.

Figura 26. Valores individuais e médios das inclinações do Grupo I, em Nb2, segundo a presença de auto-anticorpo anti-PRL

Figura 27. Valores individuais e médios das inclinações do Grupo I, em Ba/F-LLP, segundo a presença de auto-anticorpo anti-PRL 


\section{LISTA DE TABELAS}

Tabela 1- Resumo dos estudos de prevalência de macroprolactinemia..................... 79

Tabela 2- $\quad$ Resumo dos estudos de bioatividade da macroprolactina em $\mathrm{Nb} 2$........... 80

Tabela 3 - Características da pesquisa de auto-anticorpos ...................................... 29

Tabela 4 - Resumo das características clínicas do Grupo I .................................... 37

Tabela 5 - Avaliação hormonal sexual dos indivíduos do Grupo I ........................... 81

Tabela 6 - Perfil de prolactina dos casos do Grupo I................................................. 40

Tabela 7 - Características clínicas e laboratoriais do Grupo II ................................... 42

Tabela 8A - Cálculo da relação BA/IA das amostras de bbPRL do Grupo I no

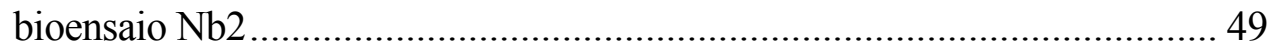

Tabela 8B - Cálculo da relação BA/IA das amostras de mPRL do Grupo II no bioensaio $\mathrm{Nb} 2$

Tabela 9A - Relação BA/IA no bioensaio Ba/F LLP para as amostras de bbPRL

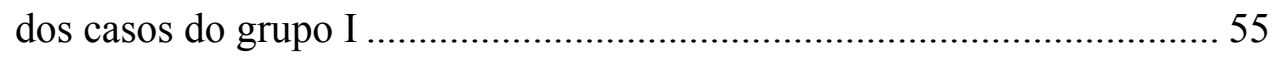

Tabela 9B - Relação BA/IA no bioensaio Ba/F LLP para as amostras de mPRL dos casos do grupo II

Tabela 10 - Inclinações das curvas obtidas com as amostras de bbPRL do Grupo I e de mPRL do Grupo II, nos bioensaios Nb2 e Ba/F-LLP. 57

Tabela 11 - Estatísticas descritivas para BA/IA, em Nb2 e Ba/F-LLP, do Grupo II.... 58

Tabela 12 - Estatísticas descritivas de BA/IA, em Nb2, dos Grupos I e II. 59

Tabela 13 - Estatísticas descritivas para a inclinação, segundo a presença ou ausência de anticorpo anti-PRL, nos bioensaios Nb2 e Ba/F-LLP........... 62

Tabela 14 - Pesquisa de auto-anticorpos no Grupo I 64 


\section{RESUMO}

Glezer A. Estudo da atividade biológica da macroprolactina humana em células Nb2 e em células Ba/F-03 transfectadas com o receptor de prolactina humano forma longa [tese]. São Paulo: Faculdade de Medicina, Universidade de São Paulo; 2005. 122p.

INTRODUÇÃO: A macroprolactinemia é condição freqüente em indivíduos com hiperprolactinemia e geralmente, sem impacto clínico. Os dados da literatura sobre a atividade biológica da macroprolactina são controversos e na maioria das vezes baseados nos resultados em bioensaio heterólogo com células $\mathrm{Nb} 2$ de rato. A atividade biológica da macroprolactina observada in vitro, porém não in vivo, pode decorrer de seu alto peso molecular que evita a passagem pela barreira dos capilares sangüíneos. Alternativamente, a bioatividade in vitro da macroprolactina possa diferir de acordo com a especificidade do receptor de prolactina. OBJETIVOS: Caracterizar a bioatividade da macroprolactina em um bioensaio homólogo: células $\mathrm{Ba} / \mathrm{F}-3$ transfectadas com receptor de prolactina humano e que o expressem de forma estável. PACIENTES E MÉTODOS: Frações de macroprolactina obtidas por cromatografia gelfiltração de indivíduos macroprolactinêmicos (Grupo I, $\mathrm{n}=18,16$ mulheres) e frações de prolactina monomérica de pacientes hiperprolactinêmicos sem macroprolactinemia (Grupo II, $\mathrm{n}=5$, dois homens) foram avaliadas nos bioensaios $\mathrm{Nb} 2 \mathrm{e} \mathrm{Ba/F-LLP.}$ RESULTADOS: No Grupo I, não houve indivíduo hipogonádico no momento da avaliação e quatro mulheres apresentavam galactorréia discreta. $\mathrm{O}$ valor médio da relação macroprolactina/ prolactina total foi $79 \%$ e da relação bioatividade/ imunoatividade (BA/IA) da macroprolactina no ensaio $\mathrm{Nb} 2$ foi 0.69 . Em contraste, não houve dose-resposta em 15 de 18 amostras avaliadas no ensaio Ba/F-LLP. No Grupo II, três pacientes apresentavam galactorréia e todos eram hipogonádicos. $\mathrm{O}$ valor médio da relação prolactina monomérica/ prolactina total foi $61 \%$ e da relação BA/IA da prolactina monomérica foi 1.35 em Nb2 e 0.91 no ensaio Ba/F-LLP. CONCLUSÕES: Os resultados indicam que a atividade da macroprolactina presente em ensaio com o receptor de rato é irrelevante, uma vez que esta atividade não foi observada em ensaio humano mediado com o receptor de prolactina humano. Por outro lado, ambos ensaios apresentaram resultados similares para atividade presente de prolactina monomérica. Estes dados são consistentes com a freqüente ausência de atividade da macroprolactina in vivo.

Descritores: 1. HIPERPROLACTINEMIA 2. PROLACTINA 3.ISOFORMAS DE PROTEÍNAS 4. BIOENSAIOS/métodos 5.RECEPTORES DA PROLACTINA 6. PROLACTINOMA 


\section{SUMMARY}

Glezer A. Human macroprolactin biological activity study in Nb2 cells and in Ba/F-03 cells expressing human long prolactin receptor [thesis]. São Paulo: "Faculdade de Medicina, Universidade de São Paulo"; 2005. 122p.

Context: Macroprolactinemia is a frequent finding in hyperprolactinemic individuals, usually without clinical impact. Data on biological activity of macroprolactin is controversial and mostly based on a heterologous rat Nb2 cell bioassay. Biological activity of macroprolactin observed in vitro but not in vivo maybe due to its high molecular weight preventing its passage through capillary barrier. Alternatively, macroprolactin bioactivity may differ depending on the prolactin receptor species specificity. Objective: Characterize the bioactivity of macroprolactin in a homologous bioassay: $\mathrm{Ba} / \mathrm{F}-3$ cells stably expressing the human prolactin receptor. Design/Setting/Patients: Chromatography-purified macroprolactin from macroprolactinemic individuals (Group I, n=18, 16 women) and monomeric prolactin from hyperprolactinemic patients without macroprolactinemia (Group II, $\mathrm{n}=5$, two men) were tested in $\mathrm{Nb} 2$ and in $\mathrm{Ba} / \mathrm{F}$-LLP bioassays. Both groups were followed at the neuroendocrinology outpatients' clinic. Main Outcome Measure: Biological activity of macroprolactin presented in the two bioassays. Results: Group I: no patient had hypogonadism and four women presented with mild galactorrhea. Mean macroprolactin/total prolactin ratio was $79 \%$ and mean ratio bioactivity/immunoactivity (BA/IA) of macroprolactin in the $\mathrm{Nb} 2$ assay was 0.69 . There was no dose-response in 15 out of the 18 samples tested in Ba/F-LLP assay. Group II: three patients had galactorrhea and all five had hypogonadism. Mean monomeric prolactin/total prolactin ratio was $61 \%$ and mean ratio BA/IA of monomeric prolactin samples was 1.35 in $\mathrm{Nb} 2$ and 0.91 in $\mathrm{Ba} / \mathrm{F}-$-LLP assay. Conclusion: While both bioassays achieve similar results with respect to monomeric prolactin activity, our results indicate that the activity displayed by macroprolactin towards the rat receptor may be irrelevant since it is not observed in the human prolactin receptor mediated assay, consistently with the apparent absence of bioactivity in vivo.

Keywords: 1. HYPERPROLACTINEMIA 2. PROLACTIN 3. PROTEIN ISOFORMS 4. BIOASSAYS/methods 5.PROLACTIN RECEPTORS 6. PROLACTINOMA 
1. Introdução 


\subsection{Prolactina: estrutura e funções}

A prolactina humana (hPRL) é um polipeptídeo composto por 199 aminoácidos, sintetizado principalmente por lactotrofos da hipófise anterior, cuja principal ação como hormônio é promover o desenvolvimento adicional da glândula mamária, durante a gestação e a lactação, garantindo a galactopoiese. Apesar de haver mais de 300 funções biológicas descritas para a prolactina $(\mathrm{PRL})^{1}$, ela foi inicialmente caracterizada por sua capacidade de promover crescimento e diferenciação do papo de pombos ${ }^{2}$. A PRL integra a família dos hormônios lactogênicos, como o hormônio de crescimento (GH), o hormônio lactogênico placentário (PL), a proliferina, o peptídeo relacionado à proliferina, a somatolactina e outros fatores PRL símiles ${ }^{3}$. Em $1971^{4,5}$, demonstrou-se que a PRL é um hormônio distinto do GH. O GH apresenta ação lactogênica em diversas espécies, incluindo a espécie humana, e devido à semelhança entre sua estrutura gênica e a da PRL (35\%), acredita-se que ambos tenham origem na duplicação de um gene ancestral comum ${ }^{6}$. A partir da clonagem do gene da $\mathrm{PRL}^{7}$ e de seu receptor $^{8}$, respectivamente em 1984 e 1988, demonstrou-se que a PRL também é uma citocina, por compartilhar diversas características dos fatores de crescimento hematopoiéticos, tais como estrutura molecular com motivos homólogos, síntese da PRL e expressão de seu receptor de forma ubíqüa, homologia estrutural entre o receptor de PRL e os receptores de citocinas, bem como vias de sinalização intracelular semelhantes aos de outras citocinas ${ }^{9}$. 
O gene da hPRL está presente em cópia única, no cromossomo 6 e apresenta cinco éxons. Em 1994, duas regiões promotoras do gene foram identificadas ${ }^{10}$ : a proximal, responsável pela tradução da PRL hipofisária, e a distal, responsável pela tradução da PRL extra-hipofisária. Apesar de duas regiões promotoras, que estão sob o controle de fatores estimulatórios e inibitórios distintos, o gene codifica uma única proteína. A Figura 1 representa a tradução da PRL em humanos.

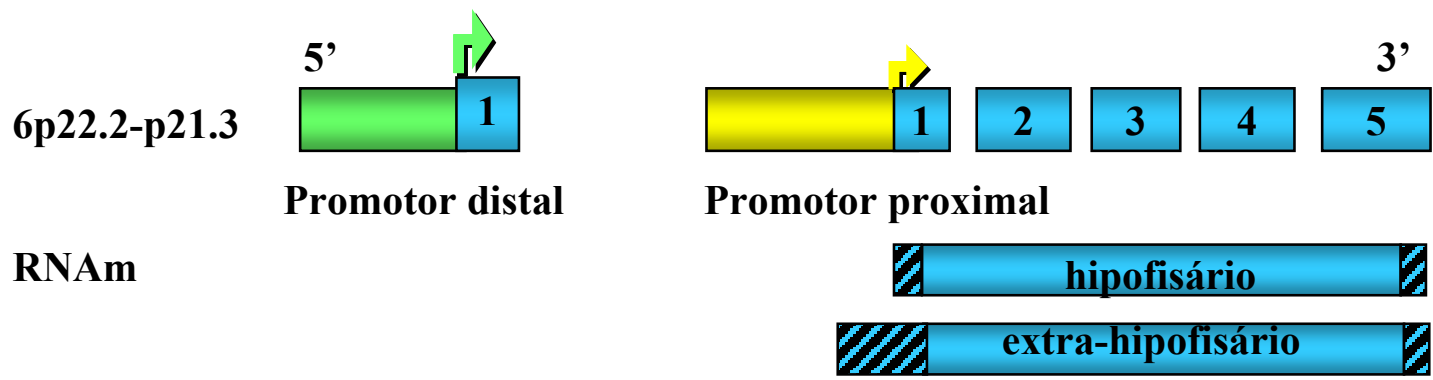

Proteína pró-hormônio (227 aa) maduro (199 aa)
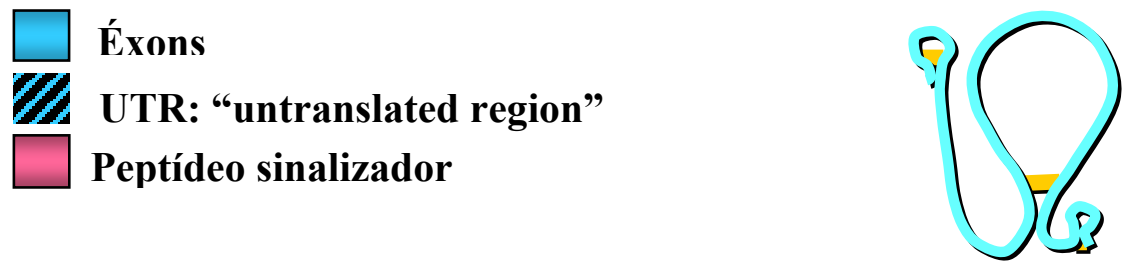

Estrutura secundária da PRL

Figura 1. Representação gráfica da tradução do gene da PRL a partir de dois promotores distintos;(pb) pares de bases;(aa) aminoácidos; (RNAm) ácido ribonucléico mensageiro; $(\mathrm{S}-\mathrm{S})$ ponte dissulfídica 
A estrutura terciária da PRL foi determinada recentemente ${ }^{11}$, em 2003 por estudos com ressonância magnética que comprovaram o modelo teórico anterior, de que ela é composta por quatro $\alpha$-hélices antiparalelas, como ilustra a Figura 2.

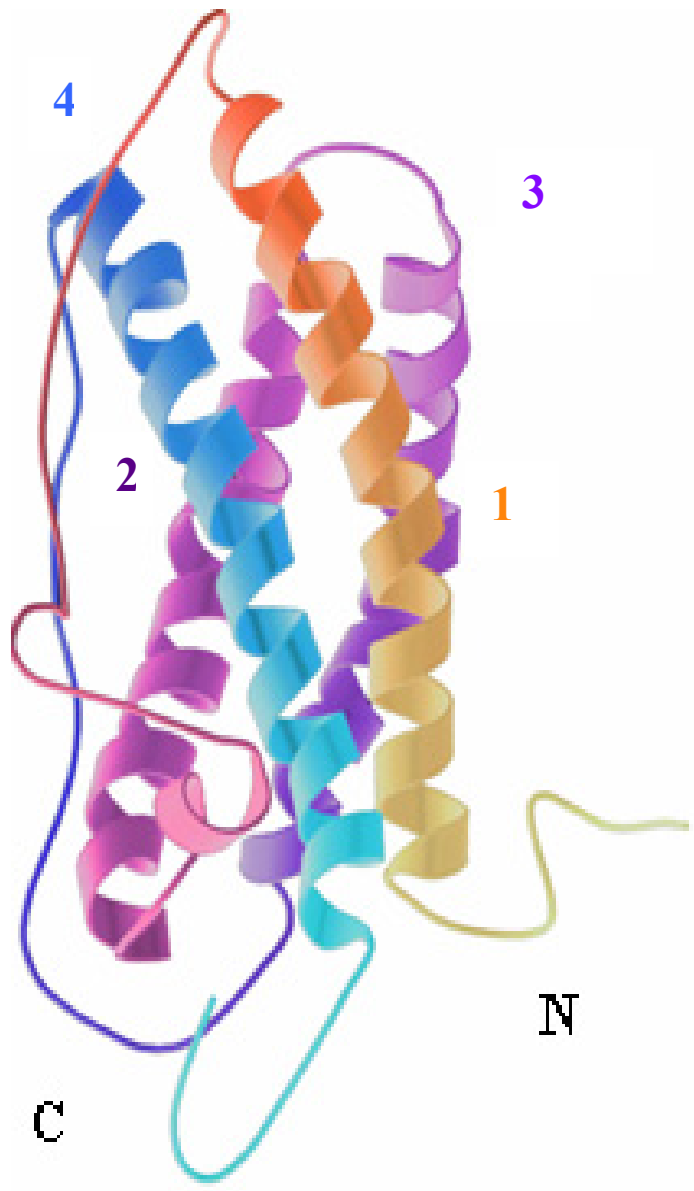

Figura 2. Estrutura terciária da prolactina humana $(\mathrm{N})$ porção aminoterminal da proteína; (C) porção carboxiterminal da proteína; (1), (2), (3) e( 4) numeração das $\alpha$-hélices 
A PRL pode sofrer diversos processos pós-traducionais, como glicosilação, acetilação, deaminação, proteólise e agregação molecular. De acordo com o peso molecular, três isoformas de PRL são identificadas: monomérica (mPRL), de $23 \mathrm{kDa}$, dimérica ou "big PRL" (bPRL), de 45 kDa a 60 kDa, e a macroprolactina ou "big-bigPRL" (bbPRL), com mais de 100k Da. No soro dos indivíduos normais e da maioria dos portadores de hiperprolactinemia, a isoforma circulante predominante é a mPRL, compreendendo de $80 \%$ a $95 \%$ da PRL total, enquanto que a bbPRL perfaz menos de $5 \%$ do total ${ }^{12-15}$. A figura 3 exemplifica o padrão de PRL comumente encontrado em cromatografia por gel-filtração.

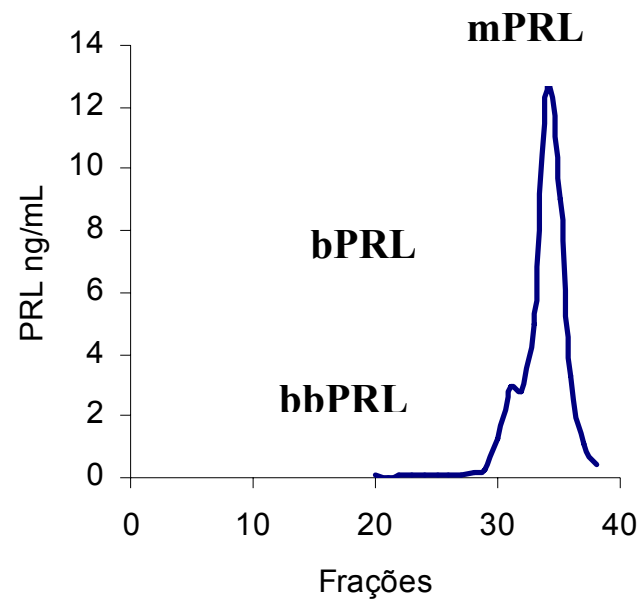

Figura 3. Perfil cromatográfico das isoformas de prolactina

A PRL sérica representa fundamentalmente a PRL de origem hipofisária. Nagy e Berczi $^{16}$ demonstraram que após hipofisectomia em ratos, ainda havia cerca de $20 \%$ da atividade biológica da PRL sangüínea. 


\subsection{Hiperprolactinemia}

A dopamina produzida no hipotálamo atinge, pela circulação portal hipofisária, as células hipofisárias secretoras de PRL, denominadas lactotrofos. A dopamina exerce um tônus inibitório sob a secreção hormonal de PRL, e a própria PRL apresenta ação de retroalimentação negativa, agindo diretamente nos lactotrofos ou nos neurônios dopaminérgicos ${ }^{17}$. A secreção de PRL é estimulada principalmente pelo hormônio liberador de TSH (TRH), estrogênios, serotonina e peptídeo intestinal vasoativo ${ }^{18}$. Quaisquer condições que impeçam a ação da dopamina, que aumentem a ação dos fatores liberadores, que reduzam a eliminação da PRL, ou que estimulem a sua secreção autônoma poderiam, portanto, causar hiperprolactinemia. A hiperprolactinemia pode ser fisiológica, como a gestação, farmacológica, por exemplo pelo uso de drogas antidopaminérgicas, ou patológica, como nos adenomas hipofisários produtores de PRL, hipotireoidismo e uremia ${ }^{19}$. A macroprolactina pode estar presente em qualquer situação de hiperprolactinemia, sendo também ela própria causa de hiperprolactinemia ${ }^{19}$. A prevalência de hiperprolactinemia depende da população estudada, variando de $0,4 \%{ }^{20}$, em adultos assintomáticos, a 70\%, em mulheres com galactorréia e amenorréia ${ }^{21}$.

A hiperprolactinemia interfere na pulsatilidade da secreção hipofisária de LH e FSH, bem como inibe a ação desses hormônios sobre as gônadas, ocasionando hipogonadismo hipogonadotrófico. Nas mulheres, geralmente se identifica um espectro clínico, relacionado ao aumento progressivo da PRL, que varia de fase luteal curta, ciclos anovulatórios, oligomenorréia até amenorréia. Nos homens, ocorre diminuição da síntese de testosterona e prejuízo da espermatogênese ${ }^{22}$. Buvat ${ }^{23}$ demonstrou que $88 \%$ dos homens com hiperprolactinemia apresentam disfunção erétil. Os sinais e os 
sintomas decorrentes da hiperprolactinemia são: galactorréia, definida como a presença de secreção láctea nas glândulas mamárias em homens, ou em mulheres fora do período de gestação ou amamentação; hipogonadismo hipogonadotrófico e redução da libido. A galactorréia está presente em $30 \%$ a $80 \%$ das mulheres com hiperprolactinemia, porém esse sinal pode também ocorrer em mulheres normoprolactinêmicas. Kleinberg et al. ${ }^{24}$ verificaram prevalência de $20 \%$ de hiperprolactinemia em 235 indivíduos com galactorréia, porém, dentre as mulheres com ciclos menstruais regulares, $86 \%$ apresentavam normoprolactinemia. Batrinos et al. ${ }^{25}$ avaliaram 404 mulheres com galactorréia, com ou sem irregularidade menstrual, e constataram prevalências de hiperprolactinemia de $42 \%$ e $15 \%$, nos respectivos subgrupos. Portanto, quando a galactorréia está presente sem que haja irregularidade menstrual, freqüentemente a concentração sérica de PRL é normal.

\subsection{Isoformas de prolactina e implicações clínicas}

A partir da década de 80, os primeiros casos de dissociação clínico-laboratorial nos quais ocorria hiperprolactinemia oligossintomática ou assintomática foram relatados ${ }^{26}$. Verificou-se que, nesses casos, a principal isoforma de PRL circulante era a macroprolactina (bbPRL), de presumível atividade biológica baixa. Cunhou-se ${ }^{27}$, então, o termo "macroprolactinemia" para designar a hiperprolactinemia decorrente predominantemente de bbPRL. Estudos posteriores demonstraram prevalência de macroprolactinemia de $0,15 \%{ }^{28}$ a $1,3 \%{ }^{29}$, em indivíduos normoprolactinêmicos e de $15,4 \%{ }^{30}$ a $46 \%^{31}$, na população hiperprolactinêmica ${ }^{30-38}$. Os estudos de prevalência de 
macroprolactinemia estão resumidos no Anexo B, Tabela 1. A média calculada de prevalência de macroprolactinemia em indivíduos hiperprolactinêmicos é de 27,5\%. Alguns autores ${ }^{31,33}$ relataram alta prevalência de macroprolactinemia, provavelmente por um viés de seleção, uma vez que os estudos foram realizados em um laboratório de referência, e, portanto, um grande número de amostras era suspeito para macroprolactinemia. Outros possíveis motivos para a diferença de prevalência nos estudos são os métodos utilizados para determinação de PRL sérica e o critério usado para o diagnóstico de macroprolactinemia. Smith et al. ${ }^{39}$ demonstraram que utilizando nove diferentes métodos para determinação de PRL sérica, em 10 soros previamente diagnosticados como macroprolactinêmicos por cromatografia por gel-filtração, obtiveram-se diversas dosagens de PRL sérica total, com variação de 2,9 a 7,8 vezes entre o valor mais alto (Elycsis, Roche ${ }^{\circledR}$ ) e o valor mais baixo (ACS: 180 e Centaur, Bayer Corp. $\left.{ }^{\circledR}\right)$.

Além de ser um fenômeno freqüente, a macroprolactinemia na maioria das vezes é benigna e dispensa tratamento. Em revisão da literatura ${ }^{26,27,30,31,34-43,45-71}$, dos 530 casos de macroprolactinemia descritos em publicações de língua inglesa, 84\% dos indivíduos eram do sexo feminino, 25,4\% apresentavam irregularidade menstrual, 22,6\%, galactorréia, e 11\%, microadenomas de hipófise. A prevalência de microadenomas nessa população foi semelhante à prevalência de incidentalomas hipofisários, diagnosticados por RM, na população geral ${ }^{72}$. "Incidentaloma de hipófise" foi o termo cunhado por Reincke et al. $^{73}$ para designar os tumores de hipófise diagnosticados acidentalmente, em indivíduos assintomáticos, por algum método de imagem, seja tomografia computadorizada (TC), seja RM. Em autópsias não selecionadas, a prevalência média de microadenomas hipofisários foi de $11,3 \%$ e, dentre 
aqueles nos quais se realizou imunohistoquímica, a positividade para PRL esteve entre $23 \%$ e $66 \%^{72}$. Portanto, o prolactinoma é o adenoma hipofisário secretor mais freqüente dentre os incidentalomas de hipófise ${ }^{74}$. Devido à freqüência de incidentalomas de hipófise e macroprolactinemia, estas duas condições podem ser encontradas em um mesmo indivíduo, fato que caracteriza dupla armadilha diagnóstica ${ }^{40}$. Com respeito à irregularidade menstrual dos casos acima compilados, nem sempre outras etiologias que pudessem causar tal alteração menstrual foram investigadas, como a síndrome dos ovários policísticos, condição clínica associada à hiperprolactinemia em até $30 \%$ dos $\operatorname{casos}^{75}$. A infertilidade descrita nas mulheres portadoras de macroprolactinemia pode decorrer de outras causas que não a hiperprolactinemia. Em geral, mulheres portadoras de macroprolactinemia são férteis, e a proporção de bbPRL ao longo da gestação se reduz gradualmente ${ }^{41,42}$. Dessa forma, a prevalência de macroprolactinemia em gestantes é menor do que a da população hiperprolactinêmica ${ }^{76,77}$.

O diagnóstico de macroprolactinemia pode ser realizado por cromatografia por gelfiltração, padrão-ouro ou por precipitação com polietilenoglicol (PEG) $)^{33}$. O PEG é um polímero com alta capacidade de atrair moléculas de água, e, quando adicionado ao soro, moléculas de alto peso, como a macroprolactina, podem se desnaturar e se precipitar. Em teoria, apenas a mPRL está presente no sobrenadante. Dessa forma, quanto maior a proporção de bbPRL na amostra, maior será a precipitação e, conseqüentemente, menor a recuperação de PRL no sobrenadante.

Calcula-se a recuperação pela fórmula ${ }^{33}$ :

Recuperação \% $=[($ PRL sobrenadante $) \times 2 /(P R L$ total inicial $) \times 100]$ 
A Figura 4 ilustra a precipitação de bbPRL na presença de PEG 6000.

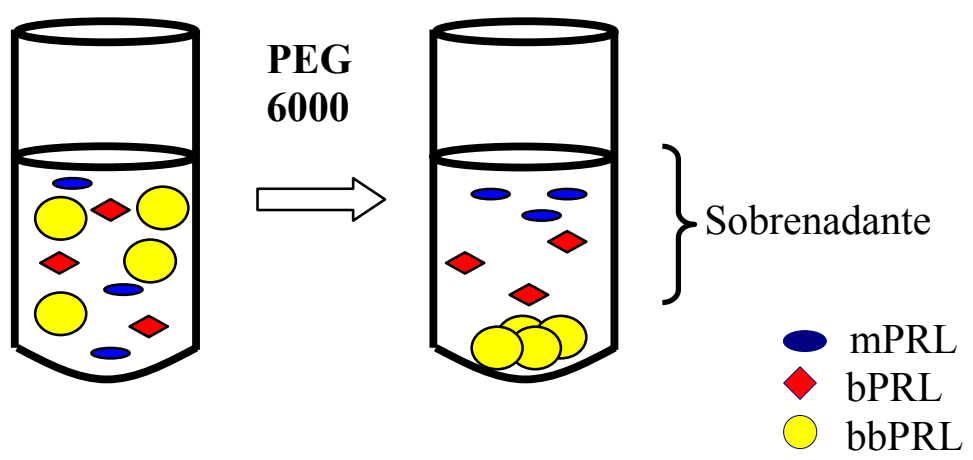

Figura 4. Precipitação com PEG (polietilenoglicol) para diagnóstico de macroprolactinemia

Para o diagnóstico de macroprolactinemia na rotina, a precipitação com PEG substitui a cromatografia por ser menos custosa e de mais fácil realização ${ }^{32,33}$, exceto quando a adição do PEG pode interferir na determinação de PRL, tais como nos ensaios AxSYM (Abbot $\left.{ }^{\circledR}\right)$, ACS: 180 (Bayer $\left.{ }^{\circledR}\right)$ e Immuno-1 $\left(\text { Bayer }^{\circledR}\right)^{39}$. Segundo Vieira et al. ${ }^{33}$, a recuperação após precipitação com PEG menor que 30\% é diagnóstica de macroprolactinemia, e a recuperação maior que $65 \%$ exclui a condição. Se a recuperação estiver entre $30 \%$ e $65 \%$, sua presença é indeterminada e deve-se proceder à cromatografia para o diagnóstico definitivo. Outros autores ${ }^{30,32,34}$ consideram $40 \%$ e 50\% os níveis de corte para diagnóstico. A diferença entre esses níveis de corte talvez esteja na temperatura de armazenamento do PEG, no tipo de coluna utilizada para cromatografia, e, mais ainda, no critério utilizado para definir macroprolactinemia ( $>$ $50 \%$ da PRL total ou apenas a presença de um pico nítido de bbPRL na cromatografia $^{78}$. Mais recentemente, alguns autores ${ }^{38}$ preconizam diferenciar $\mathrm{o}$ 
indivíduo portador de macroprolactinemia "verdadeira" quando existe macroprolactinemia e as concentrações séricas de mPRL são normais_daquele portador de hiperprolactinemia "verdadeira"_quando essas concentrações são elevadas, independentemente da presença de bbPRL. Gibney et al. ${ }^{38}$ utilizaram o valor absoluto de mPRL encontrado no sobrenadante de soros normais após a precipitação com PEG $^{79}$ ( $<11 \mathrm{ng} / \mathrm{mL}$ em mulheres e $<6,4 \mathrm{ng} / \mathrm{mL}$ em homens) para excluir a hiperprolactinemia verdadeira, em amostras com macroprolactinemia diagnosticadas pelo critério habitual do serviço, ou seja, recuperação menor que $40 \%$ após a precipitação com o PEG. Utilizando o critério de recuperação menor que $40 \%$ após uso do PEG, esses autores obtiveram cerca de $10 \%$ de falsos positivos e $1 \%$ negativos. Os autores propõem o uso do valor absoluto de PRL no sobrenadante, após a precipitação com PEG, para classificar o indivíduo como portador de hiperprolactinemia ou macroprolactinemia "verdadeira", reduzindo a realização de procedimentos desnecessários e custosos nos casos de macroprolactinemia "verdadeira".

Há outros métodos descritos para o rastreamento da macroprolactinemia, como a ultracentrifugação ${ }^{80}$, precipitação com proteína $\mathrm{A}$ sepharose ${ }^{44}$, imunoprecipitação com agarose anti-IgG humana ${ }^{81}$ e um método imunométrico do tipo "sanduíche", usando anticorpo anti-PRL e anti-IgG para toxoplasmose ${ }^{82}$, com resultados muito semelhantes aos obtidos com a precipitação com PEG.

A estrutura química da bbPRL ainda é matéria de discussão. Em 1974, foi identificada e descrita pela primeira $v^{2} z^{12}$, pela cromatografia de soros de indivíduos normais e hiperprolactinêmicos, a presença de um discreto pico de PRL próximo ao volume-morto ou void volume, caracterizando a isoforma de PRL a qual mais tarde seria denominada macroprolactina (bbPRL). Em 1992, dois grupos de pesquisa ${ }^{83,84}$ 
descreveram a presença de anticorpo anti-PRL, do tipo imunoglobulina (Ig) G, em pacientes com macroprolactinemia. Hattori et al. ${ }^{29}$ pesquisaram a presença de anticorpo anti-PRL em 208 indivíduos com hiperprolactinemia e identificaram-na em 16\% dos casos de hiperprolactinemia "idiopática", em 4,8\% dos casos secundários ao uso de drogas e em $2,7 \%$ dos de prolactinomas. Dessa forma, a macroprolactinemia pode se associar a qualquer quadro de hiperprolactinemia, no entanto, sua prevalência é mais comum na hiperprolactinemia "idiopática". A gênese do anticorpo anti-PRL não é conhecida e alguns dados apontam que a freqüência de outros autoanticorpos nesses indivíduos não se diferencia daquela encontrada na população geral ${ }^{35}$. Hattori et al. ${ }^{71}$ demonstraram que isoformas ácidas de PRL foram encontradas em indivíduos com anticorpo anti-PRL e que o anticorpo mais comum foi a IgG subtipo 4, geralmente presente em situações de estimulação antigênica crônica. Uma vez que o processo de fosforilação pode ser responsável pela geração de isoformas mais ácidas, os autores tentaram identificar diferença de fosforilação entre as isoformas de PRL, sem êxito, ao menos com a metodologia empregada. Alegaram ainda que outra possibilidade a ser investigada para a geração de isoformas ácidas é a diferença na sulfatação. Na literatura, a maioria dos casos de macroprolactina se deve à presença de anticorpo anti$\mathrm{PRL}^{29,46,47,71,76,83-88}$. No entanto, em 1989, Tanaka et al. ${ }^{89}$ descreveram a heterogeneidade da bbPRL, cuja molécula apresentava pesos moleculares diferentes (de $250 \mathrm{kDa}$ a $300 \mathrm{kDa}$ e de $500 \mathrm{kDa}$ ) e comportamento distinto quando submetidas à ação de $\beta$-mercaptoetanol (ME). O ME rompe pontes dissulfídicas que possam existir em agregados de mPRL. A geração de mPRL a partir de bbPRL só ocorreu em um dos casos. Outros autores confirmaram a presença de agregados moleculares de mPRL ${ }^{14,27,76}$, e, ainda, ligação de inespecífica de mPRL com Ig, por pontes dissulfídicas ${ }^{90}$. 
Com a possibilidade de separação cromatográfica das isoformas de PRL, estudos da atividade in vitro com essas isoformas passaram a ser realizados no final da década de 70. Em 1979, Farkouh et al. ${ }^{91}$ avaliaram a ação de bbPRL de indivíduos normais, estimulados com TRH, em radiorreceptores de fígado de rata fêmea adulta não prenha. A relação bioatividade/imunoatividade (BA/IA) foi próxima de 1,0 para mPRL e em torno de 0,27 para bbPRL. Em 1980, Tanaka et al. ${ }^{92}$ descreveram um ensaio bastante sensível e específico para hormônios lactogênicos, denominado de "Nb2". Este ensaio é realizado com células pré-T, derivadas de linfoma transplantável de rato masculino estrogenizado, da linhagem Noble $(\mathrm{Nb})$, que proliferam quase que exclusivamente na presença de hormônios lactogênicos, como a PRL e o $\mathrm{GH}$, mesmo em baixas concentrações. Nesse ensaio a bioatividade é medida pela proliferação celular, que ocorre com máxima intensidade em torno de $1 \mathrm{ng} / \mathrm{mL}$ de PRL.

Até o presente momento, pouco se conhece a respeito da isoforma dimérica da PRL (bPRL), descrita paralelamente à caracterização bbPRL ${ }^{12}$. Alguns autores ${ }^{13,35,48,59-}$ 61, 93,94 relataram indivíduos hiperprolactinêmicos com predomínio de bPRL, em sua maioria assintomáticos, totalizando pouco mais de 20 casos na literatura de língua inglesa, e incluindo dois indivíduos do sexo masculino portadores de macroprolactinoma ${ }^{61}$. Há apenas um relato na literatura ${ }^{95}$ de estudo da atividade biológica de bPRL, em radiorreceptores de glândula mamária de coelha gestante, no qual a bioatividade de bPRL foi menor que a encontrada para mPRL. Portanto, parece que a isoforma bPRL também apresenta baixa atividade biológica in vivo e in vitro, e, quando ela representar a isoforma predominante de PRL circulante, deve-se reconhecer essa situação para que intervenções desnecessárias e custosas não sejam realizadas. Não há, no entanto, teste de rastreamento para o diagnóstico. Atualmente, o único método diagnóstico disponível é a cromatografia por gel-filtração. 


\subsection{Receptores de prolactina}

Os receptores de PRL (PRLR) pertencem à superfamília dos receptores de citocina classe 1, caracterizados por uma proteína transmembrânica isenta de atividade autofosforilativa, que necessita da ligação entre o ligante e dois receptores, por sítios de ligação distintos, para sua ativação, processo denominado dimerização ${ }^{1}$. A Figura 5 mostra o processo de ativação do PRLR.

\section{PRL}

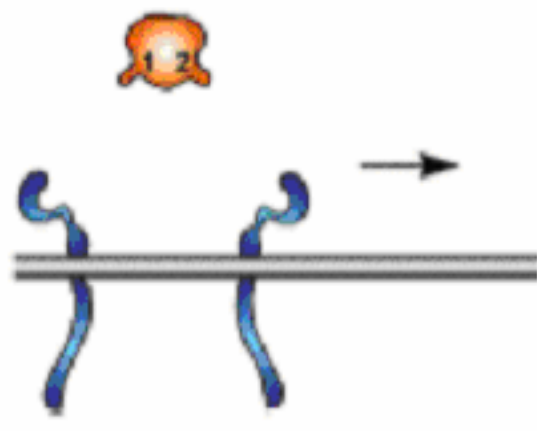

RPRL

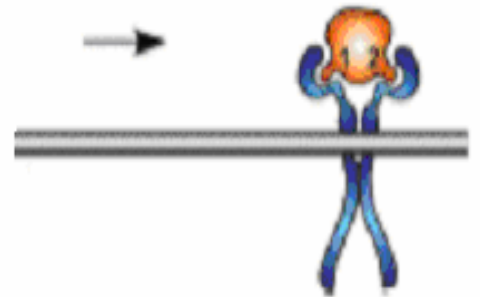

Complexo PRLR-PRLR ativado

Figura 5. Ilustração do processo de dimerização entre a prolactina e seus receptores, com representação dos sítios de ligação 1 e 2

Os PRLRs podem apresentar diferentes tamanhos quanto à extensão de sua porção intracitoplasmática e são classificados em isoformas curtas, intermediárias ou longas ${ }^{1}$.

A porção extracelular e transmembrânica são altamente conservadas entre as espécies, bem como a porção intracitoplasmática proximal à membrana celular, denominada de "Box-1". Esta é uma região rica em prolina e cuja integridade é essencial para fosforilação e ativação da Janus quinase 2 (Jak2), a principal via de 
sinalização intracelular da PRL. Não se conhece o papel exato das isoformas curtas e intermediárias, mas já se demonstrou que as isoformas curtas apresentam ação dominante-negativa ${ }^{96}$.

\subsection{Bioensaios para prolactina e bioatividade da macroprolactina in vitro}

Como citado anteriormente, o bioensaio $\mathrm{Nb} 2$ é amplamente utilizado para avaliar a bioatividade da PRL e do GH, por ser bastante sensível e reprodutível ${ }^{92}$. O PRLR da célula $\mathrm{Nb} 2$ é do tipo murino e de tamanho intermediário, com deleção de 594 pares de bases e conseqüente perda de 198 aminoácidos da proteína madura, quando comparado com a isoforma longa nativa ${ }^{97}$, como mostra a Figura 6.

Nb2 Isoforma longa

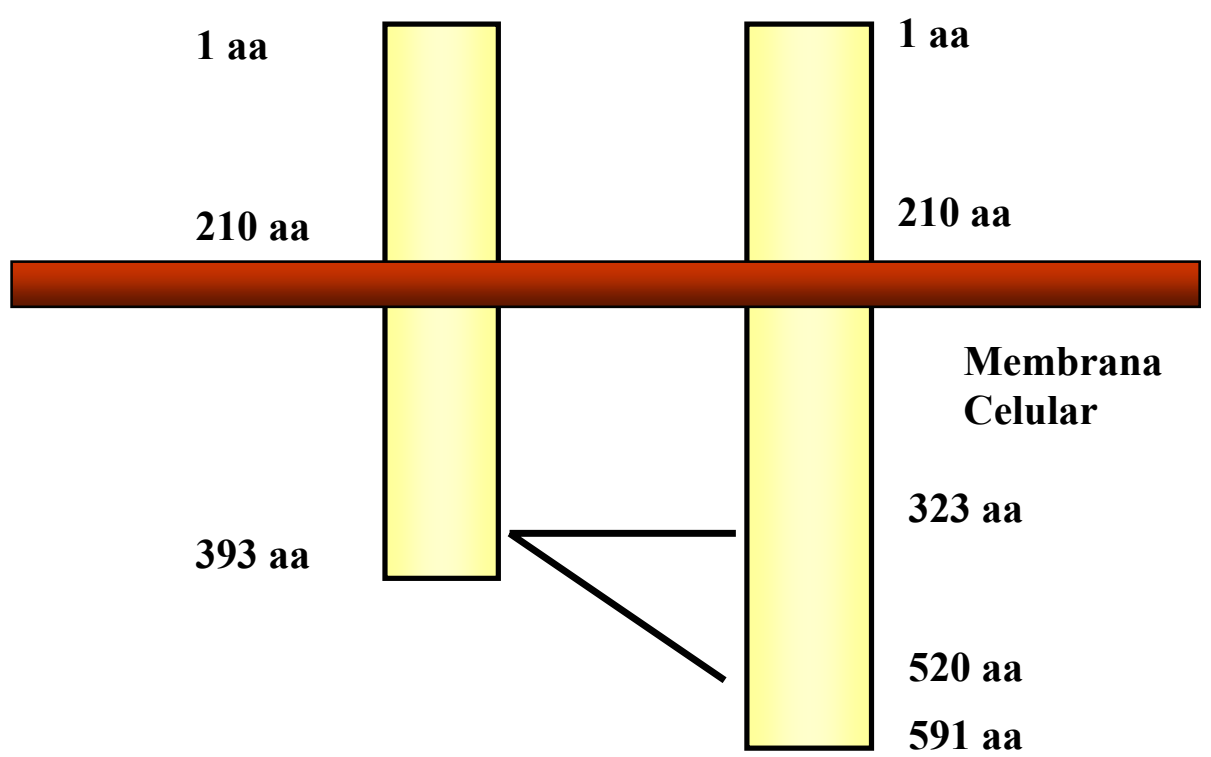

Figura 6. Comparação entre os receptores de PRL de $\mathrm{Nb} 2$ e a forma nativa longa de rato; (aa) aminoácidos 
Apesar da mutação, a sinalização intracelular se manteve preservada e este receptor apresentou afinidade à PRL de 3 a 4 vezes maior que a isoforma longa nativa. As células $\mathrm{Nb} 2$ expressam mais de 10 mil receptores em sua superfície ${ }^{98}$, fato que também deve contribuir para a alta sensibilidade do ensaio.

A partir da descrição de indivíduos portadores de macroprolactinemia, o ensaio $\mathrm{Nb} 2$ passou a ser empregado para avaliar a bioatividade da bbPRL. Os resultados desses estudos foram contraditórios, visto que em parte deles a bbPRL apresentou atividade menor que a da PRL padrão ${ }^{27,45,48,91,99}$, e, em sua maioria, a atividade da bbPRL e da PRL padrão se equipararam ${ }^{26,47,49,50,51,86,100,101}$. Esses resultados discrepantes podem ser explicados pela heterogeneidade das moléculas de bbPRL. Adicionalmente, autores ${ }^{50}$ que encontraram atividade biológica in vitro considerável da bbPRL advogam que, devido ao seu alto peso molecular, ela não ultrapasse os capilares sangüíneos e portanto não apresente atividade in vivo. Os dados resumidos dos estudos de bioatividade da bbPRL em Nb2 da literatura encontram-se no Anexo B, Tabela 2.

As isoformas do PRLR humano não são homólogas ao receptor expresso nas células $\mathrm{Nb} 2^{102}$ e estudos anteriores ${ }^{103,104}$ utilizando ensaios com células transfectadas com gene-repórter (reporter gene) demonstraram que a resposta biológica dos hormônios lactogênicos é espécie-específica. Portanto, um ensaio envolvendo um receptor murino e mutado como o $\mathrm{Nb} 2$ talvez não seja adequado para avaliar a atividade biológica da bbPRL humana, sendo mais indicado um ensaio espécie mediado, ou seja, com células que expressem o PRLR humano e que potencialmente apresentem melhor correlação com os achados in vivo dos portadores de macroprolactinemia. 
2. Objetivos 
O objetivo deste trabalho é padronizar a determinação da atividade biológica de bbPRL em células Ba/F-03 transfectadas com PRLR humano. Pretende-se ainda avaliar a atividade biológica da bbPRL de pacientes com hiperprolactinemia com predomínio de bbPRL em dois bioensaios, com células Nb2 e Ba/F-03 transfectadas com PRLR humano, comparando os métodos em função da atividade biológica da bbPRL. Finalmente, busca-se também correlacionar a atividade biológica in vitro da bbPRL com os achados clínicos e laboratoriais dos pacientes incluídos no estudo. 
3. Métodos 


\subsection{Casuística}

Estudamos indivíduos portadores de hiperprolactinemia, com e sem macroprolactinemia, matriculados nos ambulatórios de Endocrinologia e Metabologia do Hospital das Clínicas da Faculdade de Medicina da Universidade de São Paulo. Todos os indivíduos avaliados assinaram o Termo de Consentimento Livre e Informado, aprovado pela Comissão de Ética em Pesquisa do Hospital das Clínicas de São Paulo está no Anexo A.

Foram incluídos no estudo indivíduos de ambos os sexos, homens de qualquer faixa etária e mulheres em idade fértil, com concentrações de PRL séricos acima de 30ng/mL (Wallac ${ }^{\circledR}$, AutoDELFIA). Denominamos Grupo I aquele composto por indivíduos com macroprolactinemia, definida quando mais de $50 \%$ da PRL total era decorrente de bbPRL. O Grupo I foi constituído por 18 indivíduos, dois do sexo masculino e 16 do sexo feminino. O Grupo II foi composto por pacientes pós-puberais, hiperprolactinêmicos, sem macroprolactinemia, cujas amostras de mPRL foram utilizadas como controle positivo nos bioensaios. Este grupo foi constituído de cinco pacientes, dois do sexo masculino e três do sexo feminino.

Excluímos mulheres em uso de contraceptivos orais ou injetáveis, submetidas a histerectomia ou no período de climatério, por haver dificuldades na avaliação da função ovulatória. 


\subsection{Métodos}

\subsubsection{Avaliação clínica}

A avaliação clínica foi constituída por:

- Anamnese, incluindo pesquisa de etiologia da hiperprolactinemia, como, gestação, hipotireoidismo e drogas; e

- Exame físico, que incluiu a avaliação de caracteres sexuais secundários e pesquisa de galactorréia.

A fim de comparar as características clínicas com os outros dados do estudo, padronizamos os sinais e os sintomas por meio de pontuação quanto à presença de galactorréia e ao estado gonadal:

- A presença de galactorréia foi classificada em 0 , se ausente, I, se presente a expressão mamária em pequena quantidade, II, se quantidade moderada a grande e III, na presença de saída de secreção láctea espontaneamente; e

- Em homens, a pontuação foi 0 , se as concentrações de testosterona fossem normais e III, na presença de hipogonadismo hipogonadotrófico. Nas mulheres, a pontuação foi 0 , na presença de ciclos menstruais ovulatórios, I, se fase luteal curta, II, para oligomenorréia e III, para amenorréia, se fossem secundários à hiperprolactinemia e reversíveis com tratamento específico. Obtivemos a pontuação final pela soma de cada escore. 


\subsubsection{Avaliação laboratorial}

\subsubsection{Bioquímica}

A avaliação bioquímica foi composta por:

- Determinação quantitativa de uréia e creatinina para avaliação da função renal como causa de hiperprolactinemia;e

- Determinação quantitativa de alanina aminotransferase e de aspartato aminotransferase para avaliação de perfil hepático

\subsubsection{Hormonal}

A avaliação hormonal foi composta por:

- Avaliação de função tireoideana (TSH e $\mathrm{T}_{4} \mathrm{l}$ ), para descartar hipotireoidismo como causa de hiperprolactinemia;

- Avaliação da função hipofisária pelas dosagens basais de GH e IGF-I, ACTH e cortisol sérico na vigência de adenoma hipofisário;

- Determinação de gonadotrofinas (FSH e LH);

- Nos homens, determinação de testosterona total ao menos em duas ocasiões;e

- Nas mulheres, determinação de progesterona na fase luteal em ao menos dois ciclos menstruais não-consecutivos.

\subsubsection{Determinação quantitativa de PRL sérica}

Ao menos duas determinações de PRL sérica, em ocasiões distintas, entre 8 h e 11 h, foram realizadas utilizando o mesmo método (Wallac $\AA$, AutoDELFIA, PerkinElmer Life Sciences. Boston, EUA), porém obtidas em ensaios diferentes. O valor de referência em homens é de $2 \mathrm{ng} / \mathrm{mL}$ a $10 \mathrm{ng} / \mathrm{mL}$ e de $2 \mathrm{ng} / \mathrm{mL}$ a $15 \mathrm{ng} / \mathrm{mL}$ para 
mulheres e a dose mínima detectável de PRL é de $0,013 \mathrm{ng} / \mathrm{mL}$. Os coeficientes da variação intra- e interensaio foram $1,05 \%$ e $2,60 \%$, respectivamente. O padrão utilizado para calibrar a curva foi o Terceiro Padrão Internacional da Organização Mundial de Saúde (WHO 84/500).

\subsubsection{Pesquisa de macroprolactina}

A determinação quantitativa de PRL sérica foi solicitada nos indivíduos do Grupo I por diversos motivos, discriminados na Tabela 4, página 35. Como os indivíduos com hiperprolactinemia eram oligossintomáticos ou assintomáticos, a presença de macroprolactinemia foi investigada. O rastreamento da macroprolactinemia foi realizado segundo técnica previamente descrita ${ }^{33}$. Uma alíquota de $250 \mu \mathrm{L}$ de soro foi utilizada para o rastreamento, adicionada a $250 \mu \mathrm{L}$ de solução de PEG 6000 (em água, mantido a $-4{ }^{0} \mathrm{C}$ ). A solução resultante foi homogeneizada por 1 minuto com vórtex e centrifugada (9500 g, por 5 minutos, em temperatura ambiente). A PRL foi determinada no sobrenadante, por método imunofluorimétrico (Wallac ${ }^{\circledR}$, autoDELFIA), e a porcentagem de recuperação foi calculada.

A confirmação de macroprolactinemia foi realizada por cromatografia por gelfiltração, em sistema de Fast Protein Liquid Chromatography (FPLC), em coluna de 1,6 cm x 30,0 cm, Superdex 200 (Pharmacia ${ }^{\circledR}$, Upsala, Suécia), eluída por tampão constituído por $20 \mathrm{mM} \mathrm{Na} 2 \mathrm{HPO}_{4} / \mathrm{NaH}_{2} \mathrm{PO}_{4}, 15 \mathrm{mM} \mathrm{NaCl}$ e $10 \mathrm{mg} / \mathrm{L}$ de gentamicina, em pH 7,5. A coluna foi calibrada com azul-dextran $(2000 \mathrm{kDa})$ e diferentes soluções com proteínas de peso molecular conhecidos como ovalbumina (43 kDa), aldolase (158 kDa) e quimiotripsinogênio (25 kDa). Quinhentos microlitros de soro de cada indivíduo foram aplicados à coluna e eluídos a $1 \mathrm{~mL} / \mathrm{min}$. Alíquotas de $1,5 \mathrm{~mL}$ foram coletadas e as 
concentrações de PRL e GH foram determinadas em cada uma das frações (Wallac ${ }^{\text {, }}$ AutoDELFIA). A concentração de GH foi determinada porque ambos bioensaios são sensíveis à ação tanto do GH quanto da PRL e, portanto, se houvesse GH detectável nas frações utilizadas nos bioensaios, poderia haver somatória do efeito da PRL e do GH na proliferação celular. A área sob a curva do gráfico obtido com a determinação de PRL nas frações onde as alíquotas foram coletadas era equivalente às porcentagens de cada fração de PRL (mPRL, bPRL e bbPRL) e calculou-se o valor absoluto de cada isoforma nas amostras de soro. As alíquotas foram mantidas a $-80{ }^{0} \mathrm{C}$, logo após sua coleta, até o momento de utilizá-las nos bioensaios, evitando degradação da bbPRL por descongelamentos repetidos. As alíquotas foram diluídas para a obtenção de três diferentes concentrações de bbPRL, no meio de ensaio apropriado para Nb2 e Ba/F-LLP.

\subsubsection{Avaliação por imagem}

Os indivíduos estudados foram submetidos à ressonância magnética (RM) da região selar (Sigma ${ }^{\circledR}$ LX GE, Milwaukee, EUA), 1,5T, e gradiente de $23 \mathrm{mT} / \mathrm{m}$. Os cortes foram axiais, coronais e sagitais em $\mathrm{T}_{1}$, pré- e pós-gadolíneo e $\mathrm{T}_{2}$.

\subsubsection{Bioensaios}

\subsubsection{1 $\mathrm{Nb2}$}

As células Nb2 foram gentilmente cedidas pelo Prof. Dr. Paolo Bartolini (Centro de Biologia Molecular do Instituto de Pesquisas Energéticas e Nucleares_IPEN_do Conselho Nacional de Energia Nuclear, São Paulo), que as obteve diretamente do PhD Peter W. Gout (British Columbia Cancer Agency, Vancouver, Canadá). As células foram mantidas 
em suspensão, em meio de cultura RPMI 1640 suplementado com 10\% de soro de cavalo castrado (SC), $10 \%$ de soro fetal bovino (SFB), $50 \mathrm{U} / \mathrm{mL}$ de penicilina, $50 \mu \mathrm{g} / \mathrm{mL}$ de estreptomicina (Invitrogen ${ }$, Carlsbad, CA, EUA) e $0,1 \mathrm{mM}$ de $\beta$-mercaptoetanol. O bioensaio foi realizado como o descrito por Tanaka et al. ${ }^{92}$, com algumas modificações. As células foram mantidas em meio com $1 \%$ de SFB e $10 \%$ de SC, por $24 \mathrm{~h}$ antes da realização do ensaio, período denominado "pré-ensaio". Em seguida, por duas vezes foram centrifugadas e ressuspensas em meio sem SFB, acrescido de 15 mM HEPES (N-2Hidroxietilpiperazina-N'-2-ácido etano sulfônico). Foram distribuídos $100 \mu \mathrm{L}$ em placas de 96 poços, na concentração de $2 \times 10^{4}$ céls./poço. Os hormônios, diluídos no meio de ensaio, foram adicionados para um volume final de $200 \mu \mathrm{L}$. Para a construção da curva padrão foram empregadas diferentes concentrações de PRL padrão $(0 \mathrm{ng} / \mathrm{mL} ; 0,0156$ $\mathrm{ng} / \mathrm{mL} ; 0,0315 \mathrm{ng} / \mathrm{mL} ; 0,0625 \mathrm{ng} / \mathrm{mL} ; 0,125 \mathrm{ng} / \mathrm{mL} ; 0,25 \mathrm{ng} / \mathrm{mL}$ e $0,5 \mathrm{ng} / \mathrm{mL})$, conforme protocolo utilizado no Centro de Biologia Molecular do IPEN. As amostras foram analisadas em três concentrações diferentes, em quadruplicatas. As frações de mPRL e bbPRL foram obtidas após FPLC do soro do indivíduo e corresponderam ao soro diluído no tampão da coluna de cromatografia, diluído posteriormente em meio de ensaio, para obterem-se as concentrações de PRL desejadas. As células foram incubadas a $37{ }^{0} \mathrm{C}, 5 \%$ $\mathrm{CO}_{2}$ por 72 horas. A resposta do ensaio foi avaliada pela densidade óptica (DO), proporcional à proliferação celular, utilizando a reação com MTS [3(4,5-dimetiltiazol-2yl)-5(3-carboximetoxifenil)-2-(4-sulfofenil)-2H-tetrazolina] (Promega Corp. ${ }^{\circledR}$, Madison, WI, EUA). Dois miligramas por mililitro de MTS foram diluídos em PBS (tampão fosfato-salina) e adicionados ao metosulfato de fenazina (Sigma ${ }^{\circledR}$, St. Louis, MO, EUA), 0,92 mg/mL em PBS, em uma proporção de 20:1 (vol/vol). Vinte microlitros desta mistura foram adicionados a cada poço da placa de ensaio e após $2 \mathrm{~h}$ de incubação a $37{ }^{0} \mathrm{C}$ 
realizamos a leitura de DO no comprimento de onda de $490 \mathrm{~nm}$, em leitor automatizado (Dynatech ${ }^{\circledR}$, model MR4000, Chantilly, VA, EUA). O MTS é biorreduzido a formazan, na presença do metosulfato de fenazina (reagente acoplador de elétrons) na mitocôndria das células vivas. A quantidade de formazan produzido é medida pela absorvância em $490 \mathrm{~nm}$ e, portanto, quanto maior o estímulo proliferativo da PRL, maior o número de células vivas e maior a DO.

\subsubsection{Ba/F-LLP}

$\mathrm{Ba} / \mathrm{F}-03$ são células murinas pró-B, dependentes de IL-3, que foram transfectadas com um plasmídeo contendo o gene da isoforma longa do receptor de PRL humano (hPRLR). Após a transfecção estável e a adição de PRL em substituição a IL-3 ao meio de crescimento, uma população de células, dependentes de PRL e resistentes ao antibiótico geneticina, foi selecionada ${ }^{103}$. Após algumas passagens com $10 \mathrm{ng} / \mathrm{mL}$ de PRL acrescida ao meio, uma população estável denominada LP (low PRL) foi obtida ${ }^{103}$. A partir das células $\mathrm{Ba} / \mathrm{F}-\mathrm{LP}$, obtivemos outra população mais sensível, cujo crescimento máximo ocorreu a $1 \mathrm{ng} / \mathrm{mL}$ de PRL, a qual denominamos LLP (low low $P R L$ ). Estas células foram mantidas em suspensão no meio RPMI-1640, suplementado com $10 \%$ de soro fetal bovino inativado (SFBI) por incubação a $50{ }^{\circ} \mathrm{C}$ por 20 minutos, 2 $\mathrm{mM}$ de glutamina, $50 \mathrm{U} / \mathrm{mL}$ de penicilina, $50 \mu \mathrm{g} / \mathrm{mL}$ de estreptomicina, $700 \mu \mathrm{g} / \mathrm{mL}$ of geneticina e $1 \mathrm{ng} / \mathrm{mL}$ de PRL recombinante (rPRL). No dia do ensaio, as células foram mantidas de 4 h a 6 h em meio com 1\% de SFBI e depois distribuídas em placa de 96 poços, $50 \times 10^{4}$ de células por poço, em volume final de $200 \mu \mathrm{L}$, com $100 \mu \mathrm{L}$ de solução contendo as amostras. Após $72 \mathrm{~h}$, a $37{ }^{\circ} \mathrm{C}$ e $5 \% \mathrm{CO}_{2}$, a resposta proliferativa das células foi avaliada pelo método com MTS, descrito acima. Uma curva padrão com 
diferentes concentrações de PRL recombinante humana foi construída em cada ensaio (0 ng/mL; 0,168 ng/mL; 0,21 ng/mL; $0,26 \mathrm{ng} / \mathrm{mL} ; 0,33 \mathrm{ng} / \mathrm{mL} ; 0,41 \mathrm{n} \mathrm{g} / \mathrm{mL} ; 0,51$ $\mathrm{ng} / \mathrm{mL} ; 0,64 \mathrm{ng} / \mathrm{mL} ; 0,8 \mathrm{ng} / \mathrm{mL}$ e $1 \mathrm{ng} / \mathrm{mL}$ ). Para cada caso estudado, as amostras de bbPRL ou mPRL obtidas por FPLC foram diluídas em meio de ensaio e as diferentes concentrações foram analisadas em triplicatas. Nos casos em que houve resposta proliferativa frente ao estímulo das amostras, de forma dose-dependente, repetimos o ensaio adicionando anticorpo anti-PRL (anticorpo de coelho anti-prolactina humana, NIDDK-anti-hPRL-3, AFP-C11580) na diluição final de 1:4000, a fim de confirmar a especificidade da resposta.

\subsubsection{Padrões de PRL}

Para o ensaio Nb2, utilizamos o Terceiro Padrão Internacional de PRL humana pituitária da Organização Mundial de Sáude (OMS), WHO 84/500, referida neste estudo como wPRL e cuja bioatividade é considerada de $53 \mathrm{mIU} / 2,5 \mu \mathrm{g}$. Esta preparação foi gentilmente cedida pelo National Institute for Biological Standards and Control (South Mimms, Reino Unido). Para o ensaio Ba/F-LLP, empregamos como padrão uma PRL recombinante humana ${ }^{103}$, produzida em bactérias e purificada, aqui denominada de rPRL, gentilmente cedida pelo $\mathrm{PhD}$ Vincent Goffin, pesquisador da unidade U584, INSERM, Faculdade Necker, Paris, França. Uma vez que os ensaios Nb2 e Ba/F-LLP foram realizados em laboratórios diferentes, respectivamente no Centro de Biologia Molecular do IPEN e na unidade U584 INSERM, utilizamos os padrões de PRL humana disponíveis em cada um deles, a saber: wPRL no IPEN e rPRL no U584 INSERM. O padrão de referência primário (wPRL) foi utilizado para calibrar o padrão rPRL empregado nos ensaios Ba/F-LLP. 


\subsubsection{Determinação da bioatividade e sua relação com imunoatividade para as amostras de PRL}

A quantificação da PRL presente nas amostras foi realizada por dois ensaios de princípios distintos: os bioensaios, baseados na proliferação celular (Nb2 e Ba/F-LLP), para a avaliação da bioatividade (BA); e o imunoensaio para a avaliação da imunoatividade (IA). A relação entre essas atividades (BA/IA) forneceu um parâmetro para a comparação da potência das amostras estudadas.

\subsubsection{Pesquisa de auto-anticorpo anti-PRL}

A pesquisa de auto-anticorpo anti-PRL foi realizada segundo o método descrito por Hattori et al. em $1992^{87}$. Cem microlitros de soro foram adicionados a $50 \mu \mathrm{L}$ de $\left[{ }^{125} \mathrm{I}\right]$ PRL (15000 cpm/50 $\mu \mathrm{L}$ de tampão fosfato) e incubados por $1 \mathrm{~h} \mathrm{a} 37^{\circ} \mathrm{C}$, seguido da adição de $150 \mu \mathrm{L}$ de PEG $25 \%$. O volume foi homogeneizado e centrifugado a $3896 \mathrm{~g}$ por 30 minutos, em centrífuga Sorval ${ }^{\circledR}$, em rotor de $18,6 \mathrm{~cm}$ de raio (HS-4). O precipitado (pellet) foi lavado com PEG $12,5 \%$ e a radioatividade foi determinada em um contador de radiação gama. Consideramos as amostras de soro positivas para a presença de autoanticorpo anti-PRL se a radioatividade excedesse em dois desvios padrões a média obtida em 39 amostras controles (21 amostras de soro normoprolactinêmicos e 18 amostras com hiperprolactinemia por mPRL). 


\subsection{Pesquisa de auto-anticorpos}

Como a prevalência de auto-anticorpo anti-PRL nos indivíduos com macroprolactinemia é freqüente ${ }^{29,46,47,71,76,84-88}$ e a origem desse auto-anticorpo não é conhecida, procedemos a pesquisa de outros auto-anticorpos para verificar a associação entre anticorpo anti-PRL e auto-imunidade. As características dos auto-anticorpos avaliados estão dispostas na Tabela 3.

Tabela 3 - Características da pesquisa de auto-anticorpos

\begin{tabular}{|c|c|c|c|}
\hline AUTO-AC & METODOLOGIA; VR & $\begin{array}{c}\text { FREQÜÊNCIA EM } \\
\text { ASSINTOMÁTICOS }\end{array}$ & $\begin{array}{c}\text { DOENÇA } \\
\text { ASSOCIADA }\end{array}$ \\
\hline Anti-TPO & $\begin{array}{l}\text { Quimioluminescência; } \\
\qquad 35 \mathrm{UI} / \mathrm{mL}\end{array}$ & $8-27 \%{ }^{105}$ & $\begin{array}{l}\text { Tireoidite de } \\
\text { Hashimoto }\end{array}$ \\
\hline FAN & $\begin{array}{c}\text { Imunofluorescência; } \\
\text { negativo }\end{array}$ & $5-13 \%{ }^{107}$ & $\begin{array}{l}\text { Doenças } \\
\text { reumatológicas } \\
\text { auto-imunes }\end{array}$ \\
\hline Antiendomísio & $\begin{array}{l}\text { Imunofluorescência } \\
\text { indireta; ausente }\end{array}$ & $0 \%{ }^{110}$ & Doença celíaca \\
\hline Anti-GAD & $\begin{array}{l}\text { Radioimunoensaio } \\
\text { Agente marcador }{ }^{125} \mathrm{I} \\
\quad<1 \mathrm{U} / \mathrm{mL}\end{array}$ & $0,6 \%^{113}$ & $\begin{array}{c}\text { Diabetes } \\
\text { melito tipo } 1\end{array}$ \\
\hline Antimitocôndria & $\begin{array}{l}\text { ELISA; } \\
<1,1 \mathrm{UA}\end{array}$ & $0,64 \%{ }^{115}$ & $\begin{array}{l}\text { Cirrose biliar } \\
\text { primária }\end{array}$ \\
\hline Antiovário & $\begin{array}{l}\text { Hemaglutinação; } \\
\text { ausente }\end{array}$ & $0-7,7 \%{ }^{119,120}$ & $\begin{array}{c}\text { Insuficiência } \\
\text { ovariana } \\
\text { precoce }\end{array}$ \\
\hline
\end{tabular}

(AC) anticorpo; (FAN) fator antinúcleo; (GAD) ácido glutâmico descarboxilase; (TPO) peroxidase; (UI) unidades internacionais; (UA) unidades arbitrárias; (VR) valor de referência 
Antiperoxidase ou anti-TPO pode estar presente na população geral, de $8 \%$ a $27 \%$, dependendo do método diagnóstico utilizado ${ }^{105}$. O anti-TPO aparece como resposta secundária à lesão tireoideana, não sendo capaz de iniciar a doença. Sua prevalência é cinco vezes maior na população feminina e atinge de $90 \%$ a $100 \%$ dos indivíduos com tireoidite auto-imune ${ }^{105}$, quando seus títulos atingem altas concentrações, em geral acima de $200 \mathrm{U} / \mathrm{mL}^{106}$. Alguns autores ${ }^{45,56}$ demonstraram a existência de doença tireoideana auto-imune em indivíduos com macroprolactinemia, sugerindo alguma correlação patológica. No entanto ValleteKasic et al. ${ }^{35}$ avaliaram a prevalência de anti-TPO em uma grande série de casos, testando 36 indivíduos com macroprolactinemia e 12 pacientes hiperprolactinêmicos sem predomínio de bbPRL, e não houve diferença entre os dois grupos. A pesquisa de anti-TPO foi realizada por quimioluminescência (Immulite ${ }^{\circledR} 2000$, DPC), cuja sensibilidade analítica foi de 5,0 UI/mL. As amostras de soro foram consideradas positivas para valores acima de $35 \mathrm{UI} / \mathrm{mL}$.

A pesquisa de anticorpos contra constituintes do núcleo, nucléolo, citoplasma e aparelho mitótico é realizada na investigação de doenças reumatológicas auto-imunes, cujo método diagnóstico mais empregado é a pesquisa do fator antinúcleo (FAN) em células HEp-2. A positividade do teste sem correlação clínica ocorre com certa freqüência, uma vez que $5 \%$ da população geral e até $13 \%$ da população acima dos 50 anos pode apresentar títulos baixos ${ }^{107}$. As células HEp-2 são usadas como substrato da reação de imunofluorescência e diversos padrões de positividade para auto-anticorpos podem ser descritos e correlacionados a determinadas condições clínicas. As amostras de soro foram avaliadas quanto à presença de FAN por imunofluorescência indireta em células HEp-2 (VIRGO ${ }^{\circledR}$ ANA/HEp-2 IgG IFA, Hemagen Diagnostics, Inc.VIRGO ${ }^{\circledR}$ 
Products Division, Columbia, Maryland, EUA). A pesquisa é considerada positiva na presença de fluorescência e os resultados são quantificados por titulação.

A doença celíaca é uma condição clínica caracterizada por intolerância imunológica ao glúten. Manifesta-se classicamente por síndrome de má absorção e é comumente encontrada em indivíduos com outras doenças auto-imunes. O diagnóstico se faz na presença de alterações histológicas encontradas em biópsia intestinal enquanto o indivíduo ingere dieta contendo glúten e os sintomas desaparecem na ausência de glúten na dieta ${ }^{108}$. O padrão-ouro para o seu diagnóstico é a biópsia da mucosa intestinal, porém a presença do anticorpo Ig A antiendomísio apresenta especificidade de $98 \%$ para o diagnóstico e valor preditivo negativo de $98 \%$, sendo, portanto, um marcador sorológico adequado para o diagnóstico ${ }^{109}$. Um estudo ${ }^{110}$ avaliou a freqüência de auto-anticorpos específicos para doença celíaca em 42 pacientes com sintomas sugestivos de doença celíaca e 28 pacientes de clínica de gastroenterologia com outra sintomatologia e biópsia jejunal normal. A freqüência de anticorpo antiendomísio foi de $100 \%$ no primeiro grupo e de $0 \%$ no segundo. No entanto, como a doença celíaca associa-se a outras doenças auto-imunes, como a tireoidite de Hashimoto e o diabete melito tipo 1, e muitas vezes os sintomas presentes não são os clássicos, optamos por avaliar a freqüência de $\operatorname{IgA}$ antiendomísio em nossos casos de macroprolactinemia. Uma parcela dos pacientes com doença celíaca podem apresentar deficiência de $\operatorname{IgA}^{111} \mathrm{e}$ o resultado de anticorpo ser falsamente negativo. Para eliminar essa possibilidade, a IgA foi determinada nos indivíduos aqui estudados. A pesquisa de antiendomísio foi realizada por imunofluorescência indireta para IgA (Mky Oesophagus - IFA, The Binding Site ${ }^{\circledR}$, Birmingham, Reino Unido), nas amostras de soro, utilizando diluição padrão de $1 / 10$. 
GAD é a enzima ácido glutâmico descarboxilase, expressa em diversos tecidos extraneurais, incluindo as células beta pancreáticas. $\mathrm{O}$ anti-GAD, especialmente contra a isoforma $65 \mathrm{kDa}$ de GAD, é considerado o principal auto-anticorpo em diabetes melito tipo 1. É o método de escolha para confirmar a auto-imunidade como causa de diabetes, por sua reprodutibilidade e estabilidade ao longo dos anos, antes e após o diagnóstico de diabetes melito ${ }^{112}$. Esse anticorpo está presente em $70 \%$ a $80 \%$ dos pacientes com diabetes melito tipo 1 recém-diagnosticados ${ }^{112}$. Em um estudo de prevalência de anti-GAD 65 em população japonesa, o anticorpo esteve presente em $0,6 \%$ de 190 indivíduos controles não-diabéticos ${ }^{113}$. Utilizamos o radioimunoensaio para a pesquisa de anti-GAD e amostras maiores ou iguais a $1,0 \mathrm{U} / \mathrm{mL}$ foram consideradas positivas.

A cirrose biliar primária é uma doença auto-imune, órgão-específica, caracterizada pela presença de altos títulos de anticorpo antimitocôndria e destruição dos pequenos ductos biliares intra-hepáticos. O anticorpo antimitocôndria não é específico desta doença, porém entre $90 \%$ a $95 \%$ dos indivíduos com títulos acima de $1 / 40$ são portadores dessa afecção ${ }^{114}$. Outras doenças auto-imunes coexistem com a cirrose biliar primária em até $70 \%$ dos $\operatorname{casos}^{114}$. Um estudo populacional em japoneses identificou prevalência de $0,64 \%$ de anticorpo antimitocôndria positiva dentre trabalhadores saudáveis ${ }^{115}$. A pesquisa de antimitocôndria foi realizada por enzimaimunoensaio (Antimitocondria Hemagen ${ }^{\circledR}$, Columbia, Maryland, EUA) nas amostras de soro. Os resultados forma obtidos examinando-se a placa em uma leitora de microplacas a 450 nm. A leitura da densidade óptica (DO) de cada amostra e dos controles foram divididos pela leitura da DO do soro referência para determinar as Unidades Arbitrárias (UA). Foram consideradas amostras negativas, para valores menores que 0,9 UA, positivas, se acima de 1,1 UA, e duvidosas, entre 0,9 UA e 1,1 UA. 
Aproximadamente de $20 \%$ a $40 \%$ das mulheres com falência ovariana precoce também apresentam distúrbios auto-imunes, como o anticorpo antiovário. Além disso, a freqüência desse anticorpo é maior em mulheres com falência ovariana precoce do que em mulheres saudáveis ${ }^{116}$. Assim, alguns autores ${ }^{117,118}$ sugerem que o anticorpo antiovário esteja implicado na fisiopatologia da falência ovariana precoce. Dois estudos avaliaram a prevalência do anticorpo antiovário por método de imunofluorescência indireta em controles normais, utilizando histologia de ovário humano ${ }^{119}$, a freqüência foi de $52 \%$ (14/27) em mulheres com falência ovarina prematura e $0 \%$ em controles $(0 / 24)$, enquanto que utilizando histologia ovariana de primata $^{120}$, a freqüência em normais foi de $7,7 \%$ (1/13). A hemaglutinação (Bioserv Diagnostics ${ }^{\circledR}$, Rostock, Alemanha) foi o método empregado para pesquisa de Ig antiovário nas amostras do estudo.

Com exceção do anti-TPO, não há relatos na literatura de estudos de prevalência de auto-anticorpos em indivíduos com macroprolactinemia.

\subsection{Análise dos dados}

Os dados foram apresentados como média \pm desvio padrão (DP), exceto quando mencionados de forma diferente. Foram construídas tabelas com estatísticas descritivas (média, desvio padrão, mínimo, mediana e máximo) e gráficos das variáveis BA/IA, inclinação obtida no gráfico de concentração de PRL versus densidade óptica nos bioensaios $\mathrm{Nb} 2$ e Ba/F-LLP, obtidas dos Grupos I e II , visando resumir as observações da amostra. As técnicas inferenciais (testes de hipótese), aplicadas com o objetivo de extrapolar os resultados para as populações de interesse, foram o teste t-Student para 
amostras independentes, teste t-Student pareado, análise de variância com medidas repetidas e método de comparações múltiplas de Bonferroni ${ }^{121}$. Quando necessária, a suposição de igualdade de variâncias para a aplicação dessas técnicas foi checada por meio do teste de Levene ou inspeção dos resíduos ${ }^{121}$. A normalidade foi avaliada por meio da construção de gráficos de probabilidade normal dos resíduos. Nas situações em que foi detectado um desvio grosseiro da distribuição normal, o teste de Kruskal-Wallis foi aplicado. Este teste foi utilizado apenas quando a distribuição se afastou muito da normal, devido à robustez dos testes citados anteriormente à falta de normalidade ${ }^{121}$. Um nível de significância P de 0,05 foi fixado. 
4. Resultados 


\subsection{Características clínicas e laboratoriais dos Grupos I e II}

O Grupo I foi composto por 18 indivíduos com macroprolactinemia, sendo 16 do sexo feminino e 2 do sexo masculino. A mediana de idade foi de 37 (23-54) anos. A razão que motivou a determinação de PRL sérica inicial e as características clínicas desses indivíduos que motivaram a determinação da concentração sérica de PRL foram dispostas na Tabela 4. 
Tabela 4 - Resumo das características clínicas do Grupo I

\begin{tabular}{|c|c|c|c|c|}
\hline CASO & SEXO & IDADE (ANOS) & QUEIXA CLÍNICA & ESCORE \\
\hline 1 & $\mathrm{~F}$ & 52 & Irregularidade menstrual $* \#$ & I \\
\hline 2 & $\mathrm{~F}$ & 42 & Hirsutismo & 0 \\
\hline 3 & $\mathrm{~F}$ & 27 & Exame de rotina & I \\
\hline 4 & $\mathrm{~F}$ & 42 & Galactorréia há 6 anos & $\mathrm{I}$ \\
\hline 5 & M & 33 & Exame de rotina & 0 \\
\hline 6 & $\mathrm{~F}$ & 45 & Irregularidade menstrual* & 0 \\
\hline 7 & $\mathrm{~F}$ & 28 & Síndrome de Cushing & 0 \\
\hline 8 & $\mathrm{~F}$ & 28 & Queda de cabelo & 0 \\
\hline 9 & $\mathrm{~F}$ & 41 & Galactorréia* & 0 \\
\hline 10 & $\mathrm{~F}$ & 37 & Lesões na pele & 0 \\
\hline 11 & $\mathrm{~F}$ & 23 & Irregularidade menstrual* & I \\
\hline 12 & $\mathrm{~F}$ & 25 & Acne & 0 \\
\hline 13 & $\mathrm{~F}$ & 41 & Exame de rotina & 0 \\
\hline 14 & $\mathrm{~F}$ & 37 & Galactorréia * & 0 \\
\hline 15 & $\mathrm{~F}$ & 27 & Cefaléia & 0 \\
\hline 16 & M & 54 & Disfunção erétil & 0 \\
\hline 17 & $\mathrm{~F}$ & 27 & Galactorréia*\# & 0 \\
\hline 18 & $\mathrm{~F}$ & 43 & Cefaléia & 0 \\
\hline
\end{tabular}

Notas: (*) queixas prévias; (\#) em uso de agonista dopaminérgico

Legenda: (F) sexo feminino; (M) sexo masculino 
Nenhum indivíduo apresentou hipogonadismo, e os casos de números 1, 3, 4 e 11 obtiveram pontuação I por apresentarem galactorréia discreta à expressão. Todos os casos do sexo feminino apresentavam ciclos menstruais regulares e ovulatórios e não houve caso de fase luteal curta, que se caracteriza por concentração de progesterona compatível com fase luteal, antes do $14^{0}$ dia do ciclo. As determinações séricas de LH, FSH, estradiol e progesterona na fase luteal dos casos do sexo feminino, e as determinações séricas de LH, FSH e testosterona, nos casos do sexo masculin,o estão dispostos no Anexo B, Tabela 5.

No decorrer do estudo, a paciente de número 8 engravidou e no parto não houve qualquer intercorrência, e ela pode amamentar o recém-nascido.

Com exceção do caso de número 1, todos apresentavam concentrações normais de mPRL, portanto, se houvesse sinais e sintomas decorrentes de hiperprolactinemia, seriam secundários à macroprolactinemia. Os valores de PRL e de suas frações encontram-se na Tabela 6.

Os indivíduos de números 1 e 17 estavam em uso de agonista dopaminérgico durante nossa avaliação, apresentando redução, sem normalização, das concentrações séricas de PRL, mas com restauração dos ciclos menstruais ovulatórios.

Em todos os casos do Grupo I, a bbPRL correspondeu a mais de 50\% da PRL total, e, com exceção dos casos de números 1 e 10, a recuperação após a precipitação com PEG foi menor que 30\%. Nesses dois casos, o valor da recuperação esteve na zona inconclusiva e o diagnóstico definitivo obrigatoriamente seria definido pela cromatografia. Os dados de bbPRL/PRL (\%) versus recuperação de PRL após precipitação com PEG (\%) estão dispostos na Figura 7. 


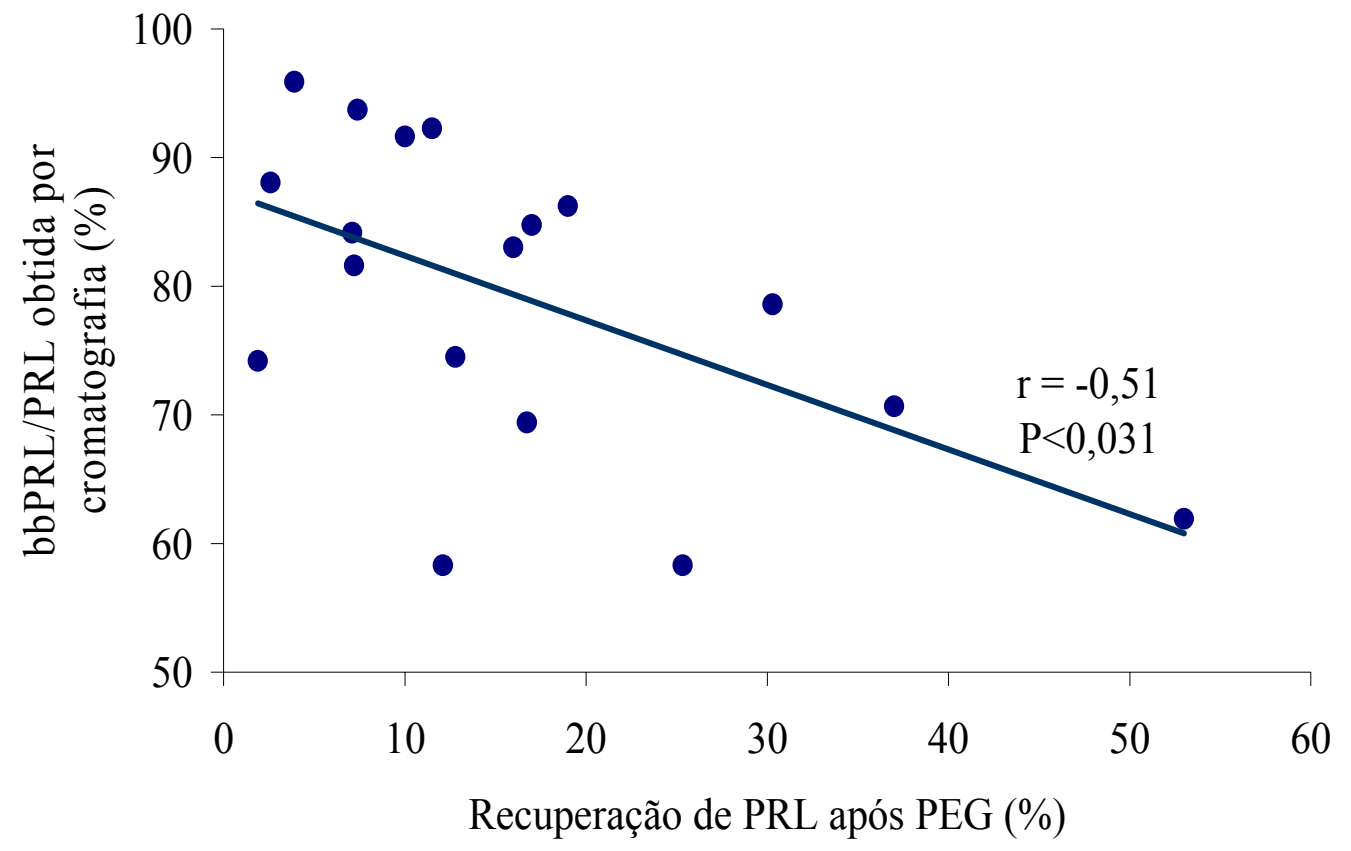

Figura 7. Relação inversa entre bbPRL/PRL(\%) e recuperação da PRL após precipitação com PEG, no Grupo I 
Tabela 6 - Perfil de prolactina dos casos do Grupo I

\begin{tabular}{|c|c|c|c|c|}
\hline CASO & $\begin{array}{c}\text { PRL } \\
(\mathrm{ng} / \mathrm{mL})\end{array}$ & $\begin{array}{l}\text { bbPRL } \\
(\mathrm{ng} / \mathrm{mL})\end{array}$ & $\begin{array}{c}\text { Relação bbPRL/PRL } \\
(\%)\end{array}$ & $\begin{array}{c}\mathrm{mPRL} \\
(\mathrm{ng} / \mathrm{mL})\end{array}$ \\
\hline 1 & 155 & 95,98 & 61,92 & 35,80 \\
\hline 2 & 57,8 & 48,98 & 84,75 & 4,96 \\
\hline 3 & 87,2 & 72,39 & 83,02 & 6,69 \\
\hline 4 & 51,2 & 38,15 & 74,51 & 0,26 \\
\hline 5 & 30,8 & 27,12 & 88,04 & 1,93 \\
\hline 6 & 56,1 & 47,21 & 84,15 & 4,09 \\
\hline 7 & 34,6 & 29,83 & 86,22 & 1,77 \\
\hline 8 & 110 & 101,47 & 92,25 & 5,54 \\
\hline 9 & 166 & 159,18 & 95,89 & 0 \\
\hline 10 & 58,2 & 41,13 & 70,67 & 3,85 \\
\hline 11 & 47,7 & 27,81 & 58,3 & 3.07 \\
\hline 12 & 30,7 & 21,31 & 69,4 & 1,75 \\
\hline 13 & 107,9 & 80,05 & 74,19 & 9,11 \\
\hline 14 & 124 & 113,65 & 91,65 & 2,16 \\
\hline 15 & 43,8 & 25,54 & 58,31 & 1,02 \\
\hline 16 & 37,5 & 35,14 & 93,71 & 1,59 \\
\hline 17 & 40,3 & 31,68 & 78,6 & 4,81 \\
\hline 18 & 82,5 & 67,3 & 81,6 & 5,4 \\
\hline TOTAL & $73,4 \pm 42,6$ & $59 \pm 38$ & $79,3 \pm 11,9$ & $5,3 \pm 8,2$ \\
\hline
\end{tabular}


Os gráficos das cromatografias de PRL dos soros dos indivíduos do Grupo I estão dispostos no Anexo C (C1). A Figura 8 representa dois exemplos de gráficos de cromatografia por gel-filtração para separação de isoformas de PRL: caso de número 1, na Figura $8 \mathrm{~A}$ e caso de número 14, na Figura 8B. Nota-se a predominância da isoforma bbPRL em ambos os casos. O primeiro pico no gráfico corresponde a bbPRL e os subseqüentes representam a bPRL e a mPRL.

A

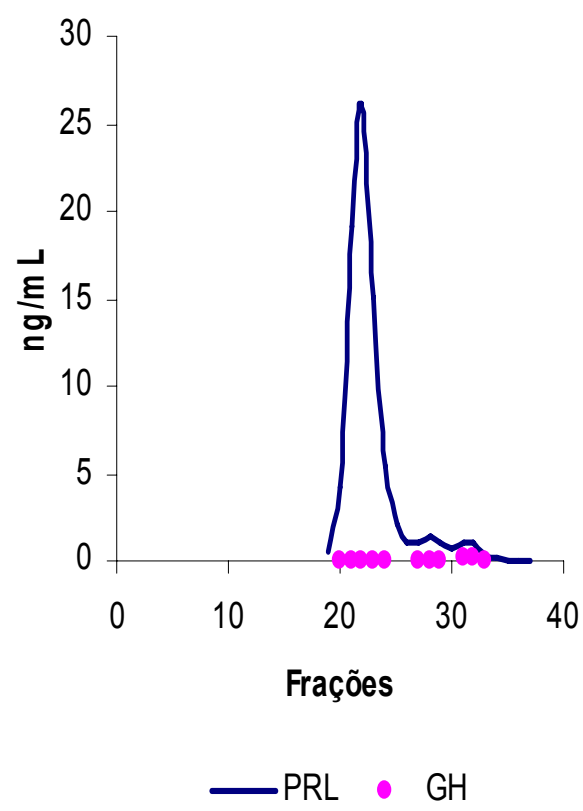

B

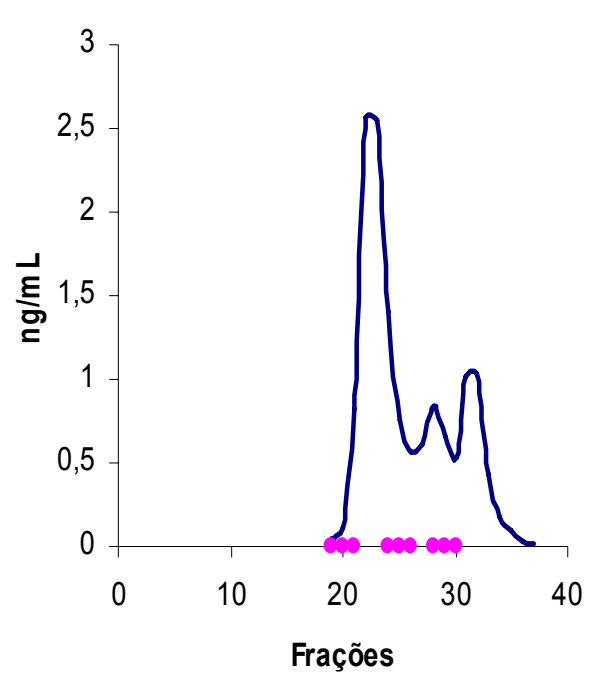

$-\mathrm{PRL} \bullet \mathrm{GH}$

Figura 8. Gráficos obtidos após cromatografia do soro de indivíduos do Grupo I: caso de número $1(\mathrm{~A})$ e caso de número 14 (B)

Sendo as células $\mathrm{Nb} 2$ e $\mathrm{Ba} / \mathrm{F}$-LLP também sensíveis à ação do $\mathrm{GH}$, a determinação desse hormônio foi realizada nos tubos correspondentes ao pico de bbPRL (AutoDELFIA, Wallac ${ }^{\circledR}$ ). Os valores, sempre desprezíveis, não interferiram nos resultados dos bioensaios. 
Quanto ao restante da avaliação laboratorial, os perfis tireoideano, hepático e renal foram normais em todos os casos, no momento da avaliação.

A RM da região selar evidenciou discreta invaginação da aracnóide na região selar no caso de número 1 e convexidade da porção superior da glândula hipofisária nos casos de números 3, 4, 8 e 9; no restante dos casos, a RM foi habitual.

O Grupo II foi composto por cinco pacientes com hiperprolactinemia, sem macroprolactina, cuja mediana de idade foi de 33 (30-37) anos. Os pacientes de números 19, 20 e 23 são do sexo feminino.

No momento de nossa avaliação, os casos de números 19 e 20 apresentavam amenorréia e galactorréia discreta à expressão mamária (pontuação IV) e o caso de número 23 apresentava apenas amenorréia (pontuação III). Os indivíduos do sexo masculino apresentavam hipogonadismo hipogonadotrófico e um deles (caso de número 21) apresentava também galactorréia, conferindo, respectivamente IV e III na pontuação clínica. As características clínicas e laboratoriais do Grupo II estão dispostas na Tabela 7.

Tabela 7 - Características clínicas e laboratoriais do Grupo II

\begin{tabular}{|c|c|c|c|c|c|c|}
\hline PACIENTE & SEXO & $\begin{array}{l}\text { IDADE } \\
\text { (ANOS) }\end{array}$ & $\begin{array}{l}\text { QUADRO } \\
\text { CLÍNICO }\end{array}$ & ESCORE & $\begin{array}{c}\mathrm{PRL} \\
(\mathrm{ng} / \mathrm{mL})\end{array}$ & $\begin{array}{c}\mathrm{mPRL} \\
(\mathrm{ng} / \mathrm{mL})\end{array}$ \\
\hline 19 & $\mathrm{~F}$ & 37 & $\begin{array}{l}\text { Amenorréia e } \\
\text { galactorréia }\end{array}$ & IV & 117,0 & 50,6 \\
\hline 20 & $\mathrm{~F}$ & 37 & $\begin{array}{l}\text { Amenorréia e } \\
\text { galactorréia }\end{array}$ & IV & 107,0 & 34,6 \\
\hline 21 & M & 30 & $\begin{array}{c}\text { Hipogonadismo } \\
\text { e galactorréia }\end{array}$ & IV & 108,0 & 93,9 \\
\hline 22 & M & 33 & Hipogonadismo & III & 53,1 & 39,3 \\
\hline 23 & $\mathrm{~F}$ & 30 & Amenorréia & III & 129,0 & 88,46 \\
\hline TOTAL & & & & & $102,8 \pm 29$ & $61,4 \pm 8$ \\
\hline
\end{tabular}

(F) sexo feminino, (M) sexo masculino 
Os gráficos das cromatografias de PRL dos soros dos pacientes do Grupo II estão no Anexo C (C2). A Figura 9 representa dois exemplos de gráficos de cromatografia por gel-filtração para separação de isoformas de PRL: caso de números 19, na Figura 9A e caso de número 23, na Figura 9B. Nota-se ausência de bbPRL em ambos os casos. O primeiro pico no gráfico representa a bPRL e o segundo pico corresponde a mPRL.

A

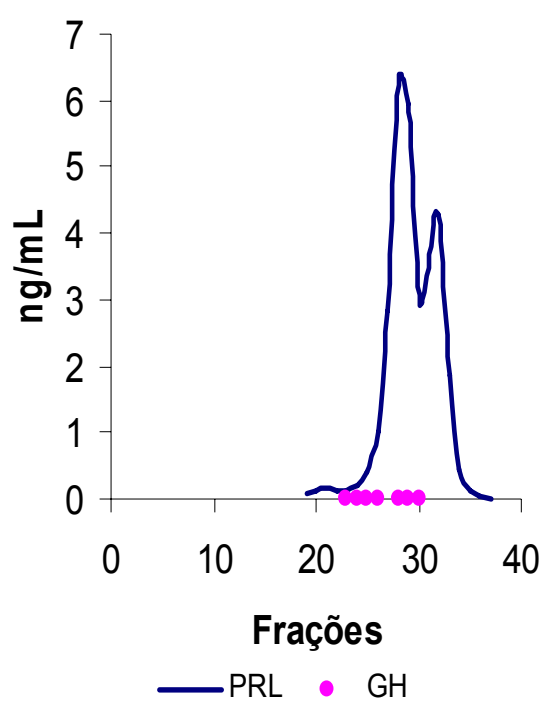

B

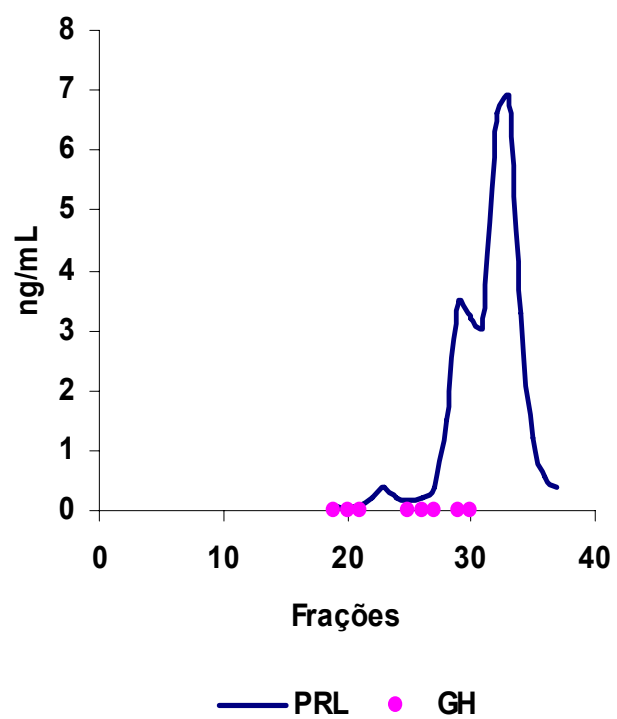

Figura 9. Gráficos obtidos após cromatografia do soro de indivíduos do Grupo II caso de número 19 (A) e caso de número 23 (B)

A RM da região selar identificou imagem compatível com adenoma hipofisário em todos os casos, cujo maior diâmetro foi superior a $1 \mathrm{~cm}$ nos casos de números 20, 21 e 23. O restante da avaliação da função hipofisária foi normal. Prolactinoma foi o diagnóstico presumível nos casos de números 19, 22 e 23 e confirmado por anátomopatológico nos casos de números 20 e 21 . Os dois últimos pacientes foram submetidos à neurocirurgia para ressecção do adenoma hipofisário por apresentarem resistência aos agonistas dopaminérgicos. 


\subsection{Bioensaios}

\subsubsection{Nb2}

As células $\mathrm{Nb} 2$ crescem em suspensão e são birrefringentes, como pode ser observado na Figura 10, que representa a visualização das células em aumento de 100 vezes, por um microscópio invertido.

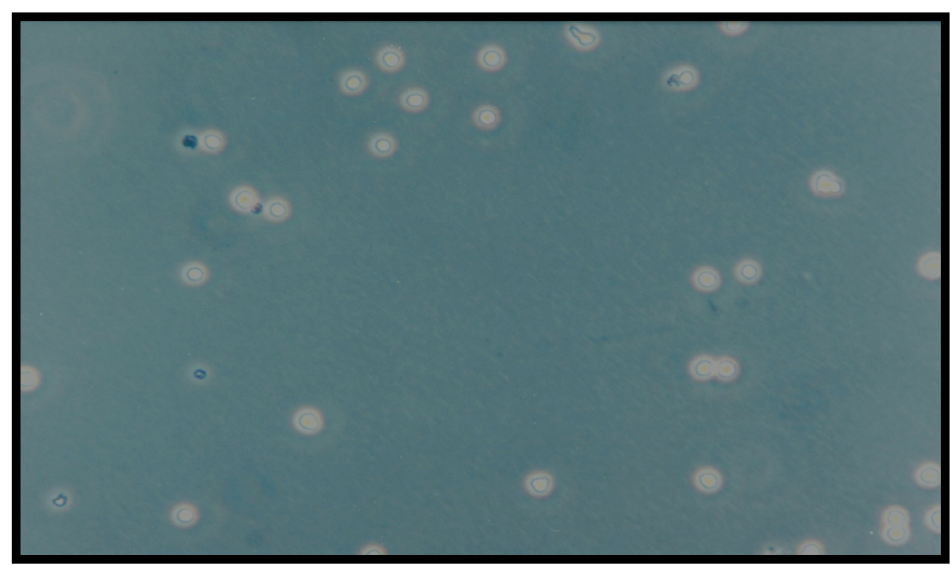

Figura 10. Microfotografia óptica com aumento de 100x das células Nb2

Usando como referência a PRL ovina (Sigma ${ }^{\circledR}$, St. Louis, MO, EUA), comparamos o meio de cultura utilizado inicialmente por Tanaka et al. ${ }^{92}$, ou seja meio de Fischer, com o meio RPMI, também utilizado por outros autores ${ }^{103}$. Optamos por utilizar o meio RPMI nos bioensaios devido à disponibilidade. A Figura 11 mostra o paralelismo da proliferação celular com os diferentes meios de crescimento acima citados. 


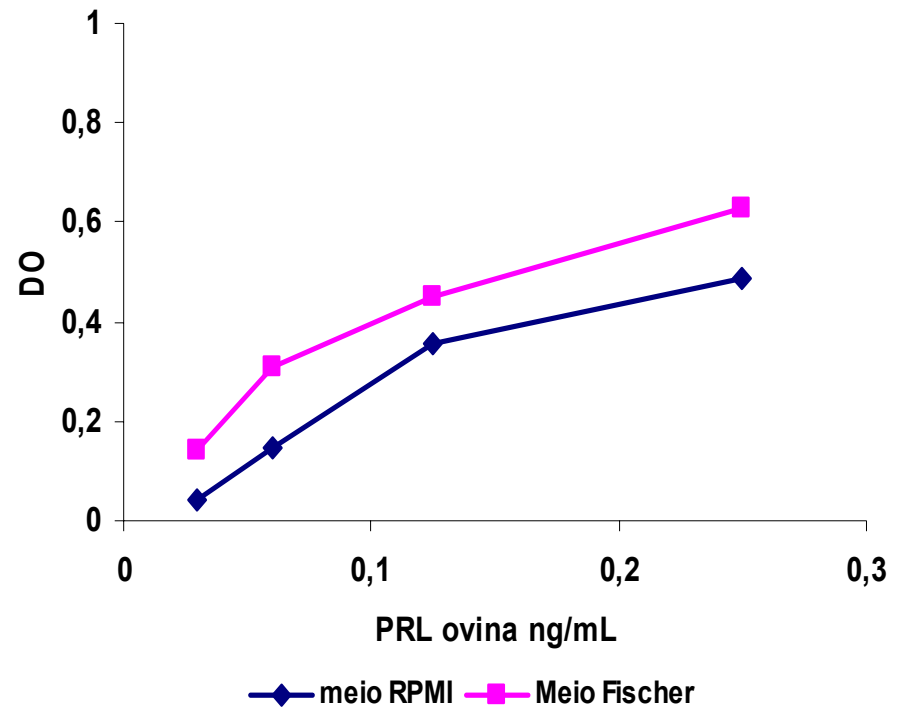

Figura 11. Comparação entre os meios de Fischer e RPMI em Nb2

Para confirmar a validação do método colorimérico com MTS, comparamos a DO no comprimento de onda de $490 \mathrm{~nm}$ com as concentrações celulares avaliadas por contagem manual. A análise dos resultados sugeriram uma correlação (Figura 12) e, portanto, utilizamos a DO como medida indireta da proliferação celular.

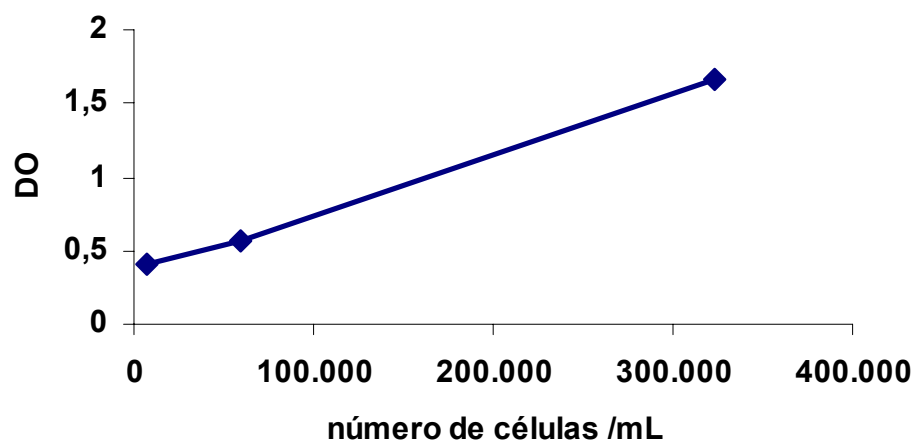

Figura 12. Densidade óptica versus número de células $\mathrm{Nb} 2$ por $\mathrm{mL}$ 
Na comparação com o padrão 84/500 da OMS (wPRL), a PRL recombinante (rPRL) apresentou potência 1,2 vezes maior no bioensaio com células $\mathrm{Nb} 2$, demonstrado na Figura 13. Embora as amostras apresentem potências diferentes, observamos paralelismo na resposta biológica.

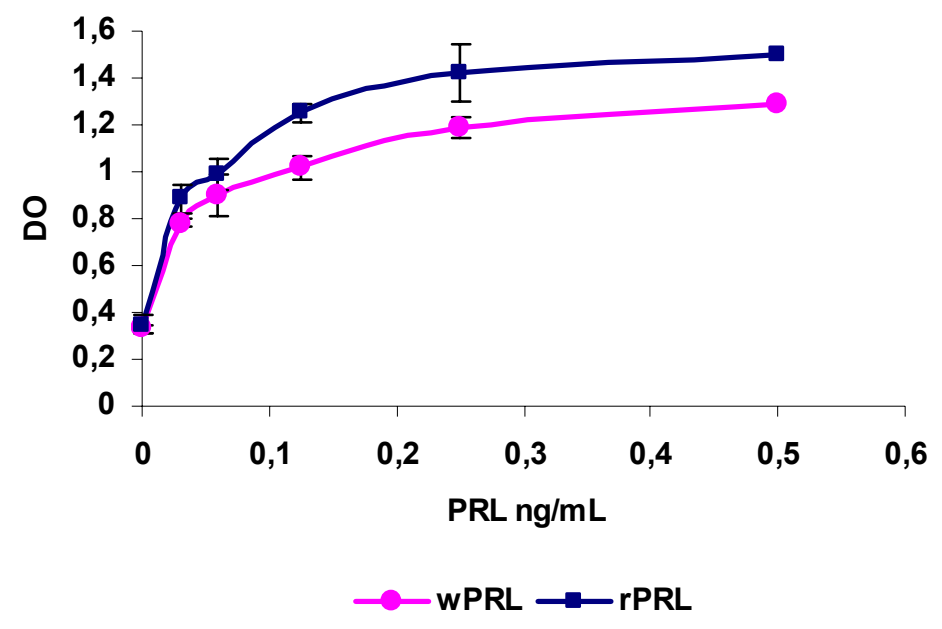

Figura 13. Comparação entre as respostas biológicas das amostras wPRL (84/500, OMS) e rPRL (prolactina recombinante)

Uma fração do padrão wPRL foi analisada mediante cromatografia por gelfiltração, cujo resultado mostrou que mais de $90 \%$ deste padrão corresponde à isoforma mPRL, como ilustrado na Figura 14.

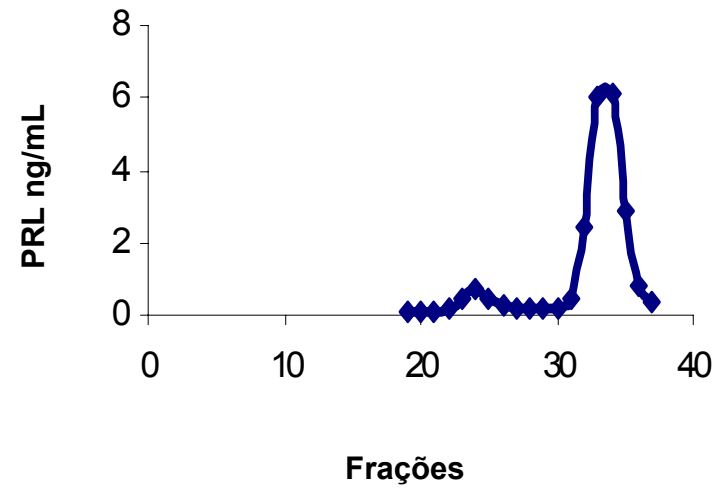

Figura 14. Gráfico obtido cromatografia por gel-filtração de wPRL 
Considerando todos os ensaios realizados com as amostras de wPRL, calculamos o coeficiente de variação de $11 \%$ no intra-ensaio e de $29 \%$ no interensaio para a concentração de $0,25 \mathrm{ng} / \mathrm{mL}$ de wPRL. Com uma curva dose-resposta realizada com wPRL, em octoplicatas, obtivemos coeficiente de variação máximo de $10 \%$, conforme a Figura 15. A mínima dose detectável (MDD), correspondente à concentração de PRL capaz de promover resposta biológica dois desvios padrão acima da concentração zero, e $50 \%$ da dose efetiva $\left(\mathrm{ED}_{50}\right)$ foram calculadas: $0,009 \mathrm{ng} / \mathrm{mL}$ e $0,35 \mathrm{ng} / \mathrm{mL}$ de $\mathrm{wPRL}$, respectivamente.

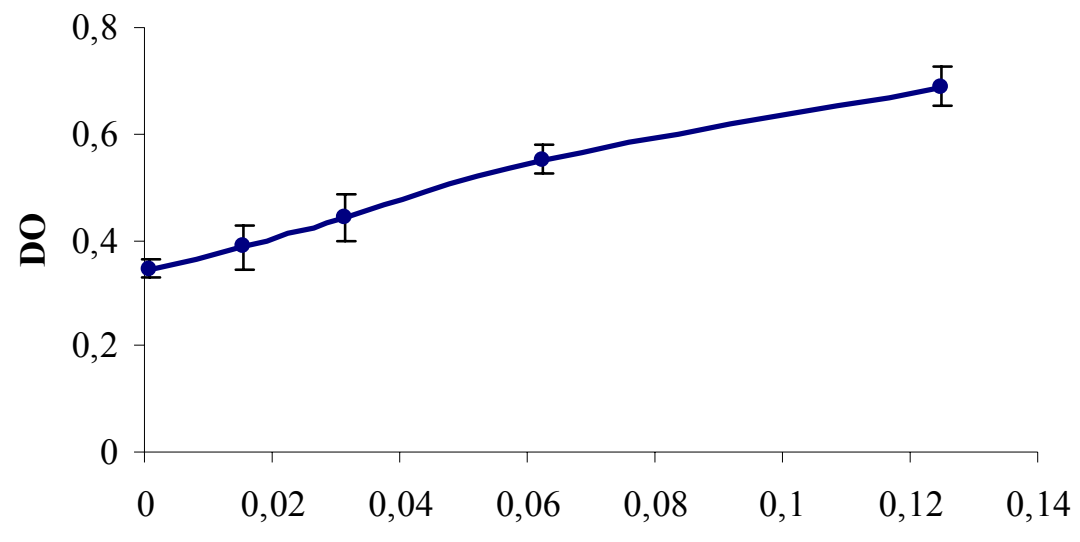

PRL ng/mL

Figura 15. Curva dose-resposta do padrão wPRL, em octoplicatas, em Nb2

A Figura 16 ilustra dois exemplos de curva dose-resposta no bioensaio $\mathrm{Nb} 2 \mathrm{de}$ amostras contendo bbPRL dos casos do Grupo I: casos de número 2 e 14, Figura 16A e 16B, respectivamente. Os demais gráficos das amostras dos indivíduos do Grupo I encontram-se no Anexo D (D1). 
A

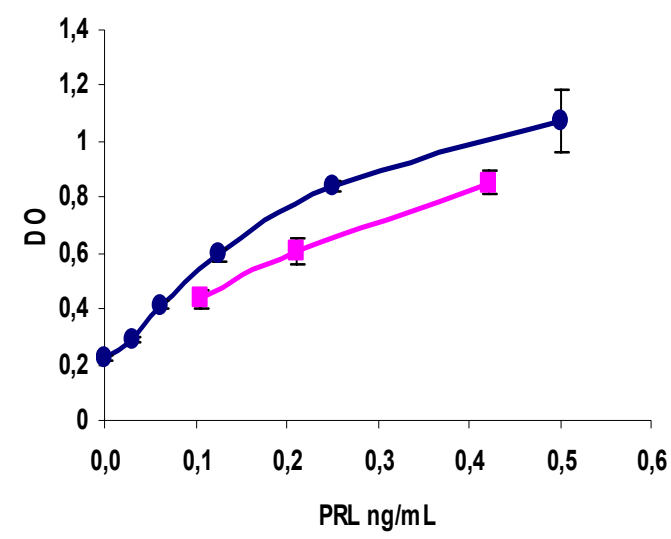

$\multimap$ wPRL - bbPRL caso 2
B

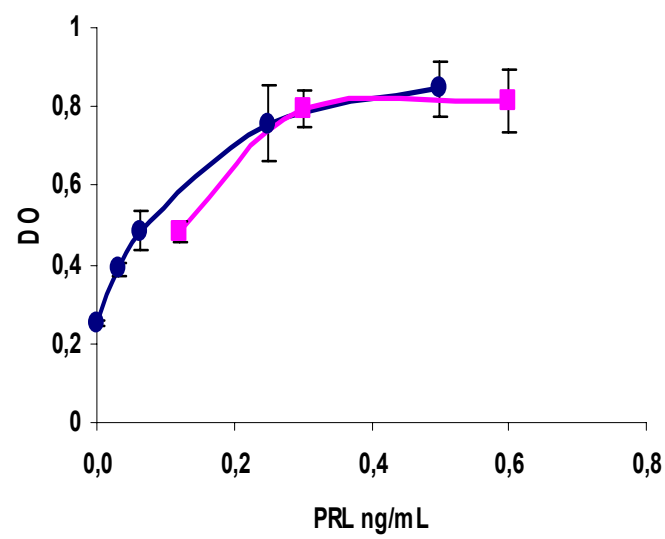

$\rightarrow$ wPRL - bbPRL caso 14

Figura 16. Atividade biológica de bbPRL dos casos de número 2 (A) e 14 (B) comparadas à wPRL, no bioensaio $\mathrm{Nb} 2$

A Figura 17 ilustra dois exemplos de curva dose-resposta no bioensaio $\mathrm{Nb} 2 \mathrm{de}$ amostras contendo mPRL dos casos do Grupo II: casos de número 21 e 22, Figuras 17A e 17B, respectivamente. Os demais gráficos das amostras dos indivíduos do Grupo II encontram-se no Anexo D (D2).

A

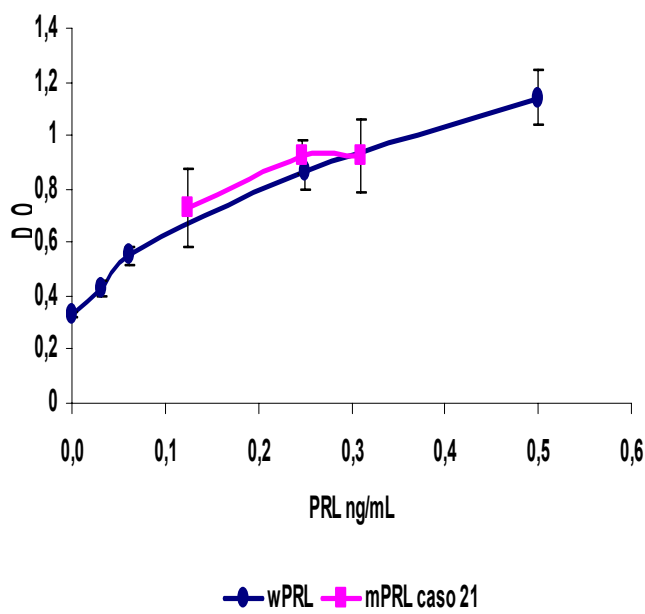

B

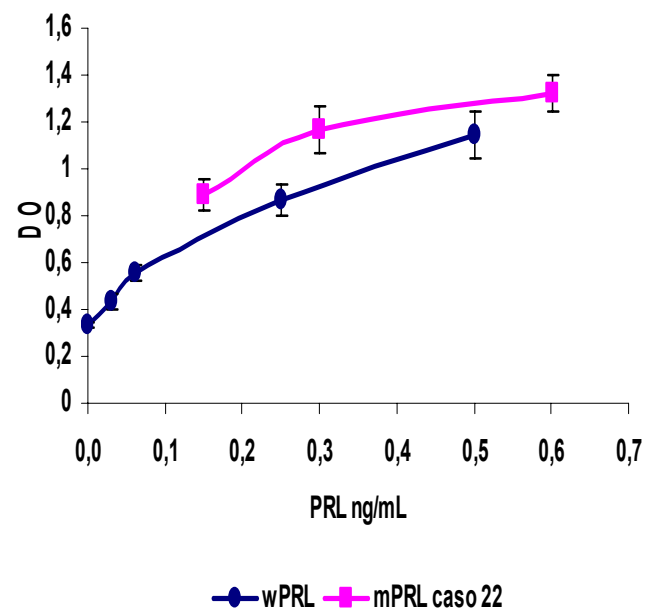

Figura 17. Atividade biológica de mPRL dos casos de número 21 (A) e 22 (B) comparadas à wPRL, no bioensaio $\mathrm{Nb} 2$ 
A relação BA/IA das amostras de bbPRL do Grupo I (casos de números 1 a 18) e de mPRL do Grupo II (casos de número 19 a 23), em Nb2, encontram-se na Tabela 8A e Tabela $8 \mathrm{~B}$, respectivamente.

Tabela 8A - Cálculo da relação BA/IA das amostras de bbPRL do Grupo I no bioensaio Nb2

\begin{tabular}{|c|c|}
\hline GRUPO I & $\mathrm{BA} / \mathrm{IA}$ \\
\hline 1 & 0,48 \\
\hline 2 & 0,59 \\
\hline 3 & 0,74 \\
\hline 4 & 0,39 \\
\hline 5 & 0,79 \\
\hline 6 & 1,26 \\
\hline 7 & 0,26 \\
\hline 8 & 0,57 \\
\hline 9 & 0,70 \\
\hline 10 & 0,56 \\
\hline 11 & 0,11 \\
\hline 12 & 0,35 \\
\hline 13 & 0,37 \\
\hline 14 & 0,79 \\
\hline 15 & 0,32 \\
\hline 16 & 1,38 \\
\hline 17 & 2,8 \\
\hline 18 & 0,31 \\
\hline TOTAL & $0,7 \pm 0,62$ \\
\hline
\end{tabular}

(BA) bioatividade; (IA) imunoatividade 
Tabela 8B - Cálculo da relação BA/IA das amostras de mPRL do Grupo II no bioensaio Nb2

\begin{tabular}{cc}
\hline GRUPO II & BA/IA \\
\hline 19 & 1,13 \\
20 & 1,87 \\
21 & 1,28 \\
22 & 1,66 \\
23 & 0,81 \\
\hline TOTAL & $1,35 \pm 0,42$ \\
\hline
\end{tabular}

(BA) bioatividade; (IA) imunoatividade

\subsubsection{Ba/F-LLP}

As células $\mathrm{Ba} / \mathrm{F}$-LP crescem em suspensão e são birrefringentes, como pode ser observado na Figura 18, que representa a visualização das células em aumento de 10 vezes por um microscópio invertido.

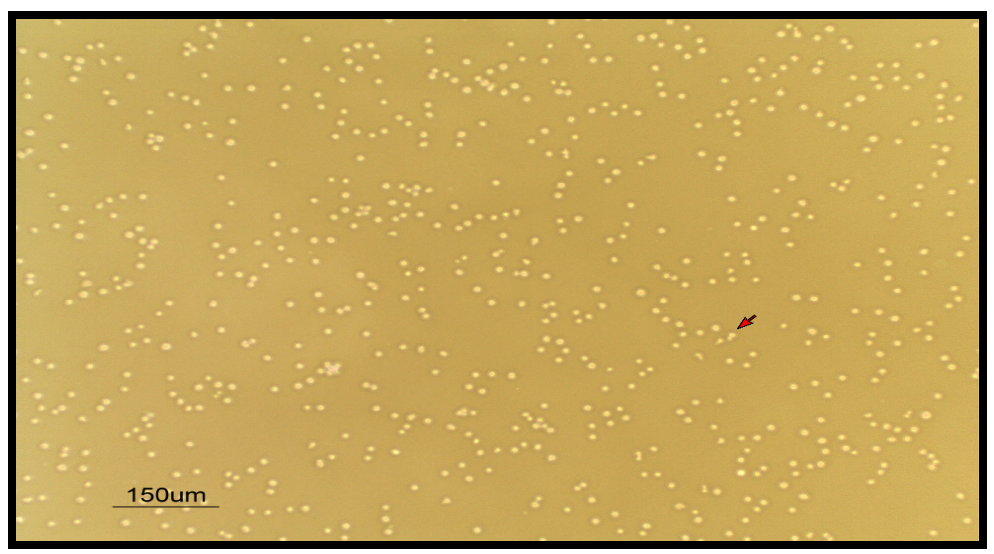

Figura 18. Microfotografia com aumento de 10x das células Ba/F-LP 
Após algumas semanas em meio de crescimento contendo concentrações mais baixas de PRL (1 ng/mL), uma subpopulação das células Ba/F-LP foi obtida, agora denominada "Ba/F-LLP” (low low prolactin). Ensaios dose-resposta com as células $\mathrm{Ba} / \mathrm{F}$-LLP demonstraram que a proliferação celular máxima ocorreu com concentrações de PRL entre $0,5 \mathrm{ng} / \mathrm{mL}$ e $1 \mathrm{ng} / \mathrm{mL}$ de $\mathrm{rPRL}$, ou seja, o novo ensaio apresentou aumento de sensibilidade de $1 \log$ de unidade, em relação ao bioensaio $\mathrm{Ba} / \mathrm{F}-\mathrm{LP}$, e resposta máxima semelhante ao do bioensaio $\mathrm{Nb} 2$.

No bioensaio $\mathrm{Ba} / \mathrm{F}$-LLP, utilizamos como padrão secundário a rPRL, calibrada contra o padrão wPRL e na comparação das duas amostras, observamos que a rPRL apresentou potência duas vezes e meia maior, conforme mostra a Figura 19. Utilizamos, então, esse fator para o cálculo da bioatividade (BA) das amostras no bioensaio $\mathrm{Ba} / \mathrm{F}$ LLP. A análise da rPRL, realizada no U584 INSERM, demonstrou que ela se constitui, por mais de $95 \%$, da isoforma monomérica, o que em parte explica a maior potência dessa amostra.

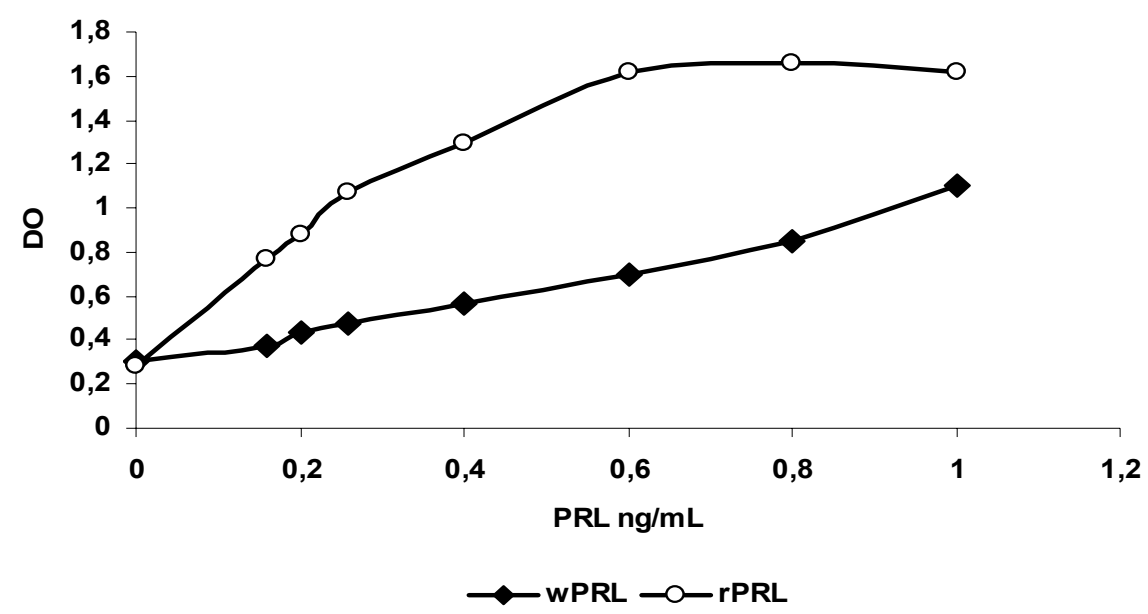

Figura 19. Comparação entre wPRL e rPRL no ensaio Ba/F-LLP 
Nossos resultados confirmam os dados da literatura, uma vez que o padrão 98/582 de PRL recombinante não-glicosilada apresenta bioatividade de $63,8 \mathrm{mIU} / \mu \mathrm{g}$, ou seja, cerca de três vezes mais potente que a wPRL (21,2mUI/ $\mu \mathrm{g})$ (http://www.nibsc.ac.uk).

O bioensaio $\mathrm{Ba} / \mathrm{F}$-LLP mostrou-se reprodutível, e obtivemos coeficiente intraensaio de 12,5\%, interensaio de 16\%, inclinação da curva dose-resposta de 2,27, mínima dose detectável (MDD) de $0,04 \mathrm{ng} / \mathrm{mL}$ e $50 \%$ da dose efetiva $\left(\mathrm{ED}_{50}\right)$ de 0,14 ng/mL. A Figura 20 representa as características do bioensaio Ba/F-LLP.

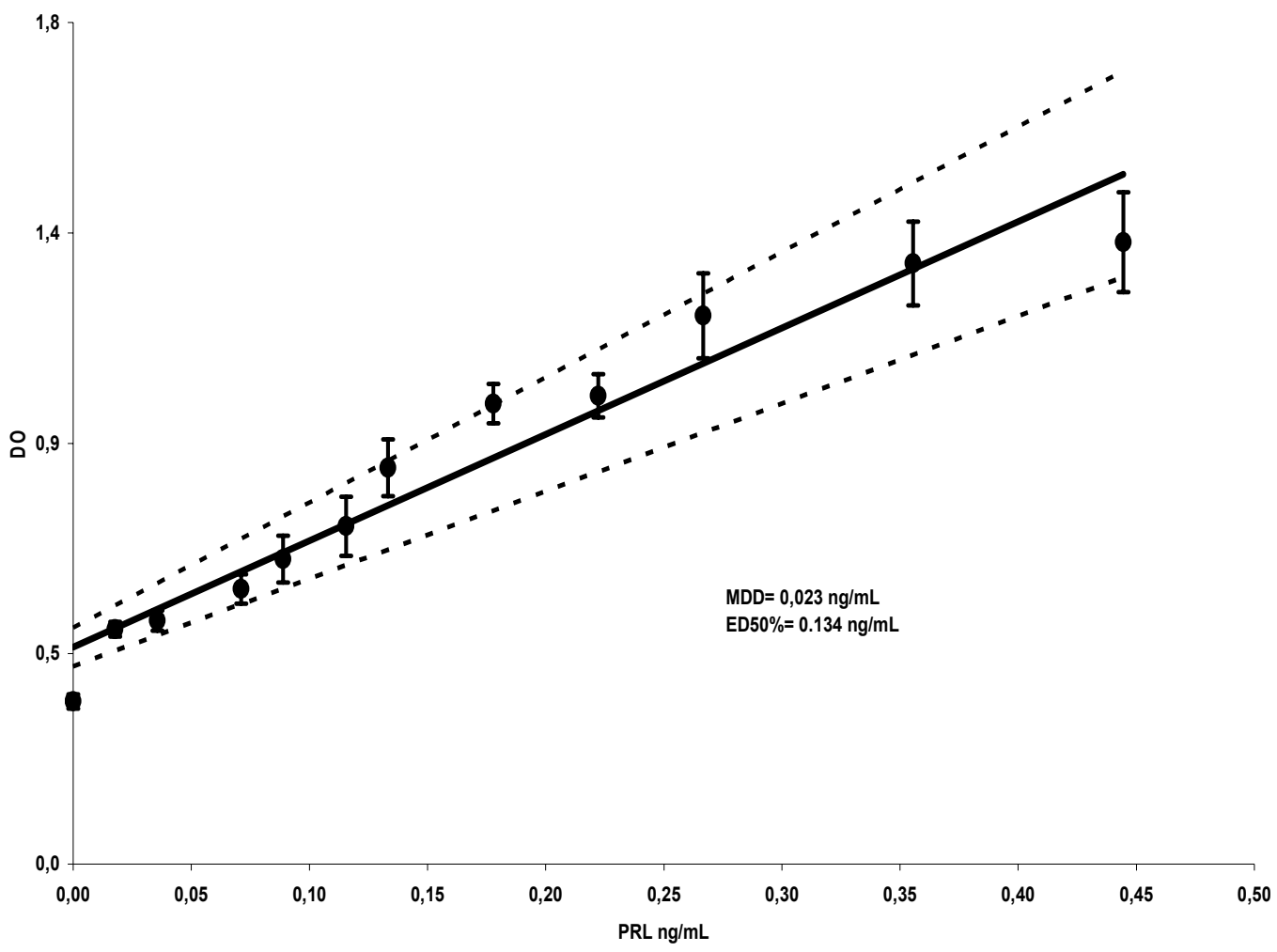

Figura 20. Ensaio de proliferação celular com células Ba/F LLP em resposta à rPRL, em octoplicatas 
A bbPRL presente nas frações obtidas por cromatografia por gel-filtração do soro dos casos do Grupo I não induziu dose-resposta no bioensaio Ba/F-LLP em 15 das 18 amostras, impossibilitando o cálculo BA/IA para esses 15 casos. As exceções ocorreram para as amostras dos casos de números 13, 14 e 16, para as quais a relação BA/IA foi 0,59, 0,73 e 0,33, respectivamente. Adicionamos anticorpo anti-PRL no ensaio desses casos e houve abolição da resposta biológica, comprovando a especificidade do resultado anteriormente citado. A Figura 21 representa a atividade biológica da bbPRL dos casos de números 2 e 14, exemplificando ausência de resposta no primeiro e presença de resposta dose-dependente no segundo, abolida na presença do anticorpo anti-PRL. Os gráficos dos bioensaios em Ba/F-LLP das amostras do Grupo I encontram-se no Anexo E (E1).

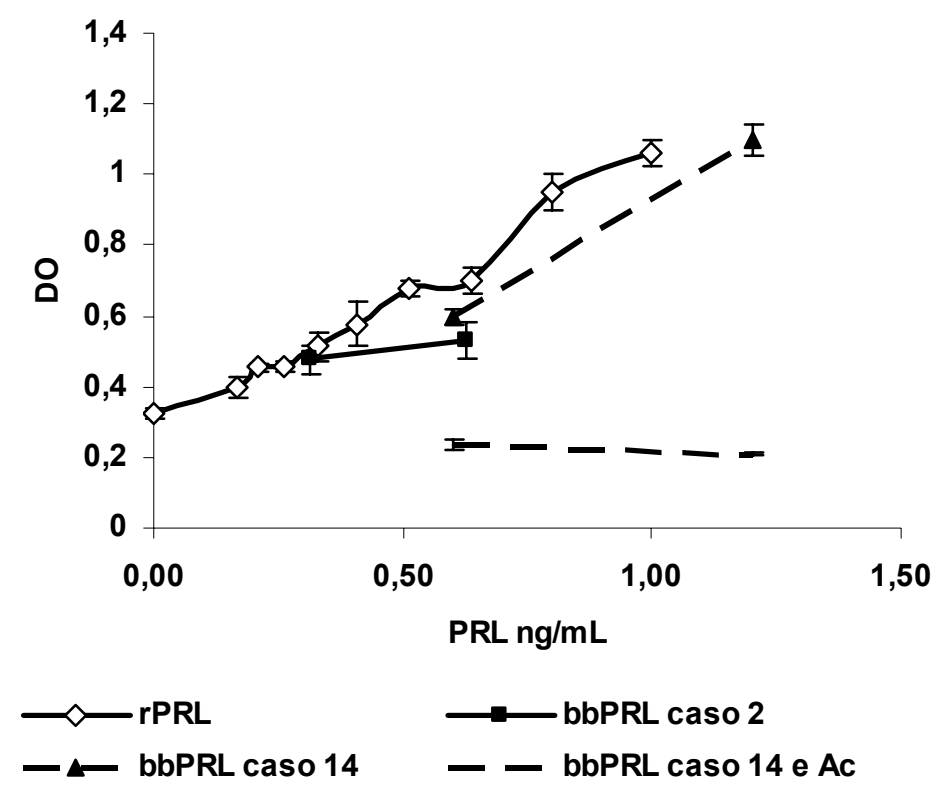

Figura 21. Exemplos de resposta das amostras de bbPRL do Grupo I em Ba/F-LLP; (Ac) anticorpo de coelho anti-PRL humana 
As amostras de mPRL presentes nas frações obtidas na cromatografia por gelfiltração do Grupo II foram utilizadas como controle positivo para o bioensaio $\mathrm{Ba} / \mathrm{F}$ LLP, uma vez que essas amostras são biologicamente ativas in vivo, era de se esperar atividade dose-dependente para esse ensaio. Todas as amostras avaliadas apresentaram curva dose-resposta no bioensaio $\mathrm{Ba} / \mathrm{F}-\mathrm{LLP}$ próxima àquela obtida com o padrão rPRL. A Figura 22 ilustra dois exemplos desses ensaios, e os gráficos de todos os ensaios das amostras do Grupo II em Ba/F-LLP encontram-se no Anexo E (E2). Após correção pelo padrão wPRL, calculamos a relação BA/IA no bioensaio Ba/F-LLP de bbPRL do Grupo I e de mPRL do Grupo II, dispostos na Tabela 9A e 9B, respectivamente.

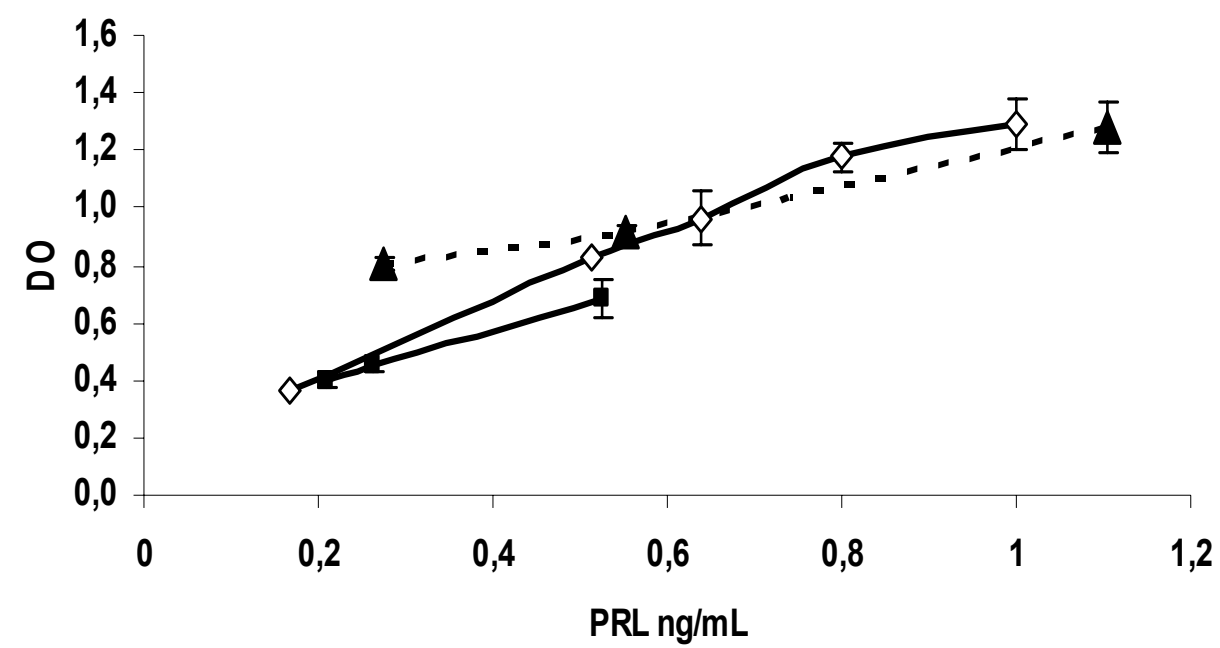

$=-\Delta--\mathrm{mPRL}$ caso $21 \multimap \mathrm{rPRL} \longrightarrow \mathrm{mPRL}$ caso 22

Figura 22. Exemplos de resposta das amostras de mPRL do Grupo II em Ba/F- LLP 
Tabela 9A - Relação BA/IA no bioensaio Ba/F LLP para as amostras de bbPRL dos casos do grupo I

\begin{tabular}{cc}
\hline GRUPO & $\mathrm{BA} / \mathrm{IA}$ \\
\hline 1 & $\mathrm{NC}$ \\
2 & $\mathrm{NC}$ \\
3 & $\mathrm{NC}$ \\
4 & $\mathrm{NC}$ \\
5 & $\mathrm{NC}$ \\
6 & $\mathrm{NC}$ \\
7 & $\mathrm{NC}$ \\
8 & $\mathrm{NC}$ \\
9 & $\mathrm{NC}$ \\
10 & $\mathrm{NC}$ \\
11 & $\mathrm{NC}$ \\
12 & $\mathrm{NC}$ \\
13 & 0,59 \\
14 & 0,73 \\
15 & $\mathrm{NC}$ \\
16 & 0,33 \\
17 & $\mathrm{NC}$ \\
18 & $\mathrm{NC}$ \\
\hline TOTAL & $0,55 \pm 0,2$ \\
\hline
\end{tabular}

(NC) não-calculada, por ausência de dose-resposta no ensaio

Tabela 9B - Relação BA/IA no bioensaio Ba/F LLP para as amostras de mPRL dos casos do grupo II

\begin{tabular}{cc}
\hline GRUPO II & BA/IA \\
\hline 19 & 0,82 \\
20 & 0,97 \\
21 & 1,24 \\
22 & 0,85 \\
23 & 0,68 \\
\hline TOTAL & $0,91 \pm 0,21$ \\
\hline
\end{tabular}




\subsubsection{Análise estatística dos dados obtidos nos bioensaios}

$\mathrm{O}$ cálculo da relação $\mathrm{BA} / \mathrm{IA}$ no bioensaio $\mathrm{Ba} / \mathrm{F}$ - LLP foi possível em apenas três casos do Grupo I, portanto, para procedermos as análises comparativas dos resultados, utilizamos a inclinação (slope) dos gráficos obtidos de bbPRL do grupo I e mPRL do Grupo II, nos bioensaios Nb2 e Ba/F-LLP. A partir do gráfico "concentração de PRL versus DO", obtivemos a equação " $\mathrm{y}=\mathrm{a}+\mathrm{bx}$ ", onde "b" é a inclinação ou slope do gráfico linear. A inclinação em Nb2 e Ba/F-LLP, dos Grupos I e II estão dispostos na Tabela 10. 
Tabela 10 - Inclinações das curvas obtidas com as amostras de bbPRL do Grupo I e de mPRL do Grupo II, nos bioensaios Nb2 e Ba/F-LLP

\begin{tabular}{|c|c|c|c|c|c|}
\hline GRUPO I & $\mathrm{Nb} 2$ & $\mathrm{Ba} / \mathrm{F}-\mathrm{LLP}$ & GRUPO II & $\mathrm{Nb} 2$ & $\mathrm{Ba} / \mathrm{F}-\mathrm{LLP}$ \\
\hline 1 & 0,77 & 0,17 & 19 & 0,87 & 1,19 \\
\hline 2 & 1,11 & 0,01 & 20 & 1,55 & 2,12 \\
\hline 3 & 1,27 & 0,03 & 21 & 1,10 & 1,66 \\
\hline 4 & 1,23 & $-0,03$ & 22 & 0,89 & 1,10 \\
\hline 5 & 1,89 & 0,07 & 23 & 1,03 & 0,83 \\
\hline 6 & 0,72 & 0,05 & - & - & - \\
\hline 7 & 1,44 & 0,08 & - & - & - \\
\hline 8 & 0,94 & 0,07 & - & - & - \\
\hline 9 & 2,24 & 0,07 & - & - & - \\
\hline 10 & 0,97 & 0,15 & - & - & - \\
\hline 11 & 0,71 & 0,01 & - & - & - \\
\hline 12 & 0,60 & 0,04 & - & - & - \\
\hline 13 & 1,26 & 0,47 & - & - & - \\
\hline 14 & 0,53 & 0,44 & - & - & - \\
\hline 15 & 0,73 & 0,165 & - & - & - \\
\hline 16 & 0,74 & 0,29 & - & - & - \\
\hline 17 & 1,84 & 0,19 & & & \\
\hline 18 & 0,53 & 0,05 & & & \\
\hline TOTAL & $1,08 \pm 0,5$ & $0,13 \pm 0,14$ & TOTAL & $1,09 \pm 0,27$ & $1,38 \pm 0,5$ \\
\hline
\end{tabular}




\subsubsection{Comparação entre Nb2 e Ba/F-LLP no Grupo I}

O teste de Bonferroni foi utilizado para comparar as médias das inclinações em $\mathrm{Nb} 2$ e $\mathrm{Ba} / \mathrm{F}$-LLP obtidas no Grupo I, e o resultado de $\mathrm{Nb} 2$ foi maior, do ponto de vista estaístico, que no bioensaio Ba/F-LLP $(\mathrm{P}<0,001)$.

\subsubsection{Comparação entre Nb2 e Ba/F-LLP no Grupo II}

Pela técnica de análise de variância com medidas repetidas foi detectado efeito de interação entre grupo e ensaio $(\mathrm{P}<0,001)$. Isto significa que a diferença entre as médias da inclinação nos dois ensaios não é a mesma nos dois grupos. O método de comparações múltiplas de Bonferroni apontou que as médias das inclinações em Nb2 e $\mathrm{Ba} / \mathrm{F}-\mathrm{LLP}$ são iguais no Grupo II $(\mathrm{P}=0,442)$.

As estatísticas descritivas para BA/IA, em Nb2 e Ba/F-LLP, do Grupo II estão dispostas na Tabela 11. Não houve diferença estatisticamente significante $(P=0,068)$ pelo teste t-pareado, na comparação entre os valores BA/IA das amostras de mPRL do Grupo II, em Nb2 e Ba/F-LLP.

Tabela 11 - Estatísticas descritivas para BA/IA, em Nb2 e Ba/F-LLP, do Grupo II

\begin{tabular}{ccccccc}
\hline BIOENSAIO & N & MÉDIA & $\begin{array}{c}\text { DESVIO } \\
\text { PADRÃO }\end{array}$ & MÍNIMO & MEDIANA & MÁXIMO \\
\hline $\mathrm{Nb} 2$ & 5 & 1,35 & 0,42 & 0,81 & 1,28 & 1,87 \\
$\mathrm{Ba} / \mathrm{F}-\mathrm{LLP}$ & 5 & 0,91 & 0,21 & 0,68 & 0,85 & 1,24 \\
Diferença & 5 & 0,44 & 0,39 & 0,04 & 0,31 & 0,9 \\
\hline
\end{tabular}




\subsubsection{Comparação entre Grupo I e II, quanto ao bioensaio Nb2}

As medianas da relação BA/IA foram comparadas por meio do teste de KruskalWallis. Concluiu-se que a mediana do Grupo II foi maior que a do Grupo I, do ponto de vista estatístico $(\mathrm{P}=0,009)$. As estatísticas descritivas para $\mathrm{BA} / \mathrm{IA}$ de cada grupo estão dispostas na Tabela 12. O gráfico dos valores individuais e as médias de BA/IA, em $\mathrm{Nb} 2$, de cada grupo, estão dispostas na Figura 23.

Tabela 12 - Estatísticas descritivas de BA/IA, em Nb2, dos Grupos I e II

\begin{tabular}{ccccccc}
\hline GRUPO & N & MÉDIA & DESVIO PADRÃO & MÍNIMO & MEDIANA & MÁXIMO \\
\hline I & 18 & 0,7 & 0,62 & 0,11 & 0,52 & 2,8 \\
II & 5 & 1,35 & 0,42 & 0,81 & 1,28 & 1,81 \\
\hline
\end{tabular}

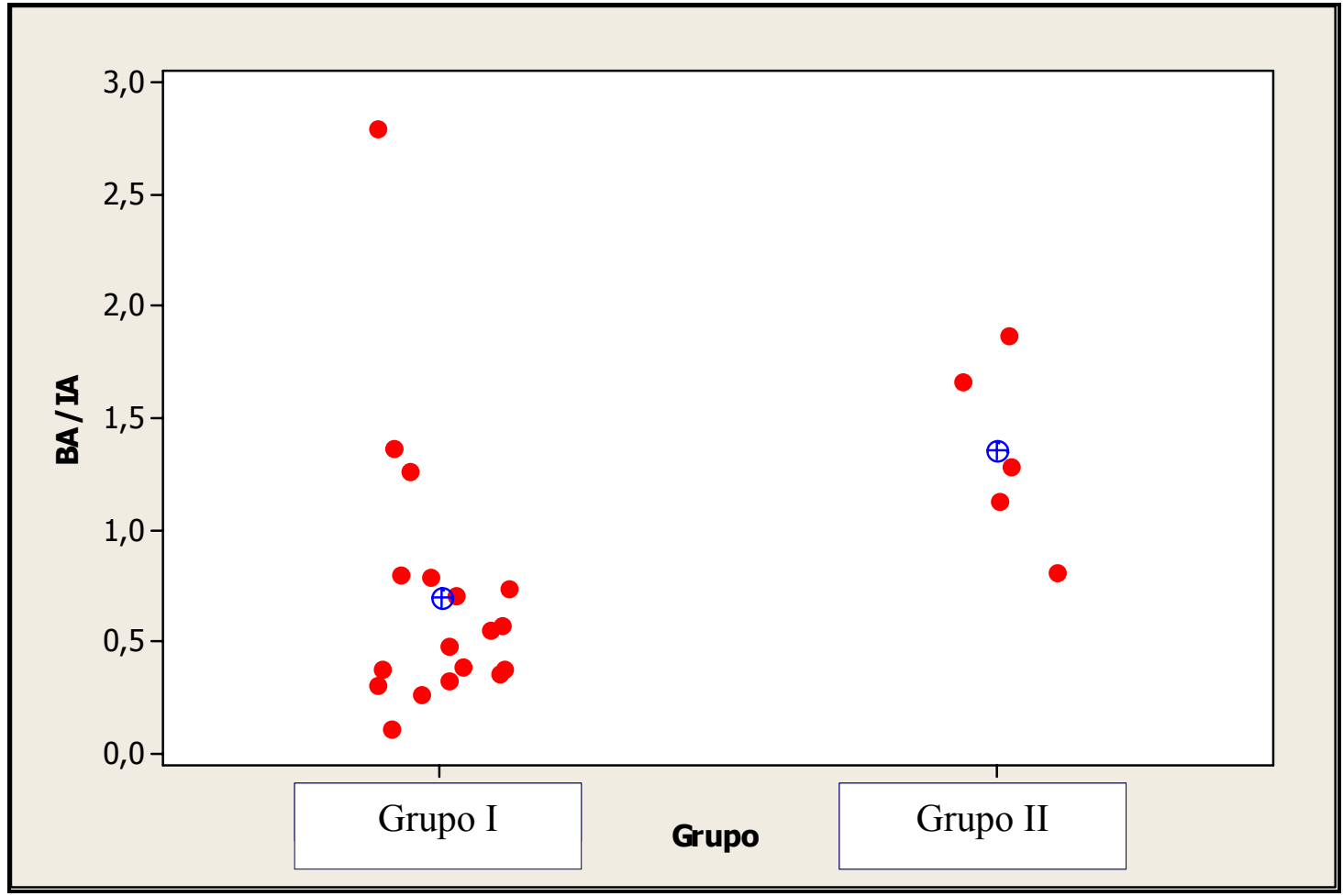

Figura 23. Valores individuais e médias de BA/IA, em Nb2, nos Grupos I e II $(\oplus)$ média; $(\bullet)$ valores individuais 
Nota-se, no entanto, que o valor máximo de BA/IA do Grupo I foi superior a todos os valores encontrados no Grupo II. Esse valor corresponde ao caso 17, e eliminando esse valor e utilizando o teste $\mathrm{t}$ de Student para amostras independentes, concluímos que a média de BA/IA do Grupo II ainda foi maior que do Grupo I, de maneira estatisticamente significante $(\mathrm{P}=0,000)$, com variâncias iguais $(\mathrm{P}=0,602)$.

\subsubsection{Comparação entre Grupo I e II, quanto ao bioensaio Ba/F-LLP}

A capacidade do bioensaio $\mathrm{Ba} / \mathrm{F}$-LLP em reconhecer isoformas ativas foi comprovada quando se fez a comparação das médias das inclinações em Ba/F-LLP entre o Grupo I e II, havendo significativamente maior média no segundo grupo $(\mathrm{P}=$ 0,02), quando utilizamos o método de comparações múltiplas de Bonferroni.

A Figura 24 resume os valores individuais e as médias das inclinações, de cada caso dos Grupos I e II, nos bioensaios Nb2 e Ba/F-LLP.

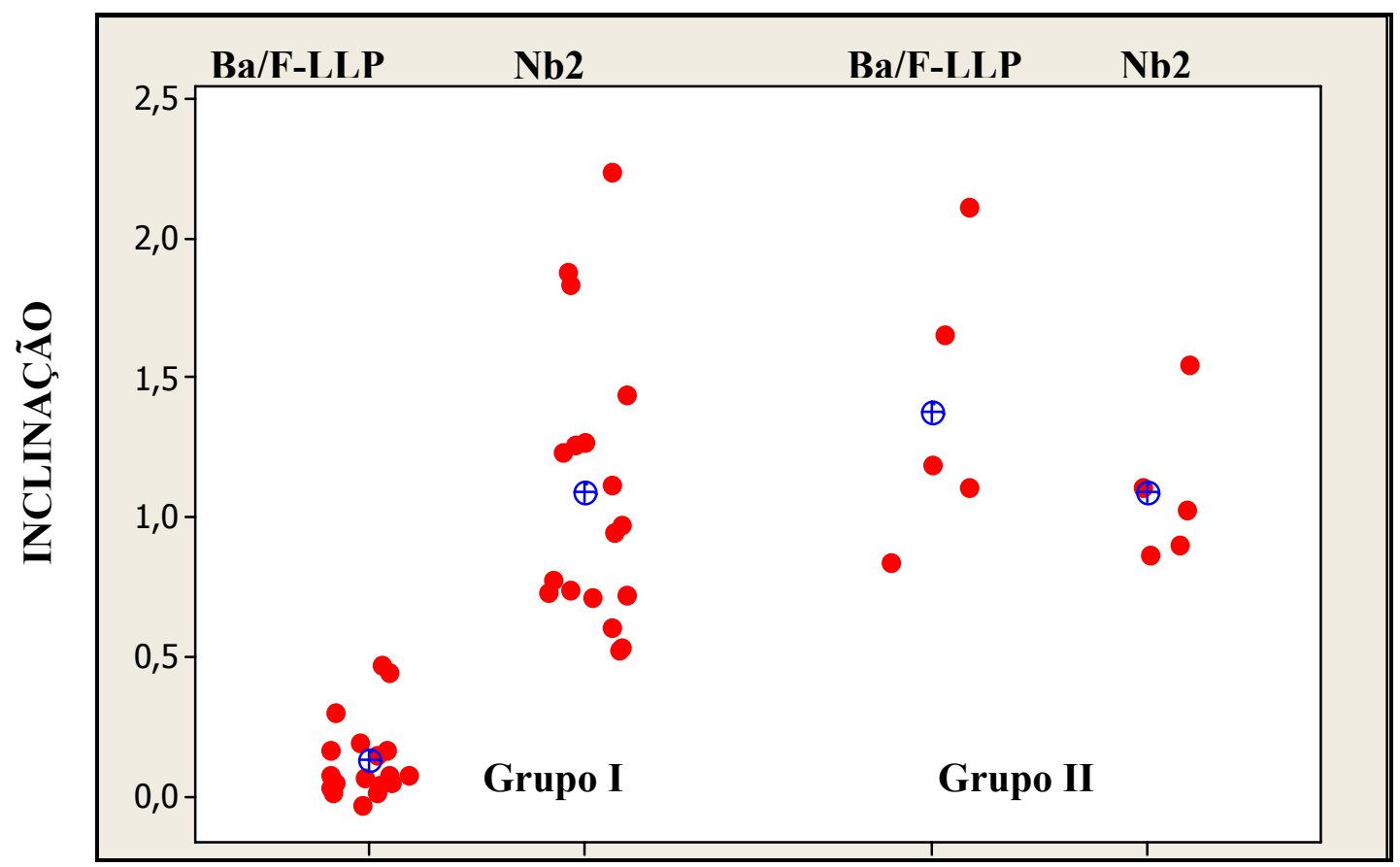

Figura 24. Valores individuais e as médias das inclinações, de cada caso dos Grupos I e II, nos bioensaios Nb2 e Ba/F-LLP; $(\oplus)$ média; $(\bullet)$ valores individuais 


\subsection{Pesquisa de auto-anticorpo anti-PRL}

Usando o método descrito por Hattori et al. ${ }^{87}$, a presença de auto-anticorpo do tipo IgG anti-PRL foi identificada em sete indivíduos macroprolactinêmicos (de números 2, $3,9,13,15,16$ e 18), ou seja, em 38\% dos casos do Grupo I. A pesquisa no Grupo II não foi realizada.

A Figura 25 representa a relação $B / T$, onde "B" é a contagem por minuto (cpm) na $\gamma$ câmara, da amostra de soro tratada, e "T" é o valor em cpm da PRL marcada total utilizada. Notamos que os pontos marcados com círculos correspondem aos sete indivíduos com anticorpo anti-PRL presentes no soro, uma vez que o valor da relação $\mathrm{B} / \mathrm{T}$ foi maior que $2 \mathrm{DP}$ acima da média dos controles negativos, representado pelo triângulo.

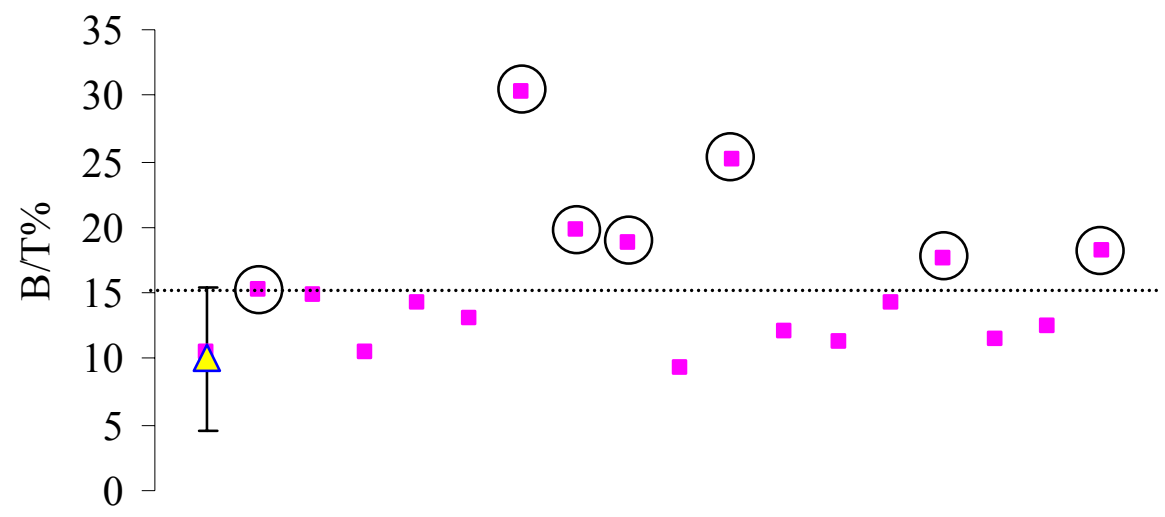

- pacientes $\triangle$ controles negativos

Figura 25. Relação B/T (\%) das amostras de bbPRL do Grupo I com o grupo de controle negativo 
Pelo teste t-Student para amostras independentes, não houve evidências para rejeitar a hipótese de igualdade das médias das inclinações nos subgrupos com e sem anticorpo anti-PRL do Grupo I, tanto em Nb2 $(\mathrm{P}=0,784)$ quanto em Ba/F-LLP $(\mathrm{P}=0,528)$. As variâncias nos grupos são iguais em Nb2 $(\mathrm{P}=0,864)$ e em Ba/F-LLP $(\mathrm{P}=0,507)$.

A Tabela 13 demonstra as estatísticas descritivas para a inclinação, segundo a presença ou ausência de anticorpo anti-PRL, nos bioensaios Nb2 e Ba/F-LLP.

Tabela 13 - Estatísticas descritivas para a inclinação, segundo a presença ou ausência de anticorpo anti-PRL, nos bioensaios $\mathrm{Nb} 2$ e Ba/F-LLP

\begin{tabular}{cccccccc}
\hline ENSAIO & ANTI-PRL & N & MÉDIA & DP & MÍNIMO & MEDIANA & MÁXIMO \\
\hline Nb2 & Não & 11 & 1,06 & 0,48 & 0,53 & 0,94 & 1,89 \\
Nb2 & Sim & 7 & 1,13 & 0,57 & 0,53 & 1,11 & 2,24 \\
$\mathrm{Ba} /$ F-LLP & Não & 11 & 0,11 & 0,13 & $-0,03$ & 0,07 & 0,44 \\
$\mathrm{Ba} /$ F-LLP & Sim & 7 & 0,16 & 0,17 & 0,01 & 0,07 & 0,47 \\
\hline
\end{tabular}

(N) número de casos; (DP) desvio padrão

A Figura 26 mostra os valores individuais e médios das inclinações do Grupo I, em $\mathrm{Nb} 2$, segundo a presença de anticorpos, e a Figura 27, as mesmas variáveis com relação ao bioensaio $\mathrm{Ba} / \mathrm{F}$-LLP. 


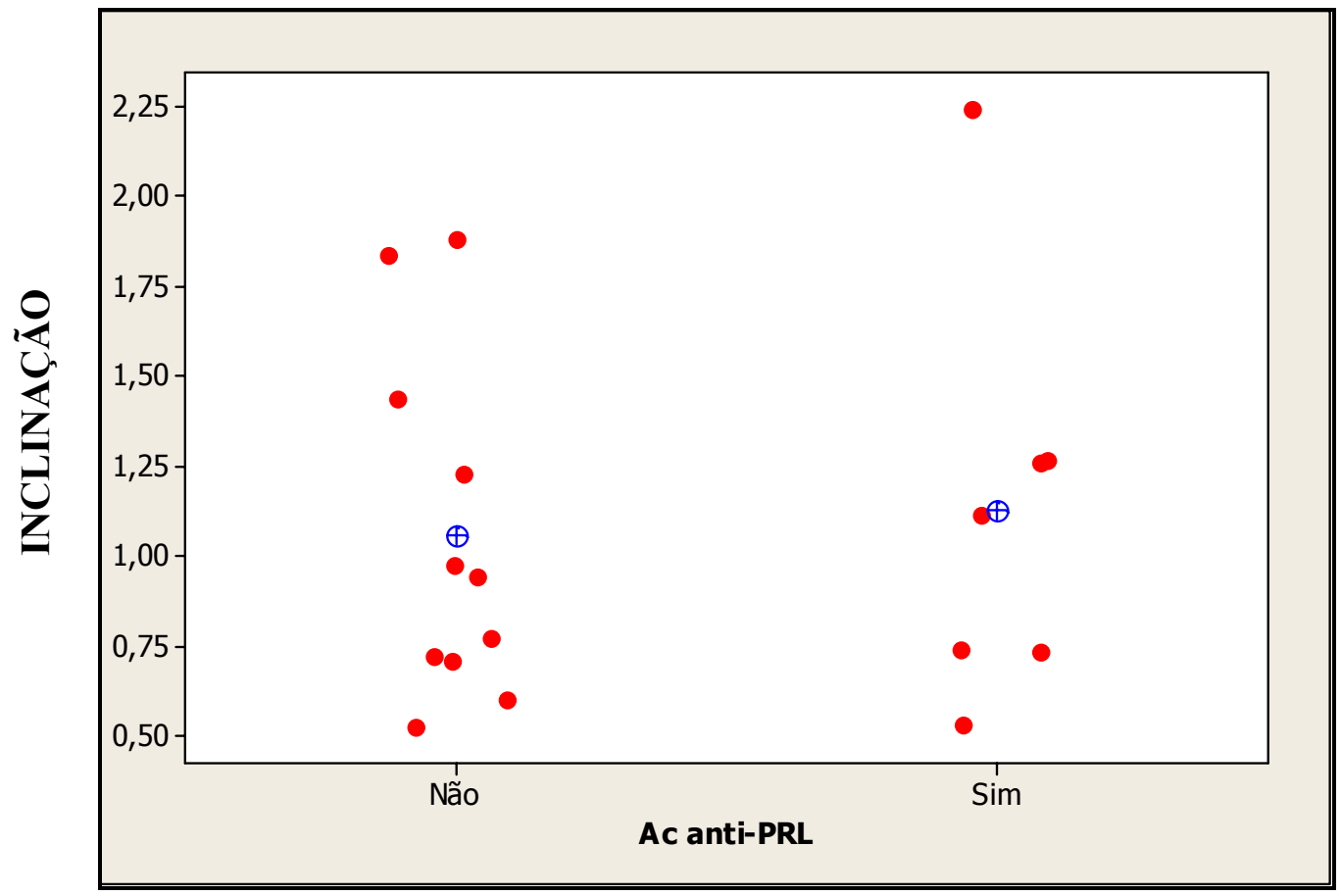

Figura 26. Valores individuais e médios das inclinações do Grupo I, em Nb2, segundo a presença de auto-anticorpo anti-PRL $(\oplus)$ média; $(\bullet)$ valores individuais

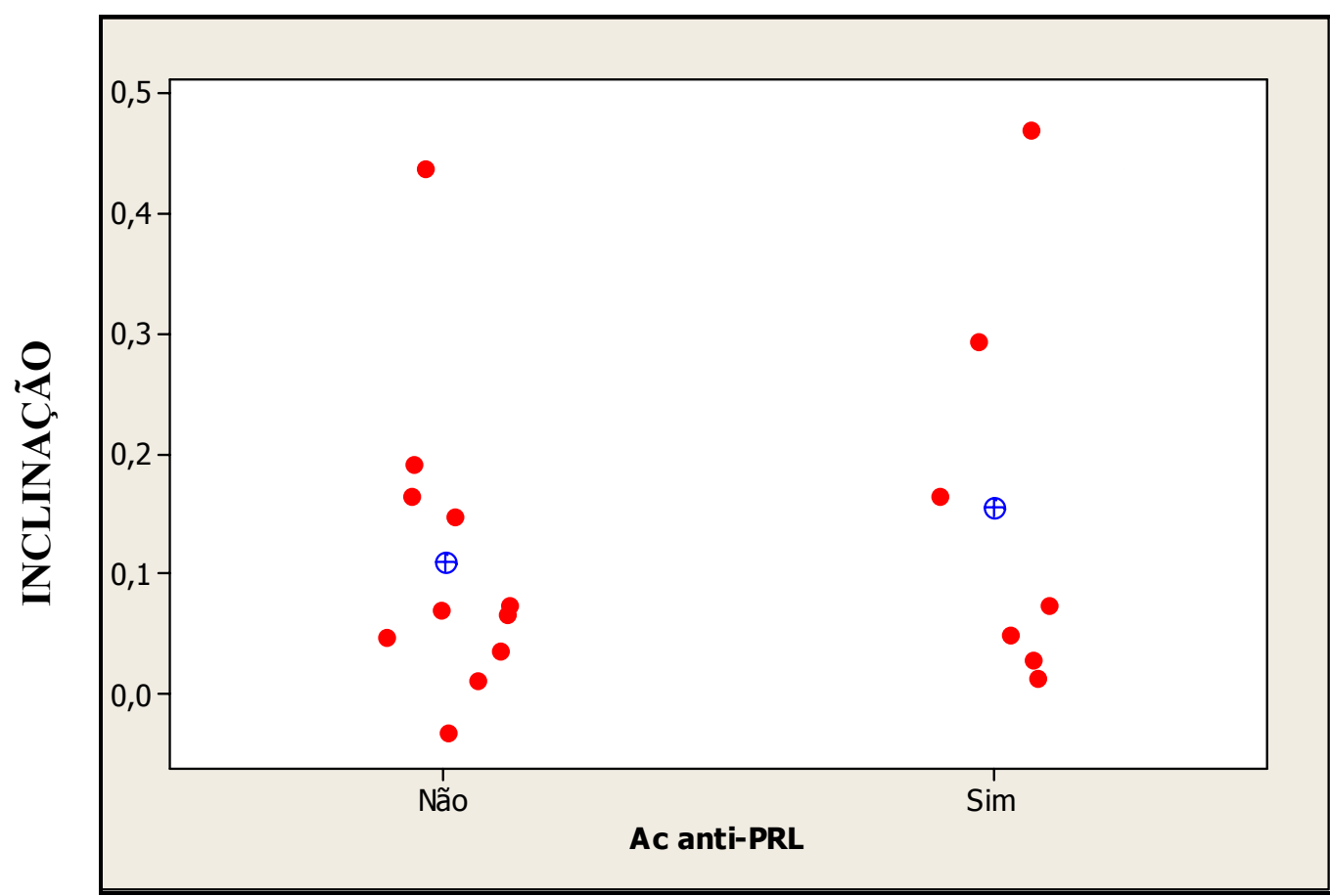

Figura 27. Valores individuais e médios das inclinações do Grupo I, em Ba/F-LLP, segundo a presença de auto-anticorpo anti-PRL $(\oplus)$ média; $(\bullet)$ valores individuais 


\subsection{Pesquisa de auto-anticorpos}

O resultado da pesquisa de outros auto-anticorpos nos indivíduos do Grupo I está disposto na Tabela 14.

Tabela 14 - Pesquisa de auto-anticorpos no Grupo I

\begin{tabular}{|c|c|c|c|c|c|c|}
\hline CASOS & $\begin{array}{c}\text { ANTI- } \\
\text { TPO }\end{array}$ & FAN & ANTIEND. & $\begin{array}{l}\text { ANTI- } \\
\text { GAD }\end{array}$ & ANTIMIT. & ANTIOV. \\
\hline 1 & $<35$ & $1 / 320^{*}$ & Negativo & $<1$ & Negativo & Negativo \\
\hline $2 * *$ & 2310 & Negativo & Negativo & $<1$ & Negativo & Negativo \\
\hline $3 * *$ & $<35$ & $1 / 160^{*}$ & Negativo & $<1$ & Negativo & Negativo \\
\hline 4 & 170 & Negativo & Negativo & $<1$ & Negativo & $1 / 10$ \\
\hline 5 & $<35$ & Negativo & Negativo & $<1$ & Negativo & Negativo \\
\hline 6 & 2360 & Negativo & Negativo & $<1$ & Negativo & Negativo \\
\hline 7 & $<35$ & Negativo & Negativo & $<1$ & Negativo & Negativo \\
\hline 8 & $<35$ & Negativo & Negativo & $<1$ & Negativo & Negativo \\
\hline $9 * *$ & 57,1 & Negativo & Negativo & $<1$ & Negativo & Negativo \\
\hline 10 & $<35$ & $1 / 640^{*}$ & Negativo & $<1$ & Negativo & Negativo \\
\hline 11 & $<35$ & Negativo & Negativo & $<1$ & Negativo & Negativo \\
\hline 12 & $<35$ & Negativo & Negativo & $<1$ & Negativo & Negativo \\
\hline $13 * *$ & $<35$ & Negativo & Negativo & $<1$ & Negativo & Negativo \\
\hline 14 & $<35$ & Negativo & Negativo & $<1$ & Negativo & Negativo \\
\hline $15^{* *}$ & $<35$ & $>1 / 5120 *$ & Negativo & $<1$ & Negativo & Negativo \\
\hline $16^{* *}$ & $<35$ & Negativo & Negativo & $<1$ & Negativo & Negativo \\
\hline 17 & $<35$ & Negativo & Negativo & $<1$ & Negativo & Negativo \\
\hline $18 * *$ & $<35$ & $1 / 160^{*}$ & Negativo & $<1$ & Negativo & Negativo \\
\hline
\end{tabular}

Nota: $\left(^{*}\right)$ padrão nuclear pontilhado com placa metafásica não corado

$(* *)$ : casos com anticorpo anti-PRL presente

Legenda: (Anti-TPO) anti-peroxidase; (FAN) fator antinúcleo;

(ANTIEND.) antiendomísio; (ANTIMIT.) antimitocôndria

(Anti-GAD) antiácido glutâmico descarboxilase; (ANTIOV.) antiovário 
Notamos títulos elevados de anti-TPO nos casos de números 2, 4, 6 e 9. O caso de número 2 apresentou hipotireoidismo transitório, após a avaliação inicial, e que reverteu espontaneamente. $\mathrm{O}$ caso de número 4 permaneceu eutireoideano durante o período de acompanhamento. $\mathrm{O}$ caso de número 6 apresentou hipertireoidismo por doença de Graves após a avaliação inicial, compensada com tratamento clínico. O caso de número 9 apresentava diagnóstico prévio de hipotireoidismo primário e esteve eutireoidena com a reposição com levotiroxina durante o acompanhamento.

Dentre os casos que apresentaram padrão de FAN positivo, aquele cujos títulos eram bastante elevados (caso de número 15) possuía diagnóstico prévio de lupus eritematoso sistêmico (LES), com acometimento pulmonar, articular e hematológico. Os outros indivíduos (casos de número 1, 3, 10 e 18) apresentaram títulos médios de FAN na ausência de quaisquer critérios diagnósticos para LES, fato pouco freqüente, mas que pode ocorrer na população geral.

A presença de anticorpo antiendomísio, anti-GAD e antimitocôndria foi negativa em todos os indivíduos, em paralelo com ausência de quadro clínico de doença celíaca, diabetes melito ou alteração do perfil das enzimas hepáticas na época de nossa avaliação. Procedemos a determinação de IgA, que foi normal em todos, descartando a possibilidade de falsos negativos para o antiendomísio.

Apenas o caso de número 4 apresentou anticorpo antiovário presente, porém com títulos bastante baixos. Nenhum caso apresentou falência ovariana no momento da avaliação. 
5. Discussão 
Dados da literatura sugerem baixa atividade biológica da macroprolactina in vivo, porém os resultados in vitro são controversos. Avaliamos clínica e laboratorialmente uma população de indivíduos com macroprolactinemia (Grupo I) e comparamos os resultados com a atividade biológica da bbPRL in vitro. O perfil clínico do Grupo I foi semelhante ao da literatura, ou seja, a maioria pertencia ao sexo feminino (88\%) e alguns casos apresentavam galactorréia (22\%). Dos 18 casos avaliados, 10 tiveram o diagnóstico de hiperprolactinemia em exames de rotina ou solicitados por queixas nãorelacionadas à hiperprolactinemia, confirmando a realização inadequada de testes hormonais, que poderiam levar a armadilhas diagnósticas ${ }^{40}$. Quanto aos oito indivíduos restantes, as queixas na época do diagnóstico poderiam ser decorrentes de hiperprolactinemia, sendo a condução diagnóstica adequada. Os casos de número 1 e 17 foram considerados portadores de hiperprolactinemia idiopática por apresentarem galactorréia e irregularidade menstrual na vigência de hiperprolactinemia e na ausência de lesões sugestivas de adenomas hipofisários na RM. Nesses casos, houve restauração dos ciclos menstruais regulares e ovulatórios com o uso de agonista dopaminérgico, porém sem normalização das concentrações séricas de PRL. Essa dissociação clínicolaboratorial levou à suspeita de macroprolactinemia, que foi confirmada. No momento de nossa avaliação, não houve casos de hipogonadismo e apenas quatro mulheres apresentaram galactorréia discreta, sinal nem sempre relacionado à presença de hiperprolactinemia ${ }^{24,25}$. O caso de número 16 apresentou queixa de disfunção erétil e redução da libido. As concentrações normais de testosterona sérica e a resolução da disfunção erétil com psicoterapia sugeriram causa psicológica para o distúrbio. 
Os casos de números 3,8 e 11 apresentaram aumento global da hipófise, sugerindo hiperplasia hipofisária. A literatura mostra que $25 \%$ a $50 \%$ das mulheres jovens apresentam essa característica ${ }^{122-6}$. Da mesma forma, aracnoidocele intrasselar pode ser encontrada ${ }^{127}$, principalmente em mulheres multíparas de meia-idade, como no caso de número 1. Essas alterações na imagem hipofisária, prevalentes na população geral, não necessariamente apresentam significado patológico. Desta forma, não havendo repercussão clínica da hiperprolactinemia nos indivíduos do Grupo I, podemos concluir que a bbPRL não apresentou atividade biológica in vivo.

Empregamos dois bioensaios, heterólogo e homólogo, para verificar a influência da especificidade do RPRL na correlação entre as atividades biológicas da bbPRL in vivo e in vitro. A atividade da bbPRL sempre mostrou-se dose-dependente no bioensaio $\mathrm{Nb}$, sem correlação com o escore clínico. Em contraste, no bioensaio Ba/F-LLP, não houve atividade biológica da bbPRL dose-dependente, com exceção de três casos, que não se distingüiram clinicamente dos demais. Entre as possíveis explicações para tal discrepância, destacamos a atividade inespecífica da bbPRL no ensaio, descartada pelo adição de anticorpo anti-PRL às amostras, e diferenças na estrutura da bbPRL, avaliada através da pesquisa do auto-anticorpo anti-PRL, que não se mostrou diferente entre esses três casos e o restante do Grupo I.

Por não haver resposta dose-dependente em 15 amostras no bioensaio Ba/F-LLP, optamos por comparar os valores da inclinação de cada amostra no gráfico de concentração de PRL versus densidade óptica. A análise estatística evidenciou diferença entre os valores médios da inclinação das amostras do Grupo I, na comparação entre $\mathrm{Nb} 2$ e $\mathrm{Ba} / \mathrm{F}$-LLP. O valor médio em $\mathrm{Nb} 2$ foi mais elevado do que o em $\mathrm{Ba} / \mathrm{F}$-LLP, portanto, o bioensaio Ba/F-LLP apresentou melhor correlação com a baixa atividade in 
vivo da bbPRL. A possibilidade do não-reconhecimento de qualquer atividade in vitro da PRL no bioensaio Ba/F-LLP foi descartada pela presença de bioatividade de amostras de mPRL, provenientes de pacientes do Grupo II, sem diferença dos resultados com o bioensaio $\mathrm{Nb} 2$. No bioensaio $\mathrm{Nb}$ 2, não houve diferença entre as médias das inclinações das amostras de bbPRL do Grupo I e de mPRL do Grupo II, indicando que o bioensaio $\mathrm{Nb} 2$ é sensível, pouco específico e capaz de detectar atividade in vitro mesmo quando esta não ocorre in vivo. Por outro lado, no bioensaio Ba/F-LLP, a média das inclinações das amostras de mPRL do Grupo II foi significativamente mais alta que a das amostras de bbPRL do Grupo I, indicando que este ensaio talvez seja mais adequado para avaliar a atividade da bbPRL.

A atividade biológica de um ligante depende da sua concentração, de sua afinidade com o receptor, do número de receptores expressos e do tempo de exposição ao receptor. As diferenças de bioatividade encontradas entre os dois bioensaios, $\mathrm{Nb} 2 \mathrm{e}$ $\mathrm{Ba} / \mathrm{F}-\mathrm{LLP}$, provavelmente são decorrentes da diferença na característica dos seus receptores de PRL, uma vez que o tempo de exposição ao receptor e a resposta biológica avaliada são os mesmos. No bioensaio $\mathrm{Nb} 2$, o receptor de PRL é do tipo murino e de tamanho intermediário, enquanto que nas células $\mathrm{Ba} / \mathrm{F}-\mathrm{LLP}$, o receptor é humano longo.Embora os receptores humanos de PRL possam ser curtos, intermediários ou longos, nenhuma das isoformas descritas é homóloga ao receptor de PRL da célula $\mathrm{Nb} 2$. Comparando a seqüência de aminoácidos desses dois receptores no "BLAST 2 Sequences" (http://www.ncbi.nlm.nih.gov/blast/bl2seq/bl2.html), notamos que há conservação de grande parte da seqüência (71\%), especialmente dos domínios extracelular, transmembrânico e de BOX-1. Diferenças na região intracitoplasmática podem, entretanto, ser responsáveis por respostas celulares distintas e talvez possam 
explicar a importância da especificidade do ensaio. Alguns autores ${ }^{103,128}$ já haviam demonstrado a importância da especificidade do receptor para lactogênios, em bioensaios transfectados com um reporter gene. Da mesma forma, Gertler et al. ${ }^{128}$ demonstraram que o hormônio lactogênio placentário de ruminante liga-se ao receptor humano de GH, porém, não ao receptor de GH de ruminante. Bernichtein et al. ${ }^{103}$ estudaram a atividade de antagonistas de PRL nos bioensaios de Nb2 e Ba/F-LP e sugeriram que os resultados divergentes devem decorrer de características intrínsecas de cada bioensaio; como exemplo, o antagonista de PRL de primeira geração, G129RhPRL apresentou atividade agonista em $\mathrm{Nb} 2$ e antagonista no bioensaios Ba/F-LP ${ }^{3}$. Além da diferença na especificidade do RPRL, há, entre os dois bioensaios, diferenças na afinidade e na densidade de receptores. O RPRL em Nb2 apresentaram afinidade à PRL três a quatro vezes maior que o receptor nativo e sua densidade é superior a 10 mil por célula ${ }^{97,98}$. Em contraste, as células Ba/F-LP expressam menos que 300 RPRL por célula $^{103}$, não havendo estudos de análise scatchard para as células Ba/F-LLP. Provavelmente, pela maior afinidade à PRL e pela maior densidade de RPRL, as células Nb2 são mais sensíveis.

Em nosso estudo, $38 \%$ dos indivíduos com macroprolactinemia apresentaram autoanticorpo anti-PRL do tipo IgG. De Schepper et al. ${ }^{47}$ identificaram anticorpo anti-PRL em $92 \%$ de 50 indivíduos com macroprolactinemia, utilizando o método de imunoprecipitação com agarose anti-IgG humana. Mounier et al ${ }^{69}$, utilizando a mesma metodologia empregada ${ }^{87}$ em nosso estudo, avaliaram cinco pacientes com macroprolactinemia quanto à presença de anticorpo anti-PRL e não identificaram-no em nenhum caso. Hattori et al. ${ }^{29}$ demonstraram que a proporção de macroprolactina detectada pode variar de acordo o método utilizado: $15 \%$ para o uso de PRL- ${ }^{125}$ I, $47,9 \%$ 
para coluna de proteína $\mathrm{G}$, e $83,4 \%$ para precipitação com PEG. Além da heterogeneidade da macroprolactina, pode-se apontar a diferença dos métodos utilizados na pesquisa do auto-anticorpo anti-PRL como responsável pela diversidade dos resultados citados. No entanto, não houve diferença na atividade biológica da bbPRL in vivo ou in vitro, em ambos os bioensaios, ao avaliarmos a presença de auto-anticorpo anti-PRL, fato corroborado por De Schepper et al. ${ }^{47}$, que não encontraram diferenças clínicas e de bioatividade da bbPRL em $\mathrm{Nb} 2$, quanto à presença ou ausência de autoanticorpo anti-PRL.

Não houve diferença na prevalência de outros auto-anticorpos entre os indivíduos com macroprolactinemia, com e sem auto-anticorpo anti-PRL, como descritos por outros autores $^{35}$. 
6. Conclusões 
Demonstramos que o bioensaio Ba/F-LLP, desenvolvido neste estudo, apresentou sensibilidade superior aos demais ensaios descritos que utilizaram RPRL humano.

A bbPRL não apresentou atividade biológica no bioensaio $\mathrm{Ba} / \mathrm{F}-\mathrm{LLP}$, contrariamente aos resultados no bioensaio $\mathrm{Nb} 2$, e compatível com a atividade biológica in vivo nos indivíduos avaliados. Consideramos, portanto, que o ensaio Ba/F-LLP foi o mais adequado para a avaliação da bioatividade de bbPRL de soro humano, podendo ser uma ferramenta promissora para o estudo das isoformas de PRL humana e para a melhor compreensão da importância fisiopatológica da macroprolactinemia. Estudos com maiores séries de indivíduos com macroprolactinemia, entretanto, são necessários para confirmar nossos resultados. 
7. Anexos 


\section{Anexos}

Anexo A

HOSPITAL DAS CLÍNICAS

DA

FACULDADE DE MEDICINA DA UNIVERSIDADE DE SÃO PAULO

TERMO DE CONSENTIMENTO LIVRE E ESCLARECIDO

(Instruções para preenchimento no verso)

I - DADOS DE IDENTIFICAÇÃO DO SUJEITO DA PESQUISA OU RESPONSÁVEL LEGAL

1. NOME DO PACIENTE

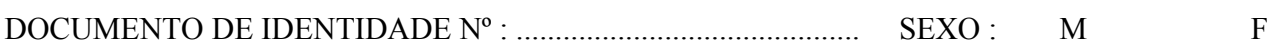

DATA NASCIMENTO: $/ /, /$

CIDADE :

CEP:

TELEFONE: DDD (

.)

2. RESPONSÁVEL LEGAL

NATUREZA (grau de parentesco, tutor, curador etc.)

DOCUMENTO DE IDENTIDADE : SEXO: M $\quad \mathrm{F}$

DATA NASCIMENTO.: / /

ENDEREÇO

$\mathrm{N}^{\mathrm{o}}$

APTO:

BAIRRO:

CIDADE :

CEP:

TELEFONE: DDD

...)

\section{II - DADOS SOBRE A PESQUISA CIENTÍFICA}

1.TÍTULO DO PROTOCOLO DE PESQUISA: "Estudo da atividade biológica da macroprolactina em células $\mathrm{Nb} 2$ e células $\mathrm{Ba} / \mathrm{F}-03$ transfectados com receptor de PRL humano."

2.PESQUISADOR: Dr. Marcello Delano Bronstein

CARGO/FUNÇÃO: Médico assistente e Chefe das Unidades de Neuroendocrinologia do Departamento de Endocrinologia e Metabologia do Hospital das Clínicas da FMUSP.

INSCRIÇÃO CONSELHO REGIONAL Nº 15798

UNIDADE DO HCFMUSP: Unidades de Neuroendocrinologia do Departamento de Endocrinologia e Metabologia

3. AVALIAÇÃO DO RISCO DA PESQUISA:

$\begin{array}{lll}\text { SEM RISCO } & \text { RISCO MÍNIMO X } & \text { RISCO MÉDIO } \\ \text { RISCO BAIXO } & \text { RISCO MAIOR } & \end{array}$

(probabilidade de que o indivíduo sofra algum dano como conseqüência imediata ou tardia do estudo)

4. DURAÇÃO DA PESQUISA : Tempo estimado de 4 anos 


\section{III -REGISTRO DAS EXPLICAÇÕES DO PESQUISADOR AO PACIENTE OU SEU REPRESENTANTE LEGAL SOBRE A PESQUISA, CONSIGNADO:}

1. justificativa e os objetivos da pesquisa: A macroprolactina (molécula derivada do hormônio prolactina, normalmente dosável na circulação sangüínea de todos os indivíduos) elevada como causa de aumento da prolactina sérica total parece ser uma situação freqüente na população mundial, variando de 8 a $46 \%$. Até o momento, os estudos já publicados não chegaram a um consenso quanto ao real papel da macroprolactinemia e se esta condição necessita de tratamento. Este estudo tenta responder a estas questões, através da comparação do perfil clínico e laboratorial dos pacientes, do seu nível de macroprolactina e da ação da macroprolactina, isolada dos pacientes estudados, em culturas celulares.

2. Procedimentos que serão utilizados e propósitos, incluindo a identificação dos procedimentos que são experimentais: Os pacientes incluídos no estudo serão submetidos à:

Avaliação clínica: consulta médica.

Avaliação laboratorial: dosagem sérica de hormônios sexuais, da macroprolactina e isolamento, do soro retirado, da macroprolactina para o estudo em cultura de células, no laboratório de pesquisa. A avaliação laboratorial será feita após a coleta de cinco $\mathrm{ml}$ de sangue, através de uma picada com agulha estéril e descartável.

Avaliação por imagem: realização de ressonância magnética da hipófise, com o uso de contraste endovenoso (gadolíneo), para avaliar a presença de adenoma hipofisário, que pode estar associado à macroprolactinemia

3. Desconfortos e riscos esperados: O desconforto da coleta de sangue é a dor da picada e eventual aparecimento de um pequeno hematoma (mancha arroxeada ao redor da picada), que desaparecerá em menos de uma semana. A ressonância magnética não deve ser realizada se o indivíduo apresentar próteses fixas ou clips em seu corpo. Não será realizada na suspeita ou confirmação de gestação e seu risco está na possibilidade de causar desconforto por ser realizada em um ambiente fechado.

4. Benefícios que poderão ser obtidos: o estudo pode trazer dados suficientes para decidir que a condição de macroprolactinemia pode ser apenas observada em acompanhamento médico ou que necessite de tratamento (medicamentoso), que pode amenizar possíveis distúrbios sexuais decorrentes da situação indicada, tais como, diminuição da libido, irregularidade menstrual, dificuldade para engravidar ou disfunção erétil.

5. Procedimentos alternativos que possam ser vantajosos para o indivíduo: - 
IV - ESCLARECIMENTOS DADOS PELO PESQUISADOR SOBRE GARANTIAS DO SUJEITO DA PESQUISA;

1. Acesso a qualquer tempo, às informações sobre procedimentos, riscos e benefícios relacionados à pesquisa, inclusive para esclarecer eventuais dúvidas.

2. Liberdade de retirar seu consentimento a qualquer momento e de deixar de participar do estudo, sem que isto traga prejuízo à continuidade da assistência.

3. Salvaguarda da confidencialidade, sigilo e privacidade.

4. Disponibilidade de assistência no HCFMUSP, por eventuais danos a saúde, decorrentes da pesquisa.

\section{INFORMAÇÕES DE NOMES, ENDEREÇOS E TELEFONES DOS RESPONSÁVEIS PELO ACOMPANHAMENTO DA PESQUISA, PARA CONTATO EM CASO DE INTERCORRÊNCIAS CLÍNICAS E REAÇÕES ADVERSAS.}

Avenida Enéas de Carvalho Aguiar, 255 CEP 05403-900

Procurar Dra. Andrea Glezer ou Dr. Marcello D. Bronstein, em casos de intercorrências, no ambulatório de Neuroendocrinologia do Hospital das Clínicas, no PAMB 5º andar, bloco 4 A, ou pelo telefone 3069-6383 .

VI. OBSERVAÇÕES COMPLEMENTARES: 


\section{CONSENTIMENTO PÓS-ESCLARECIMENTO}

Declaro que, após ter sido convenientemente esclarecido pelo pesquisador, e ter entendimento o que me foi explicado consinto em participar do presente; Protocolo de Pesquisa

São Paulo,

assinatura do sujeito ou responsável legal

assinatura do pesquisador

(carimbo ou nome Legível) 


\section{Anexo B}

Tabela 1- Resumo dos estudos de prevalência de macroprolactinemia

\begin{tabular}{|c|c|c|c|}
\hline AUTORES & $\mathrm{N}$ & $\begin{array}{c}\text { DIAGNÓSTICO DE } \\
\text { MACROPROLACTINEMIA }\end{array}$ & $\begin{array}{c}\text { MACROPROLACTINEMIA } \\
(\%)\end{array}$ \\
\hline B $\phi j$ ro et al. ${ }^{28}$ & 605 & Cromatografia & 26 \\
\hline Fahie-Wilson et al. ${ }^{32}$ & 79 & Cromatografia & 25 \\
\hline \multirow[t]{2}{*}{ Vieira et al. ${ }^{33}$} & 1220 & Cromatografia & 42 \\
\hline & & Precipitação com PEG & \\
\hline Olukoga et al. ${ }^{30}$ & 188 & Precipitação com PEG & 15,4 \\
\hline Leslie et al. ${ }^{34}$ & 1225 & Precipitação com PEG & 26 \\
\hline \multirow[t]{2}{*}{ Hauache et al. ${ }^{31}$} & 113 & Cromatografia & 46 \\
\hline & & Precipitação com PEG & \\
\hline Vallete-Kasic et al. ${ }^{35}$ & 368 & Cromatografia & 29 \\
\hline Toldy et al. ${ }^{36}$ & 270 & Precipitação com PEG & 23 \\
\hline Strachan et al. ${ }^{37}$ & 273 & Precipitação com PEG & 21 \\
\hline Gibney et al. ${ }^{38}$ & 439 & Precipitação com PEG & 22 \\
\hline TOTAL & 4780 & Média & 27,5 \\
\hline
\end{tabular}

(PEG) polietilenoglicol; $(\mathrm{N})$ número de indivíduos no estudo 
Tabela 2-Resumo dos estudos de bioatividade da macroprolactina em Nb2

\begin{tabular}{|c|c|c|}
\hline AUTOR & AMOSTRAS (N) & RESULTADOS \\
\hline Farkouh et al. ${ }^{91}$ & 08 & $\mathrm{BA} / \mathrm{IA}$ bbPRL $<\mathrm{mPRL}$ \\
\hline Jackson et al. ${ }^{27}$ & 05 & $\mathrm{BA} / \mathrm{IA}$ bbPRL $<\mathrm{mPRL}$ \\
\hline Leite et al. ${ }^{45}$ & 11 & $\mathrm{BA} / \mathrm{IA}$ bbPRL $<\mathrm{mPRL}$ \\
\hline Gambino et al. ${ }^{99}$ & 02 & $\mathrm{BA} / \mathrm{IA}$ bbPRL $<\mathrm{mPRL}$ \\
\hline Guitelman et al. $^{48}$ & 01 & $\mathrm{BA} / \mathrm{IA}$ bbPRL $<\mathrm{mPRL}$ \\
\hline TOTAL & 27 & \\
\hline Andersen et al. ${ }^{49}$ & 01 & $\mathrm{BA} / \mathrm{IA}$ bbPRL $\sim \mathrm{mPRL}$ \\
\hline Whitaker et al. ${ }^{26}$ & 06 & $\mathrm{BA} / \mathrm{IA} \quad \mathrm{bbPRL} \sim \mathrm{mPRL}$ \\
\hline Rennie et al. ${ }^{100}$ & 03 & $\mathrm{BA} / \mathrm{IA} \quad \mathrm{bbPRL} \sim \mathrm{mPRL}$ \\
\hline Bonhoff et al. ${ }^{101}$ & 01 & $\mathrm{BA} / \mathrm{IA} \quad \mathrm{bbPRL} \sim \mathrm{mPRL}$ \\
\hline Hattori et al ${ }^{86}$ & 04 & $\mathrm{BA} / \mathrm{IA}$ bbPRL $\sim \mathrm{mPRL}$ \\
\hline Cavaco et al. ${ }^{50}$ & 12 & $\mathrm{BA} / \mathrm{IA} \quad \mathrm{bbPRL} \sim \mathrm{mPRL}$ \\
\hline Leaños-Miranda et al. ${ }^{51}$ & 01 & $\mathrm{BA} / \mathrm{IA}$ bbPRL $\sim \mathrm{mPRL}$ \\
\hline De Schepper et al. ${ }^{47}$ & 37 & $\mathrm{BA} / \mathrm{IA}$ bbPRL $\sim \mathrm{mPRL}$ \\
\hline TOTAL & 65 & \\
\hline
\end{tabular}

(N) número de amostras; (BA/IA) relação entre bioatividade e imunoatividade; (bbPRL) macroprolactina; (mPRL) prolactina monomérica do indivíduo ou padrão; $(<)$ menor que; $(\sim)$ semelhante a 
Tabela 5 - Avaliação hormonal sexual dos indivíduos do Grupo I

\begin{tabular}{|c|c|c|c|c|c|}
\hline CASO & $\begin{array}{c}\text { FSH } \\
(\mathrm{UI} / \mathrm{L})\end{array}$ & $\begin{array}{c}\mathrm{LH} \\
(\mathrm{UI} / \mathrm{L})\end{array}$ & $\begin{array}{l}\text { ESTRADIOL } \\
(\mathrm{pg} / \mathrm{mL})\end{array}$ & $\begin{array}{l}\text { PROGESTERONA } \\
(\mathrm{ng} / \mathrm{mL})\end{array}$ & $\begin{array}{c}\text { TESTOSTERONA } \\
(\mathrm{ng} / \mathrm{dL})\end{array}$ \\
\hline \multirow{2}{*}{$\mathrm{VR}^{*}$} & $1,7-5,9 \mathrm{~F}$ & $0,95-8,4 \mathrm{~F}$ & $40-228$ & $>2,5$ & $271-965$ \\
\hline & $1-12 \mathrm{M}$ & $1,4-9,2 \mathrm{M}$ & & & \\
\hline 1 & 13,1 & 11,7 & 57,9 & 4 & - \\
\hline 2 & 5,2 & 2,9 & 101 & 11,8 & - \\
\hline 3 & 2,3 & 3,6 & 138 & 15,7 & - \\
\hline 4 & 4,1 & 3,7 & 93,7 & 13,4 & - \\
\hline 5 & 5,7 & 4,3 & - & - & 504 \\
\hline 6 & 2,5 & 2,2 & 156 & 9,1 & - \\
\hline 7 & 1,8 & 7,7 & 162 & 18,1 & - \\
\hline 8 & 1,3 & 7,9 & 167 & 11 & - \\
\hline 9 & 3,8 & 9,8 & 83,2 & 3,3 & - \\
\hline 10 & 2,3 & 3,6 & 95 & 8,9 & - \\
\hline 11 & 3,1 & 3,4 & 117 & 16,2 & - \\
\hline 12 & 4,5 & 5,9 & 138,8 & 5,9 & - \\
\hline 13 & 2,7 & 4,1 & 102,4 & 18,1 & - \\
\hline 14 & 6,4 & 3,6 & - & 14,6 & - \\
\hline 15 & 2,4 & 2,7 & 116,1 & 9,1 & - \\
\hline 16 & 2,7 & 2,7 & - & - & 640 \\
\hline 17 & 3 & 4,3 & 133 & 6,9 & - \\
\hline 18 & 4,3 & 2,1 & 221 & 5,2 & - \\
\hline
\end{tabular}

(VR) valor de referência; (*) para homens ou mulheres na fase luteal;

(F) sexo feminino; (M) sexo masculino 
Anexo C

C1. Gráficos das cromatografias de PRL dos soros dos indivíduos do Grupo I

Os picos de PRL correspondem, em ordem de aparecimento no gráfico, a bbPRL, bPRL e mPRL. Nota-se que para todas as amostras do Grupo I, havia predomínio de bbPRL. Os valores de GH eram desprezíveis.

\section{Caso 1}

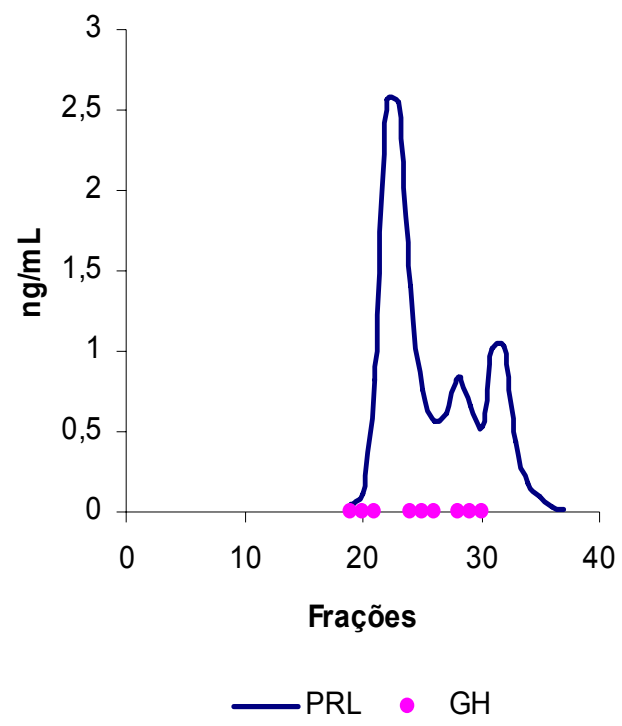

Caso 2

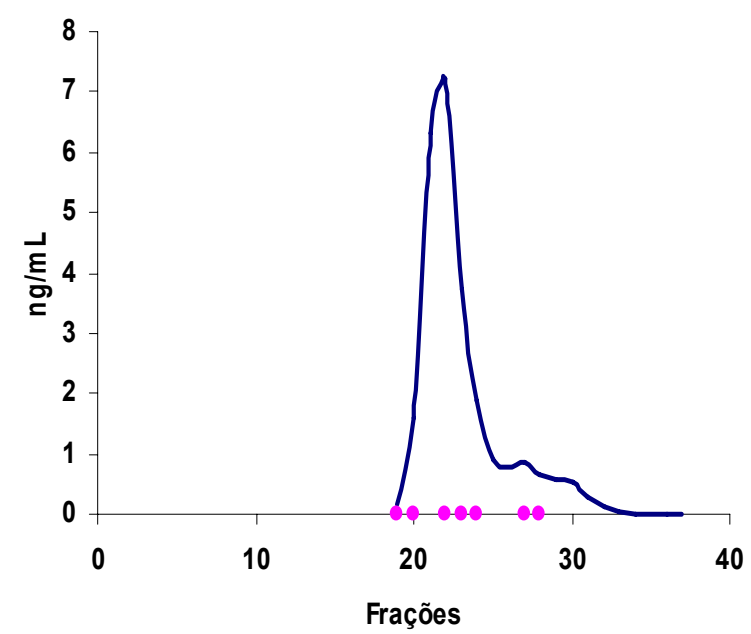

$\longrightarrow$ PRL $\bullet \mathrm{GH}$ 
Caso 3

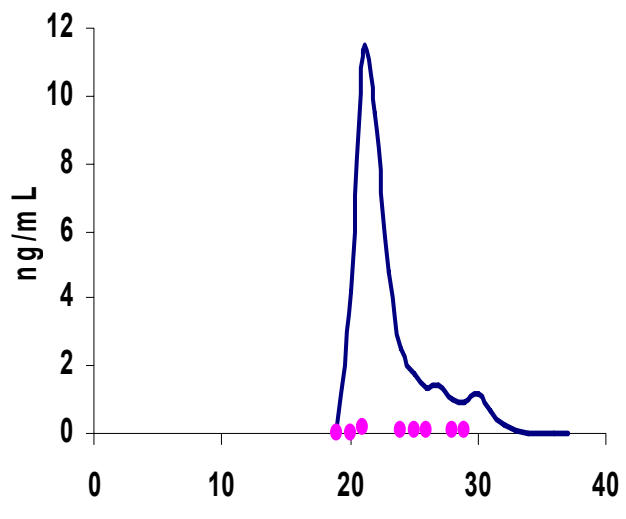

Frações

-PRL • $\mathrm{GH}$

\section{Caso 5}

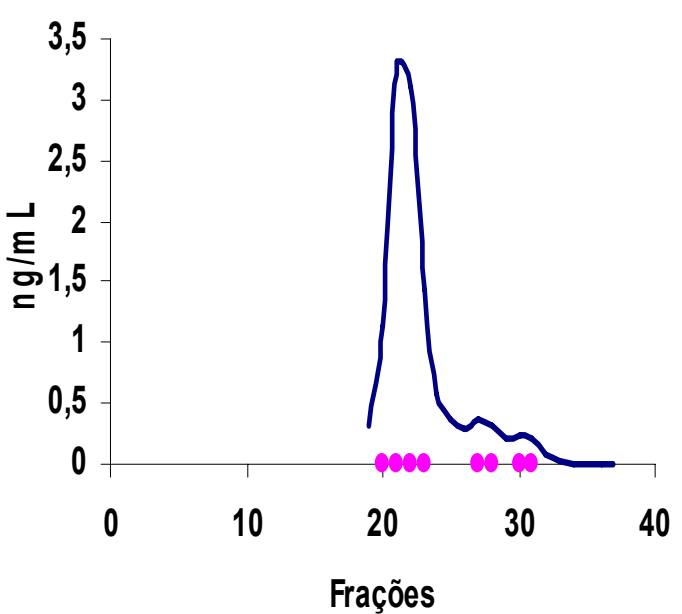

-PRL • $\mathrm{GH}$
Caso 4

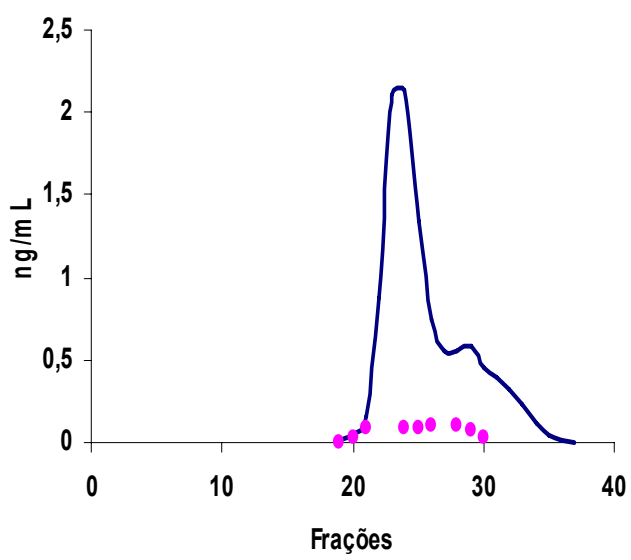

$\longrightarrow \mathrm{PRL} \cdot \mathrm{GH}$

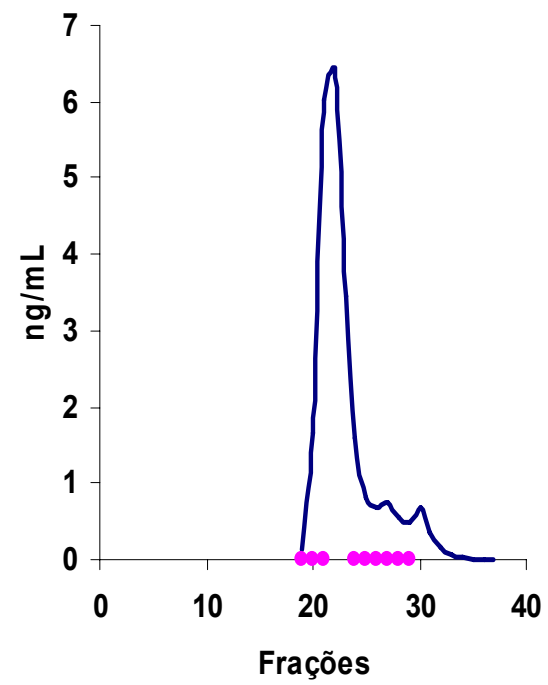

-PRL - $\mathrm{GH}$ 
Caso 7

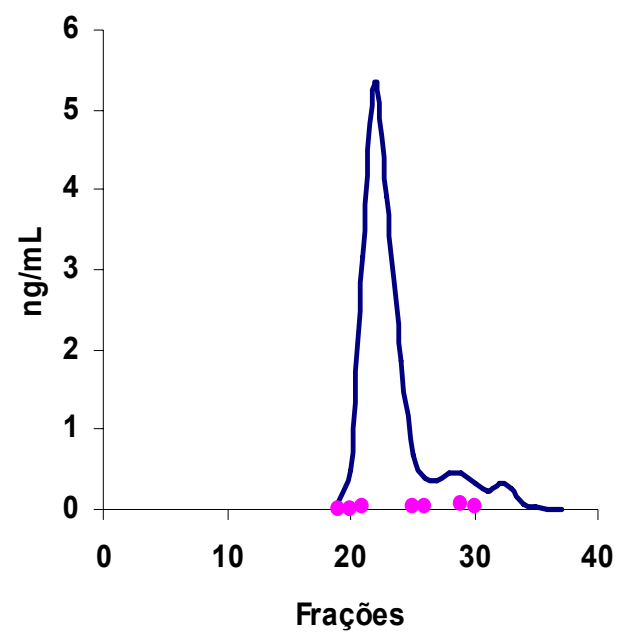

$\longrightarrow$ PRL $\bullet \mathrm{GH}$
Caso 8

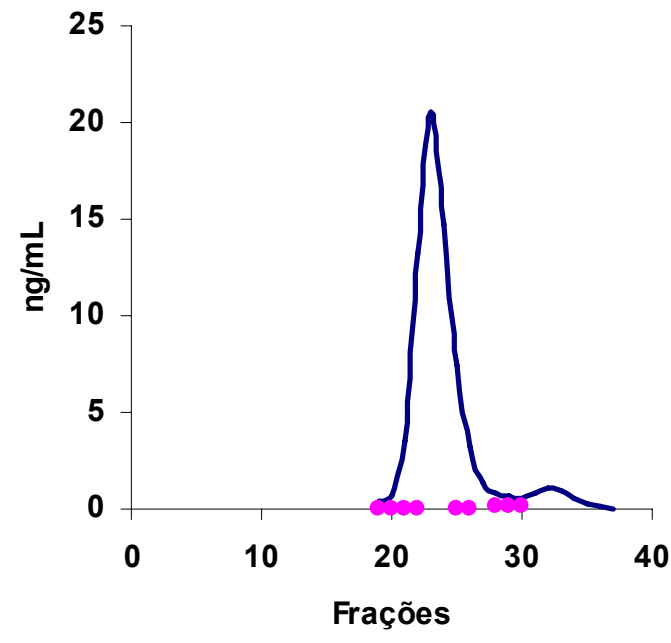

- PRL $\quad$ GH
Caso 9

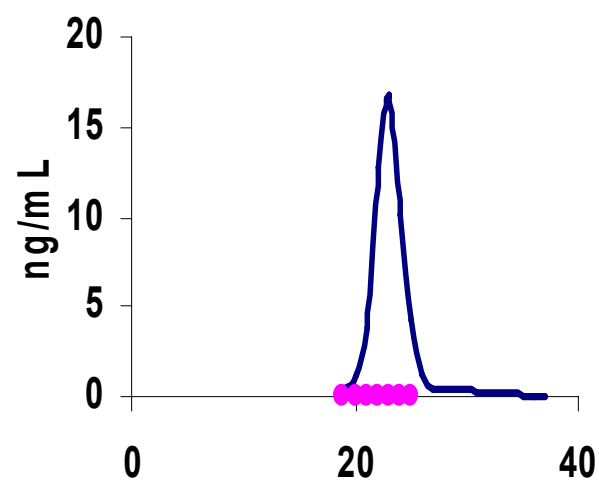

Frações

PRL $\bullet \mathrm{GH}$
Caso 10

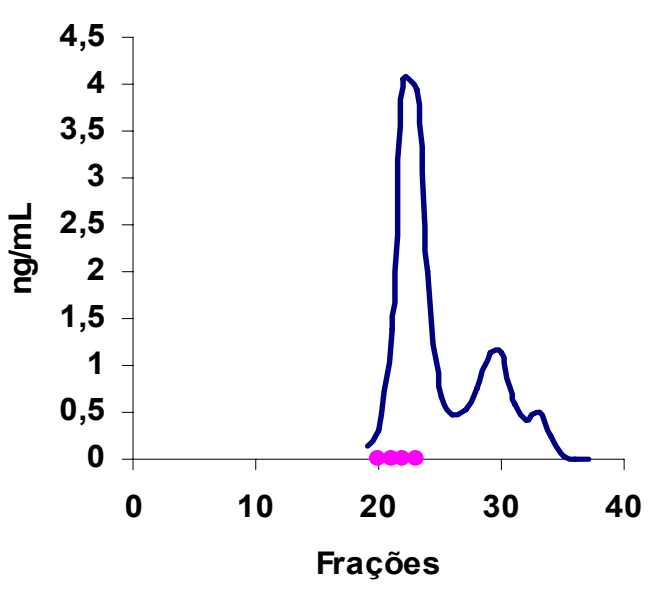

$\longrightarrow$ PRI $-\mathrm{GH}$ 
Caso 11

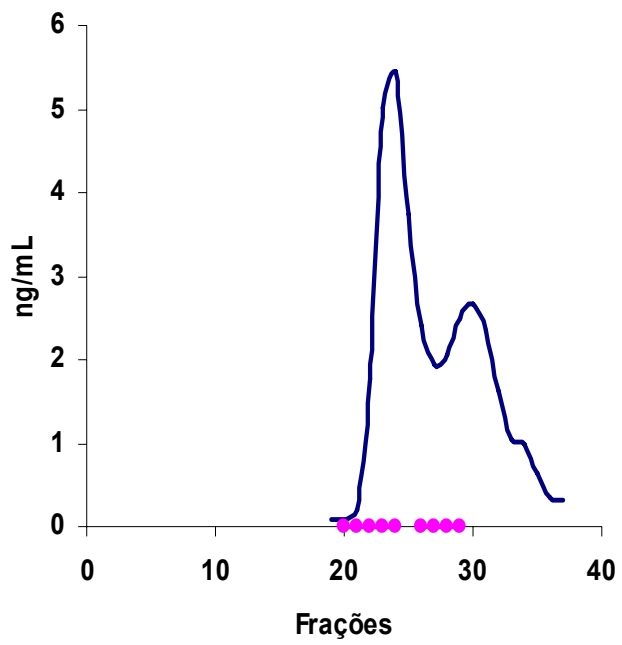

$\longrightarrow$ PRL $\longrightarrow \mathrm{GH}$
Caso 12

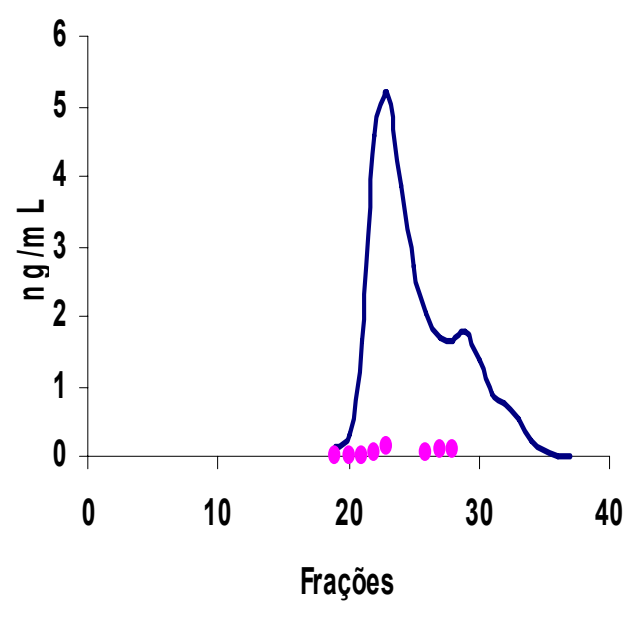

-PRL $・ \mathrm{GH}$

\section{Caso 13}

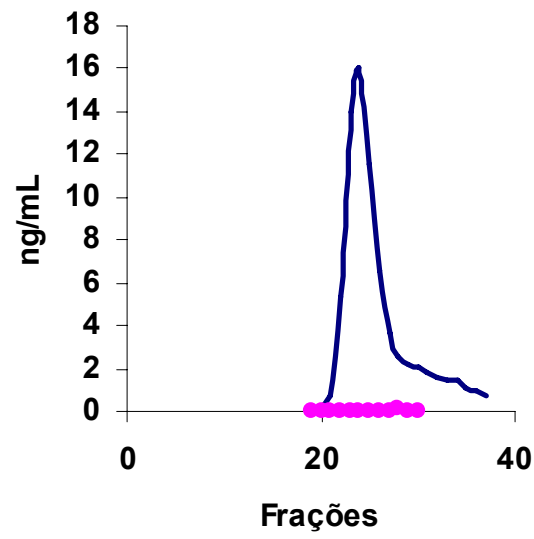

-PRL $\bullet \mathrm{GH}$

\section{Caso 14}

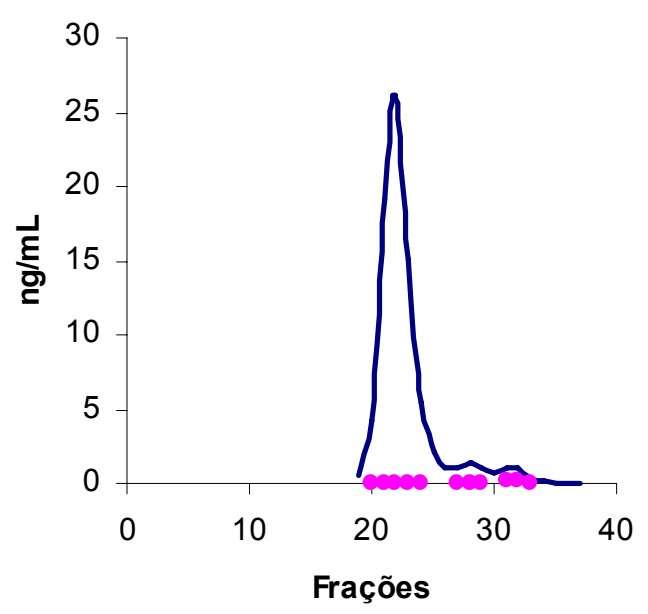

$\longrightarrow \mathrm{PRL} \bullet \mathrm{GH}$ 
Caso 15

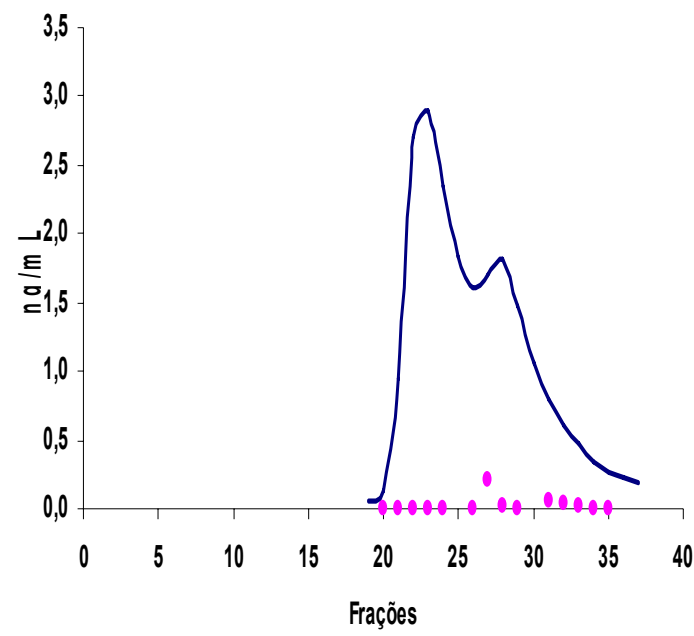

—PRL • $\mathrm{GH}$

\section{Caso 17}

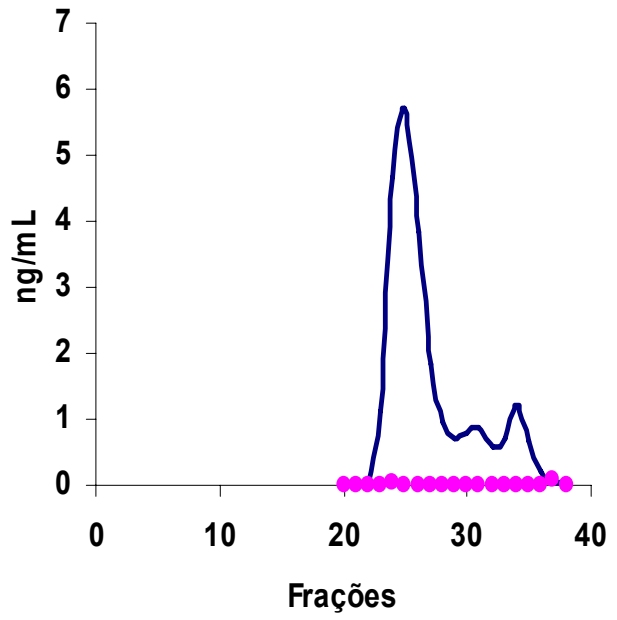

—PRL $\bullet \mathrm{GH}$
Caso 16

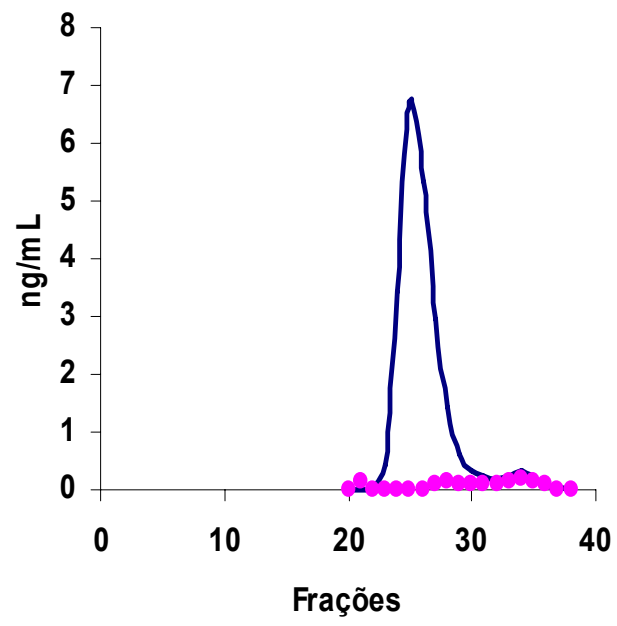

$\longrightarrow P R L ・ G H$

\section{Caso 18}

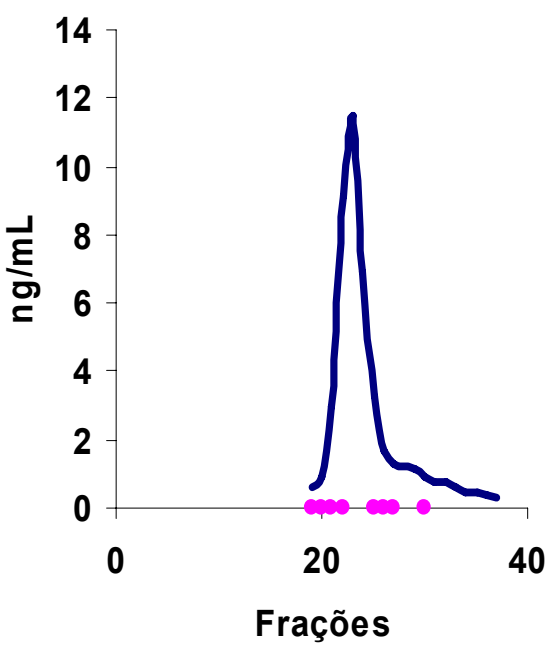

$\longrightarrow$ PRL $\bullet \mathrm{GH}$ 
C2. Gráficos das cromatografias de PRL dos soros dos indivíduos do Grupo II

Os picos de PRL correspondem, em ordem de aparecimento no gráfico, a bbPRL, bPRL e mPRL. Nota-se que para todas as amostras do Grupo II, havia ausência de bbPRL. Os valores de GH eram desprezíveis.

Caso 19

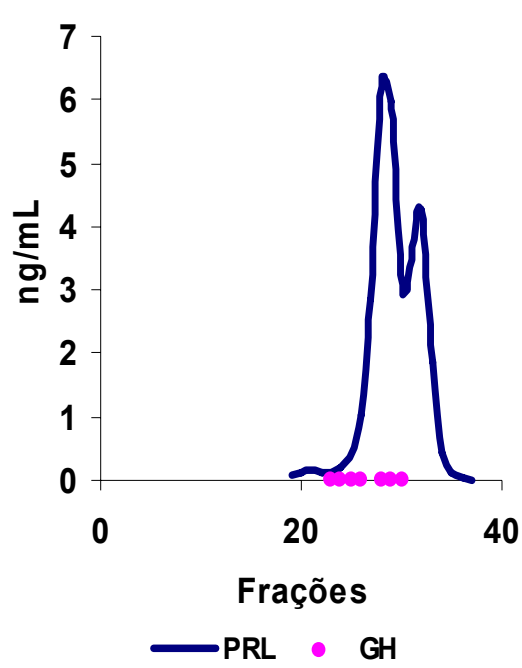

Caso 20

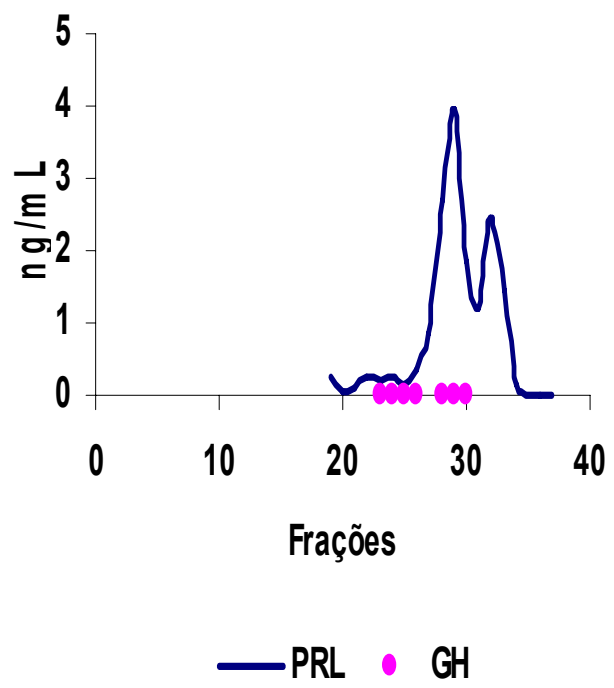


Caso 21

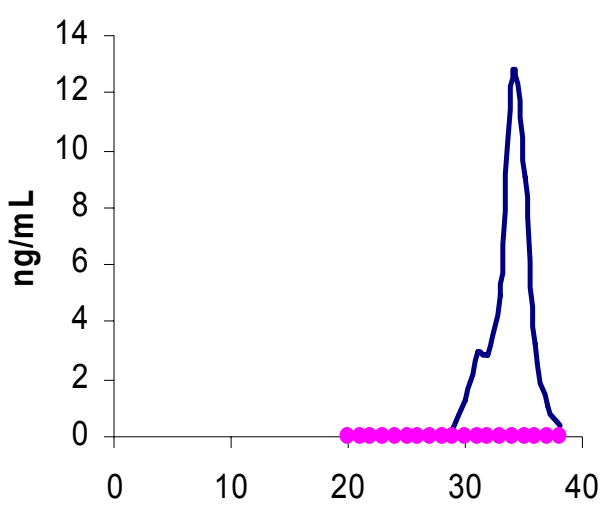

Frações

$-\mathrm{PRL} \bullet \mathrm{GH}$
Caso 22

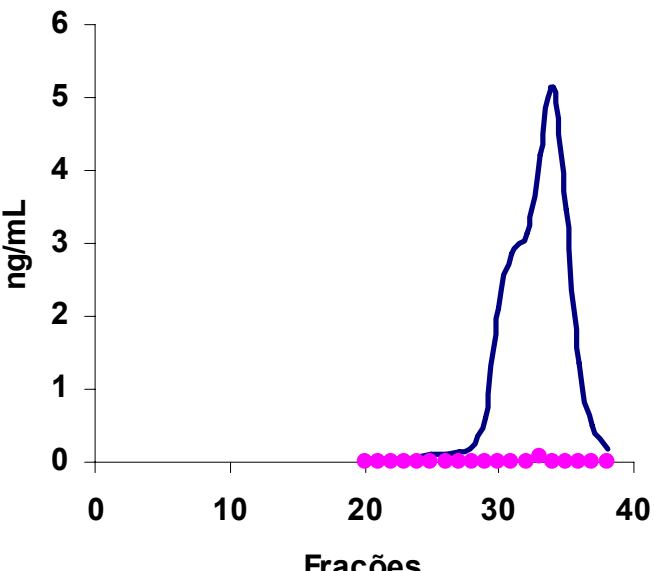

Frações

PRL $\bullet \mathrm{GH}$

\section{Caso 23}

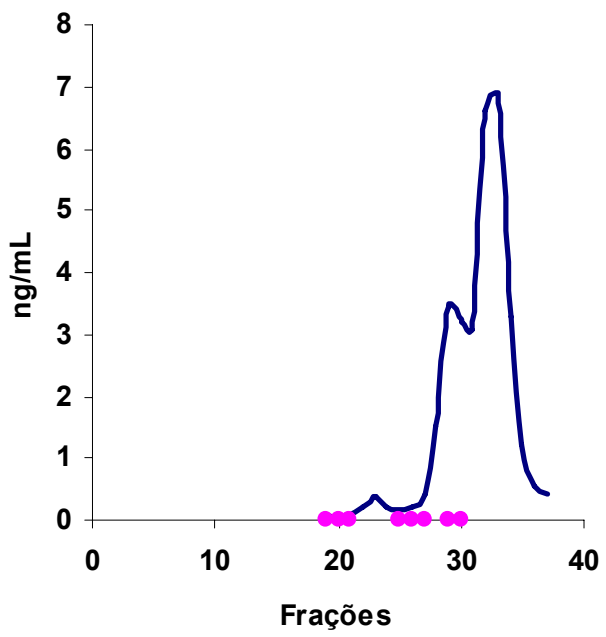

PRL • GH 
Anexo D

D1. Gráficos da atividade biológica da bbPRL das amostras obtidas por cromatografia dos soros dos indivíduos do Grupo I, com predomínio de bbPRL, no ensaio $\mathrm{Nb}$.

Caso 1

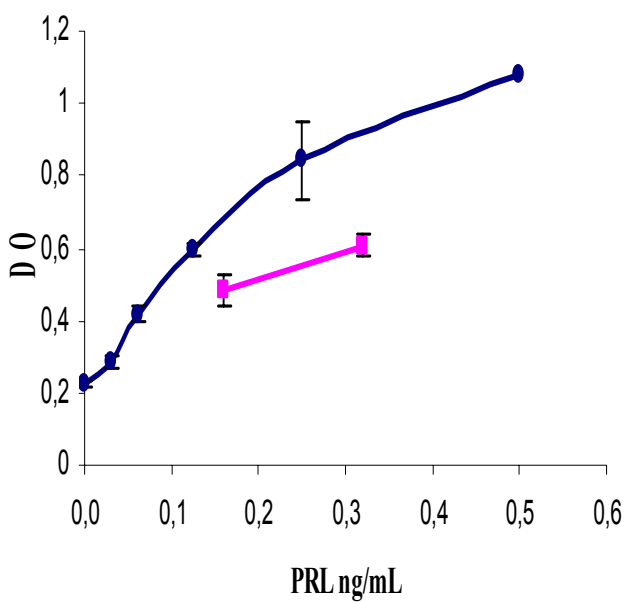

$\rightarrow$ WPRL $\rightarrow$ bbPRL caso 1
Caso 2

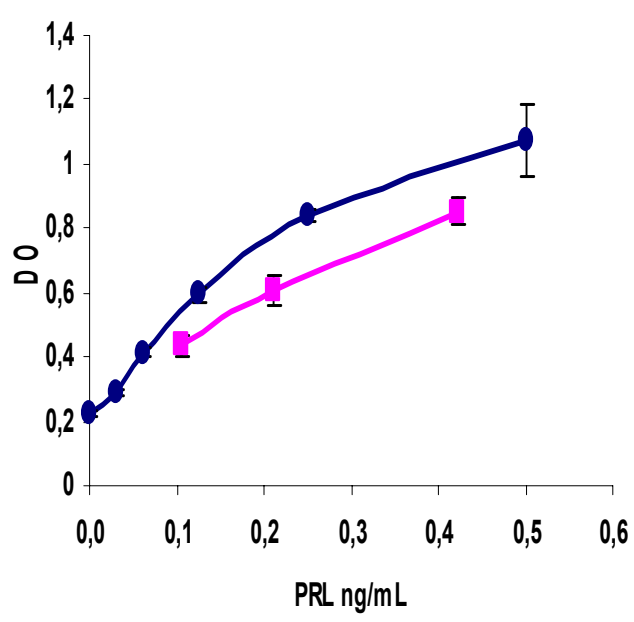

$\rightarrow$ WPRL $\rightarrow$ bbPRL caso 2 


\section{Caso 3}

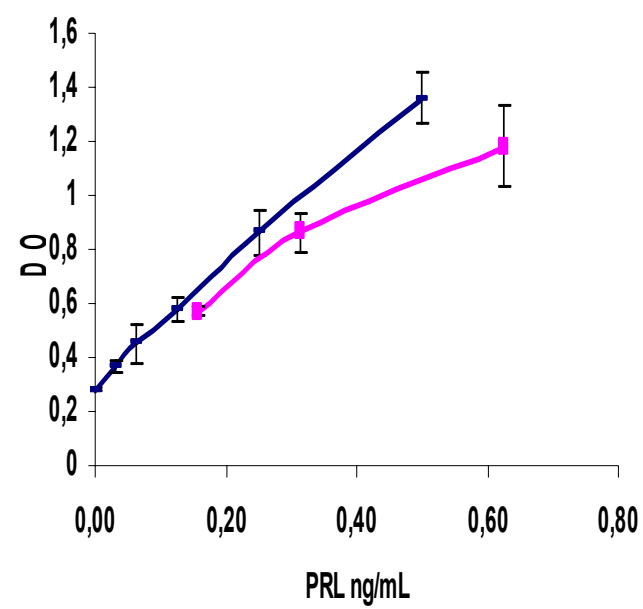

-wPRL $\_$bbPRL caso 3
Caso 4

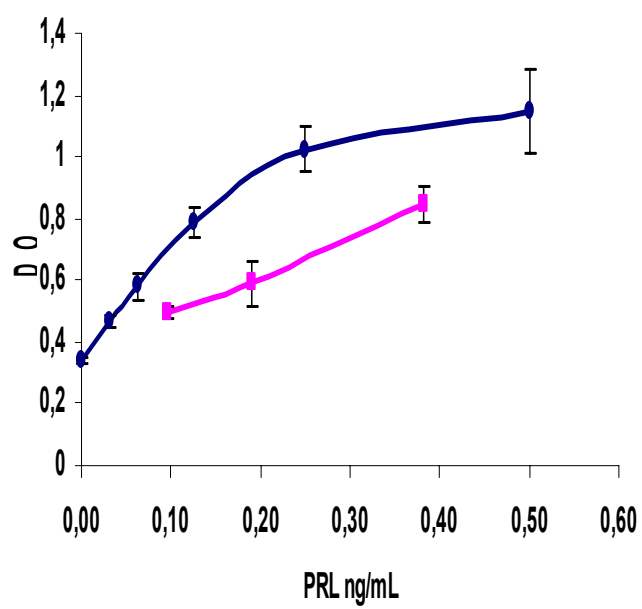

$\rightarrow$ WPRL $4-b b P R L$ caso 4

\section{Caso 5}

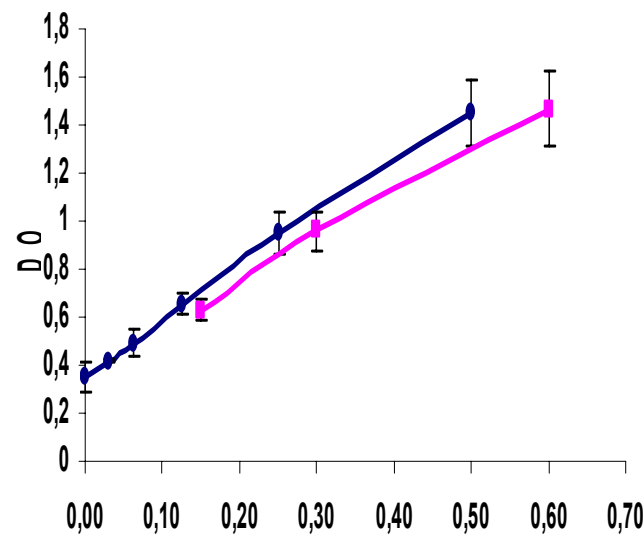

PRLnglmL

$\rightarrow w P R L \perp b b P R L$ caso 5

\section{Caso 6}

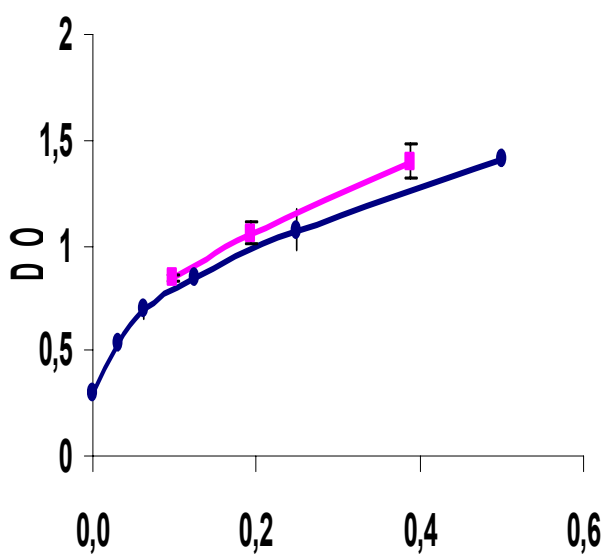

PRL ng/mL

$\rightarrow$ WPRL $\rightarrow$ bbPRL caso 6 


\section{Caso 7}

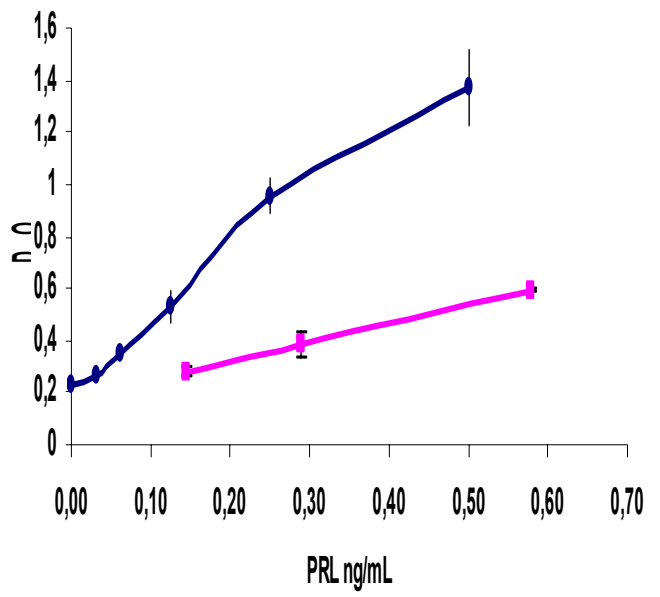

$\rightarrow$ WPRL + bbPRL caso 7

\section{Caso 9}

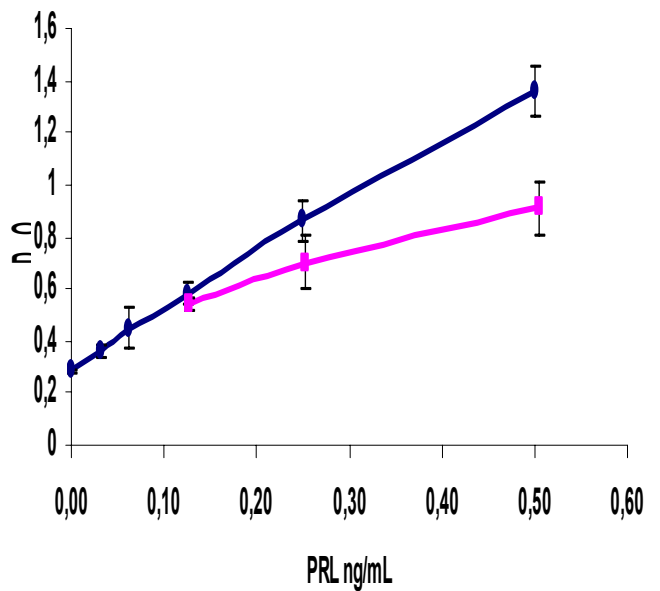

—WPRL +-bbPRL caso9

\section{Caso 8}

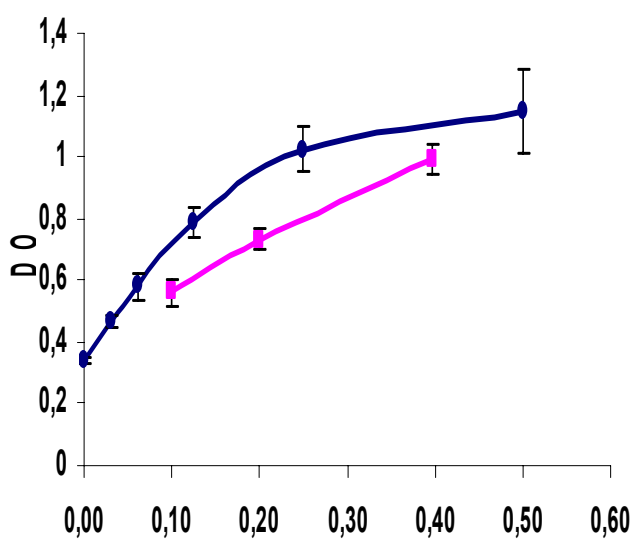

PRL ng/mL

$\rightarrow$ WPRL —bbPRL caso 8

\section{Caso 10}

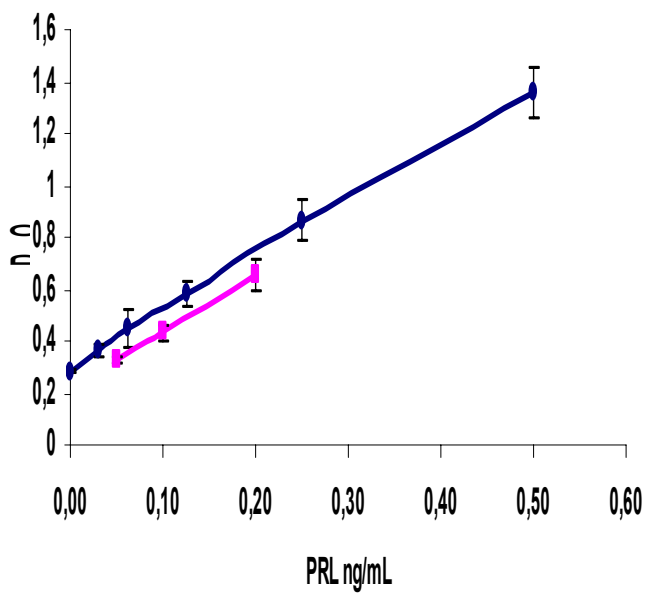

$\leftarrow$ WPRL + bbPRL caso 10 


\section{Caso 11}

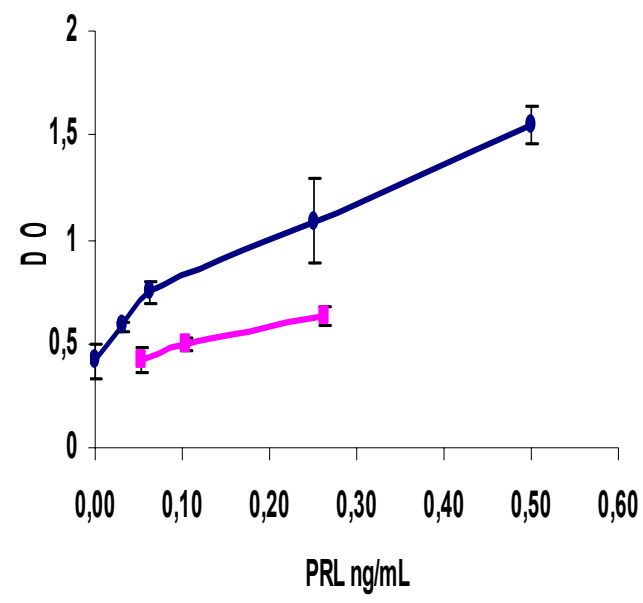

$\rightarrow W P R L=b b P R L$ caso 11
Caso 12

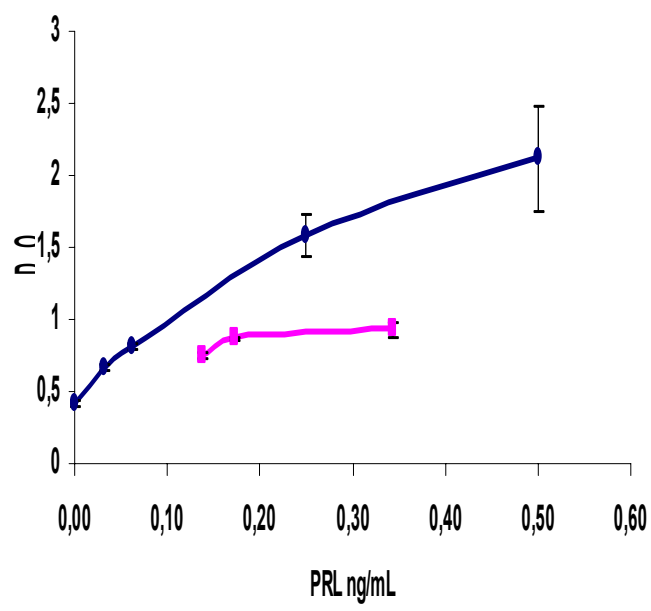

—WPRL + boPRL caso 12

\section{Caso 13}

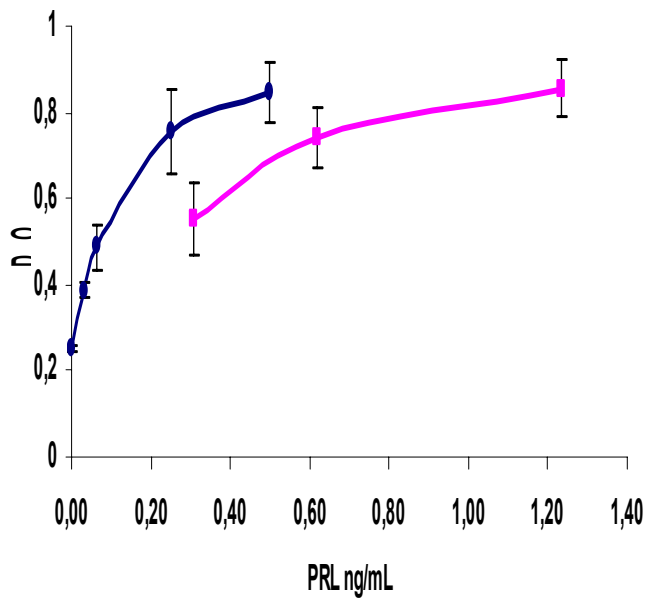

$\leftarrow$ WPRL —-bbPRLcaso 13

\section{Caso 14}

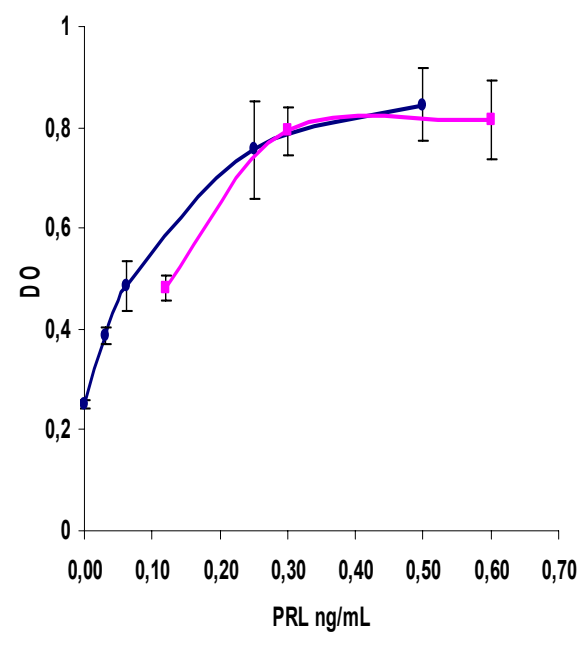

$\rightarrow$ wPRL $\rightarrow$ bbPRL caso 14 


\section{Caso 15}

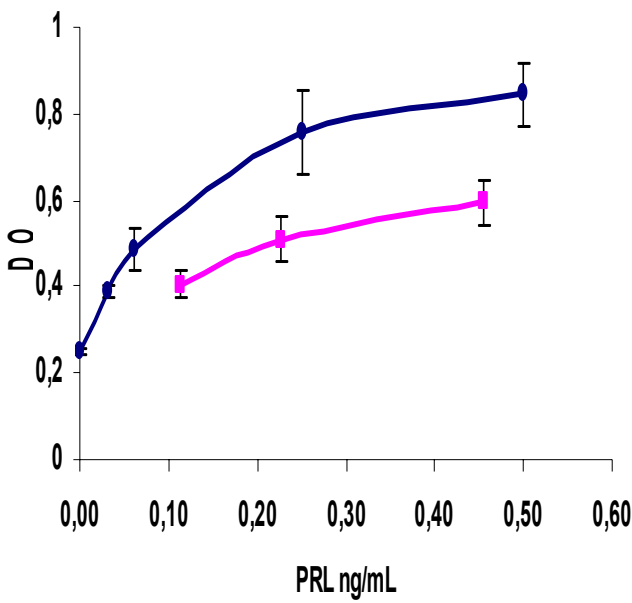

$\rightarrow$-wPRL + bbPRL caso 15

\section{Caso 17}

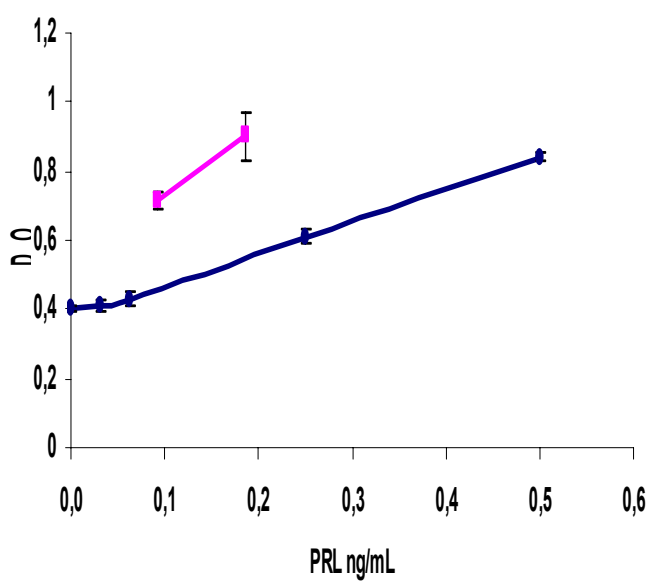

$\rightarrow$ WPRL + -bbPRL caso 17
Caso 16

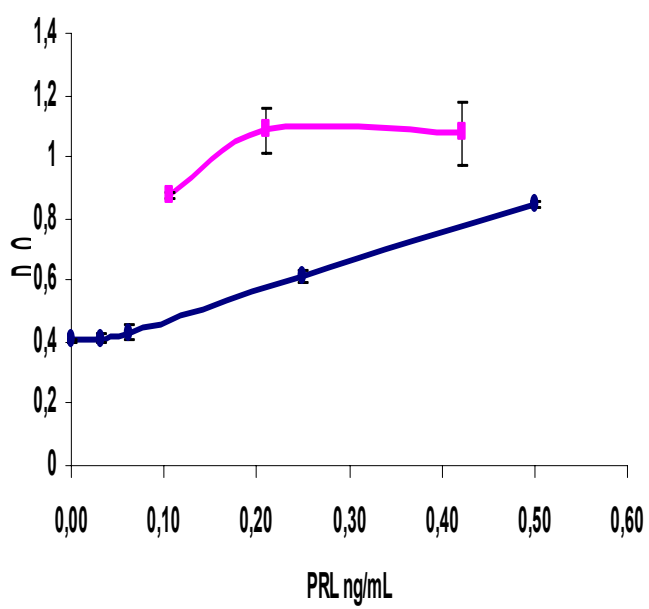

$\rightarrow$ WPRL $+b b P R L$ caso 16

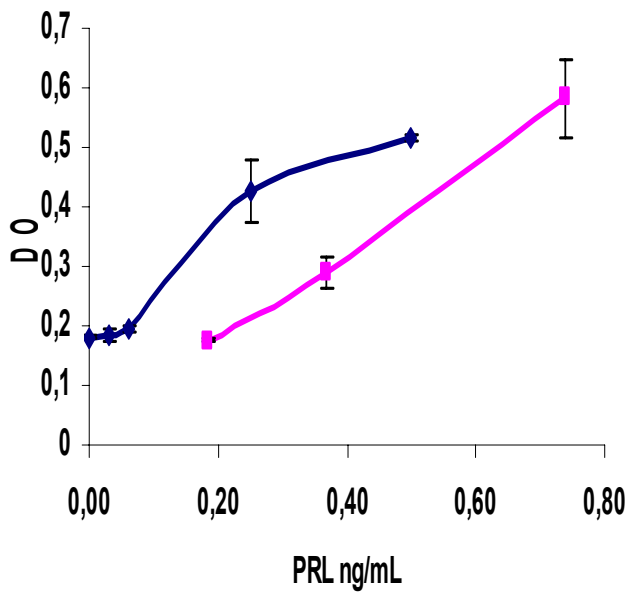

$\leftarrow$ WPRL $\rightarrow$ bbPRL caso 18 
D2. Gráficos da atividade biológica da mPRL das amostras obtidas por cromatografia dos soros dos indivíduos do Grupo II, com predomínio de bbPRL, no ensaio Nb.

Caso 19

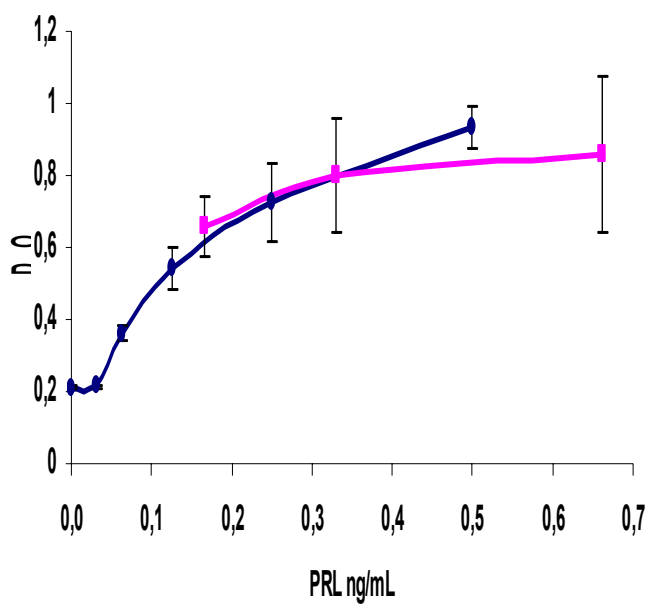

$\leftarrow-$ PRL $\perp-m P R L$ caso19
Caso 20

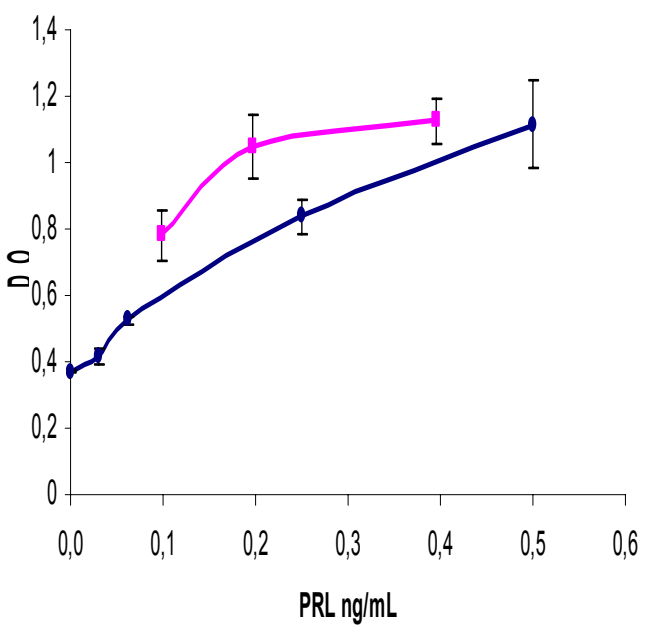

$\rightarrow$ WPRL + mPRL caso 20 
Caso 21

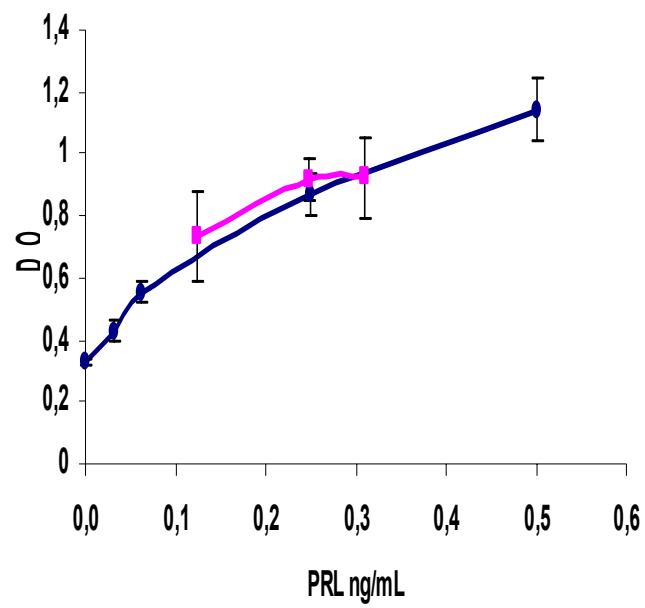

$\rightarrow$ WPRL $+m P R L$ caso21

\section{Caso 22}

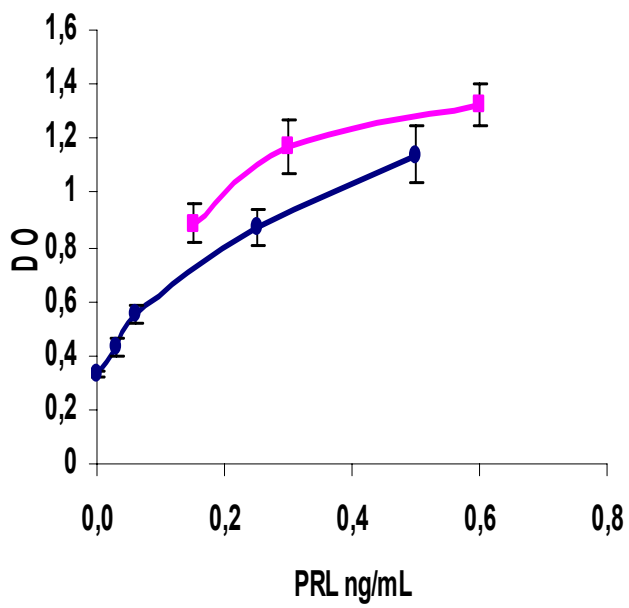

-WPRL $-\mathrm{mPRL}$ caso 22

\section{Caso 23}

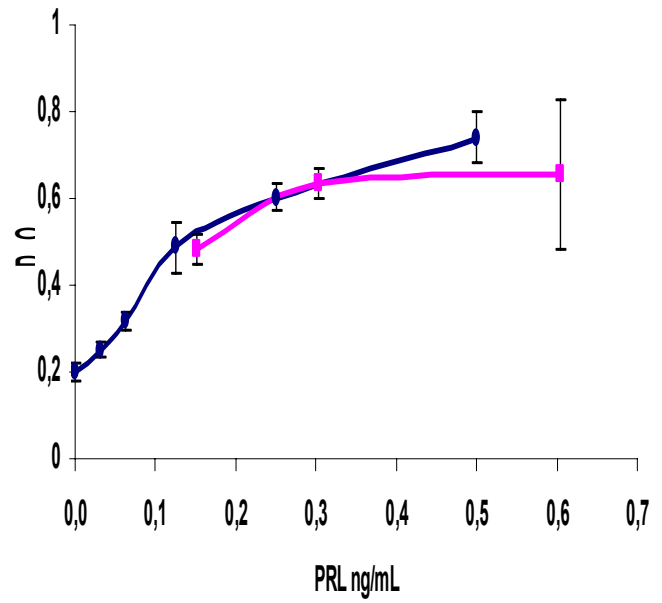

$\rightarrow$ WPRL + mPRL caso 23 
Anexo E

E1. Gráficos da atividade biológica da bbPRL das amostras obtidas por cromatografia dos soros dos indivíduos do Grupo I, com predomínio de bbPRL, no ensaio Ba/F-LLP.

\section{Caso 1}

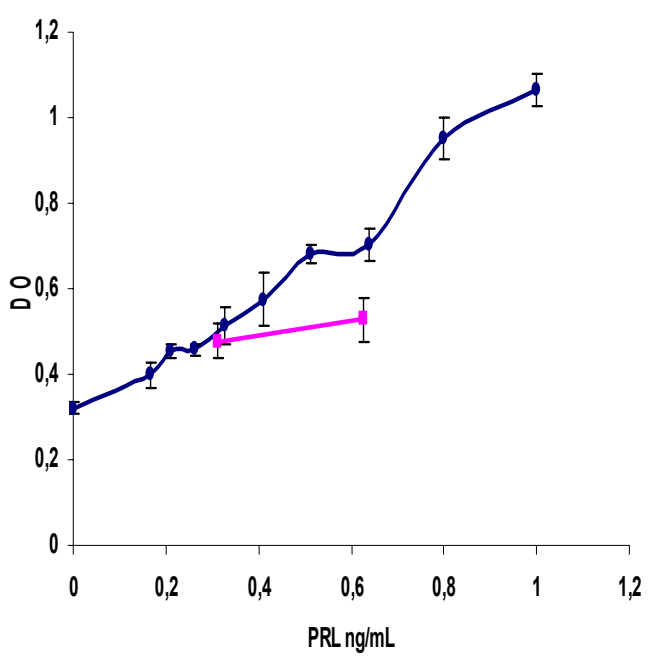

$\rightarrow \mathrm{PPRL} \rightarrow \mathrm{bbPRL}$ caso 1
Caso 2

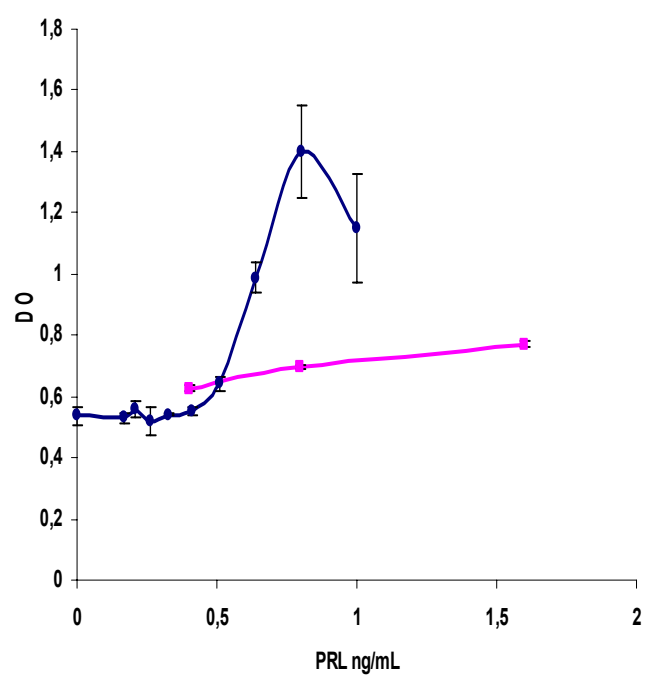

$\rightarrow \mathrm{rPRL}=\mathrm{bbPRL}$ do caso\#2 
Caso 3

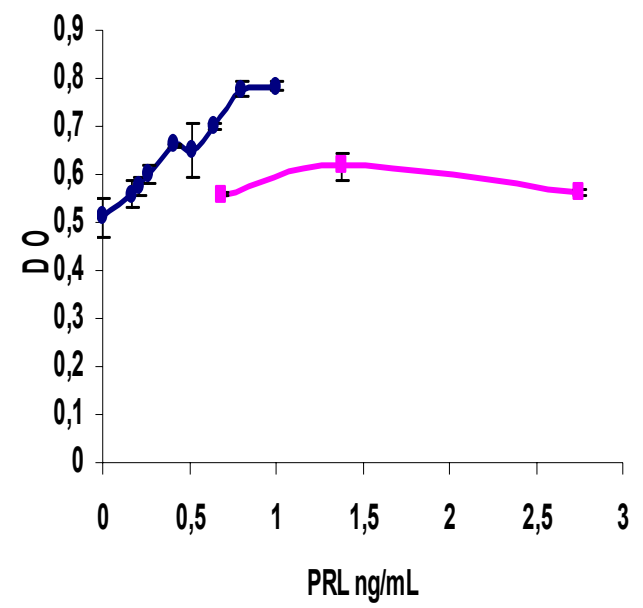

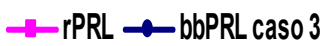

\section{Caso 5}

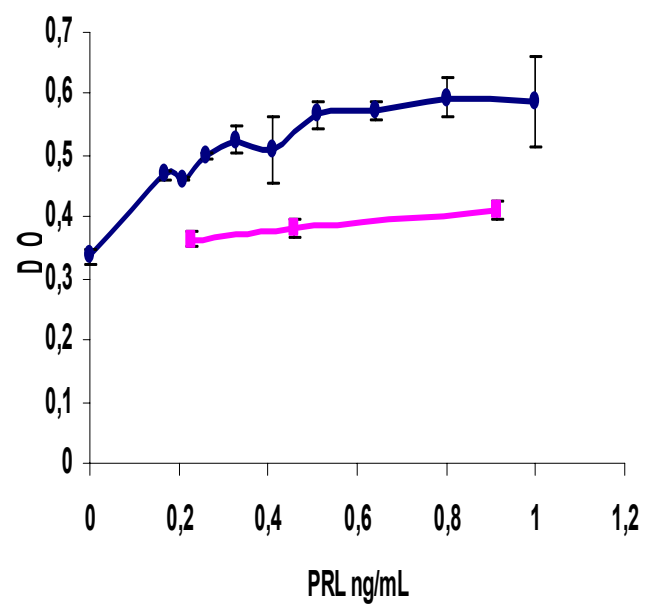

$\rightarrow r P R L=b b P R L$ caso 5
Caso 4

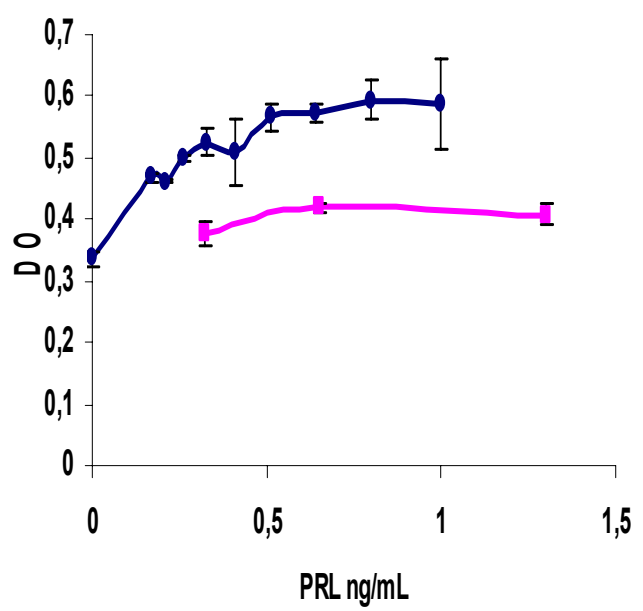

$\rightarrow r P R L=b b P R L$ caso 4

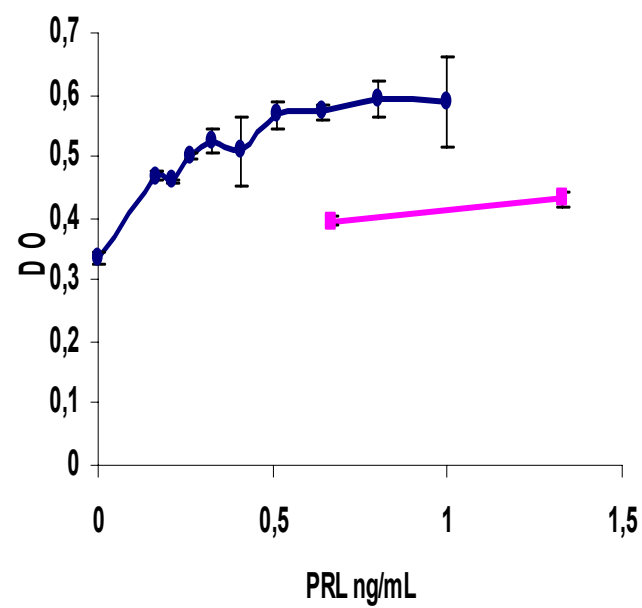

$\rightarrow r P R L=b b P R L$ caso 6 
Caso 7

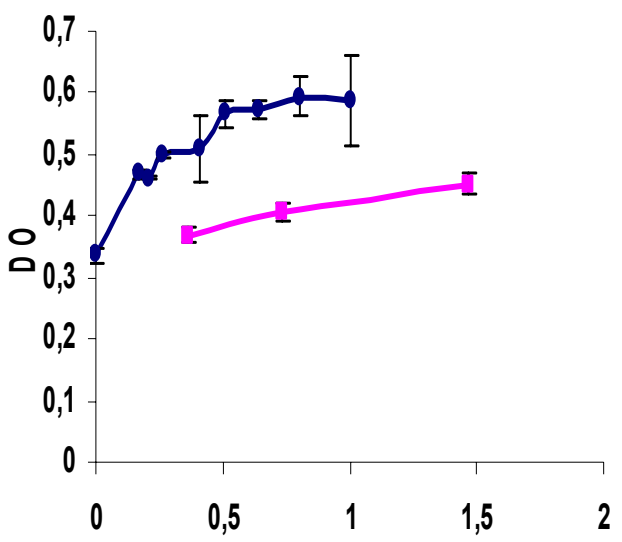

PRL ng/mL

$\rightarrow$ rPRL - -bbPRL caso 7

\section{Caso 9}

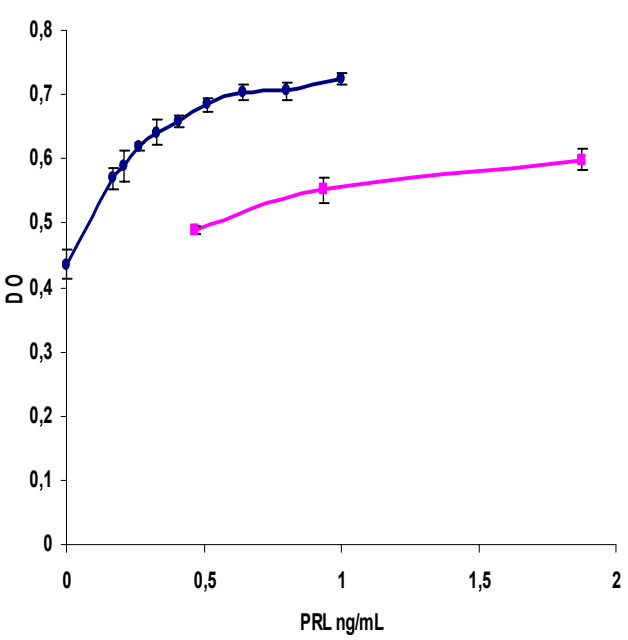

$\rightarrow$ rPRL $\_$bbPRL caso 9
Caso 8

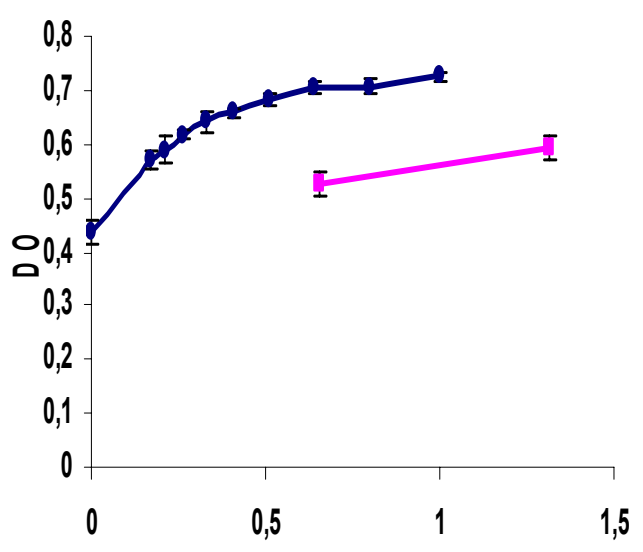

PRL ng/mL

$\rightarrow r P R L=b b P R L$ caso 8

\section{Caso 10}

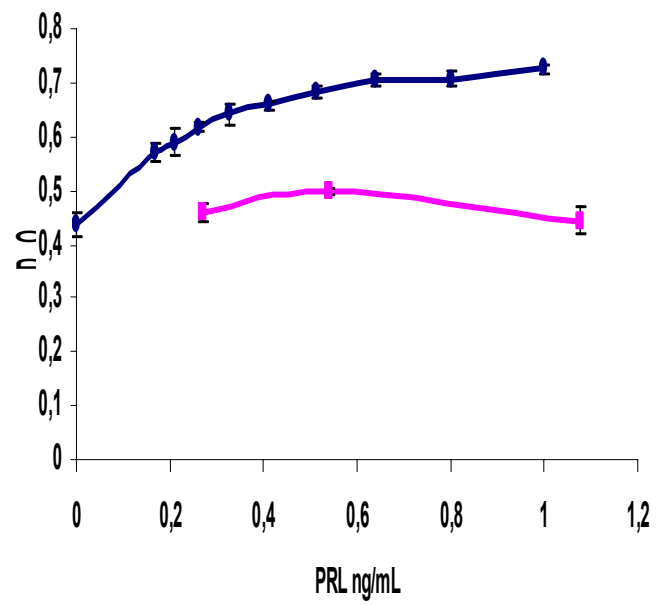

-PPRL + bbPRL caso 10 


\section{Caso 11}

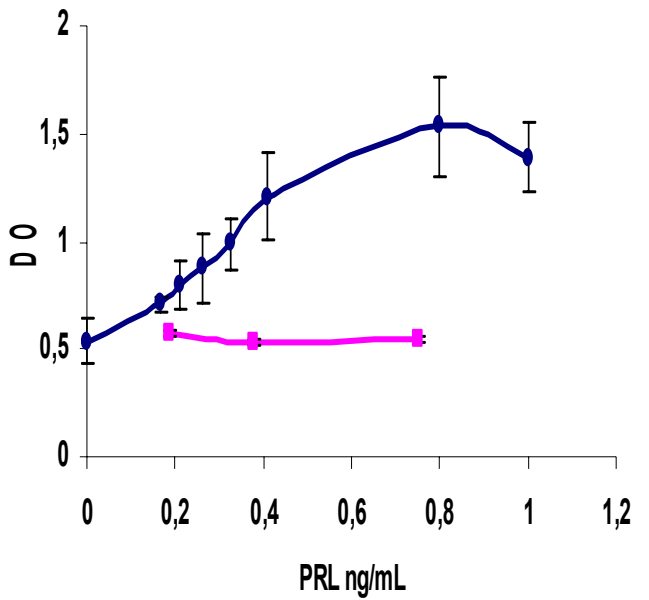

$\rightarrow r P R L=b b P R L$ caso11

\section{Caso 13}

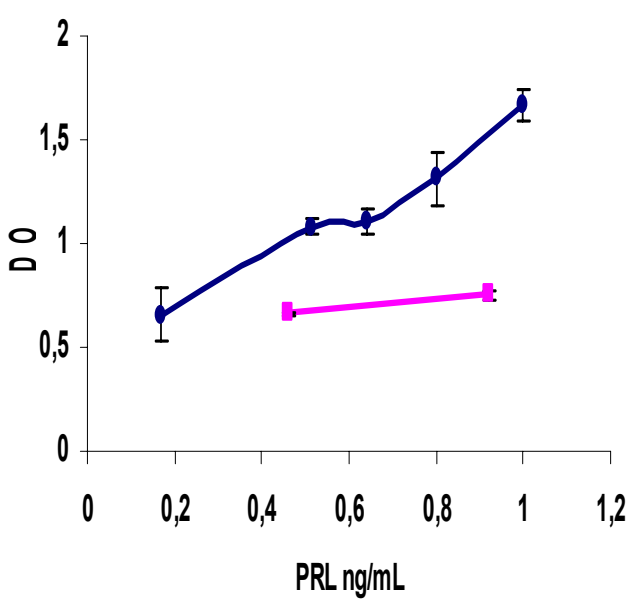

$\rightarrow r P R L=-b b P R L$ caso 13

\section{Caso 12}

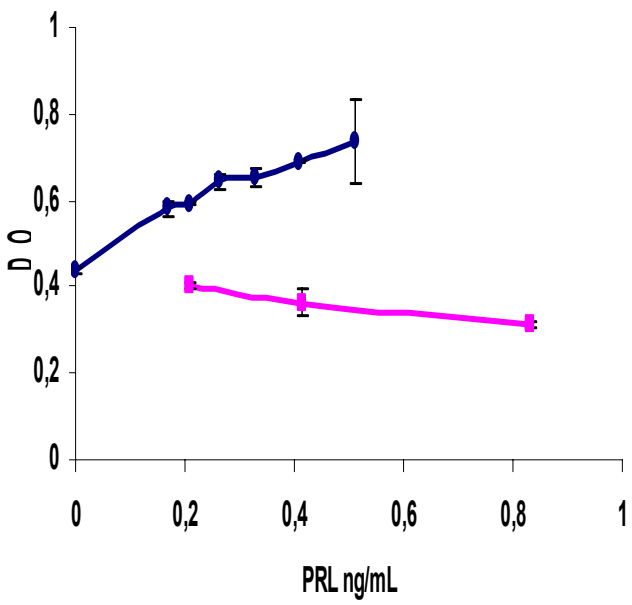

$\leftarrow$ PPRL + bbPRL caso 12

\section{Caso 14}

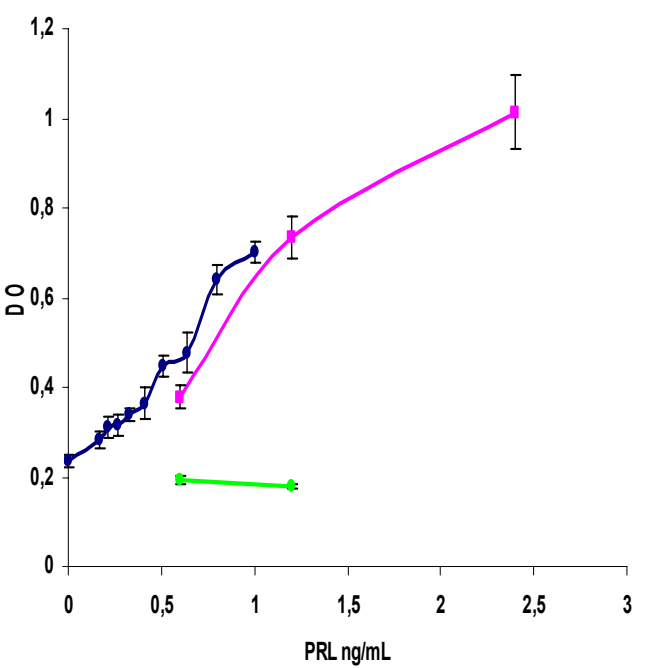

$\rightarrow r P R L=b b P R L$ caso $14-b b P R L$ caso 14 com Ac 


\section{Caso 15}

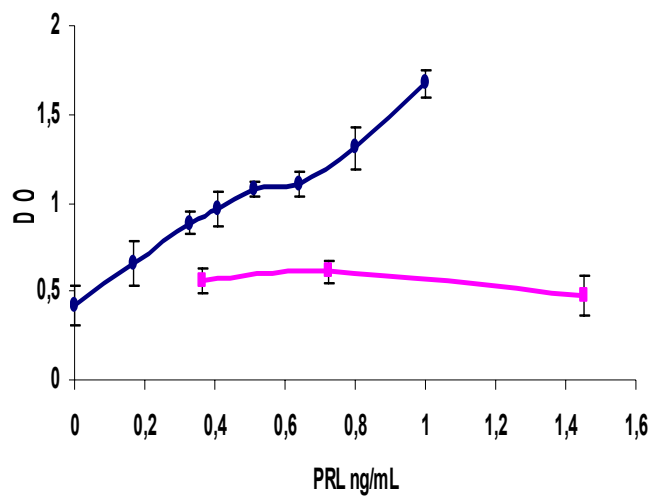

$\rightarrow$ rPRL - -bbPRL caso 15

\section{Caso 17}

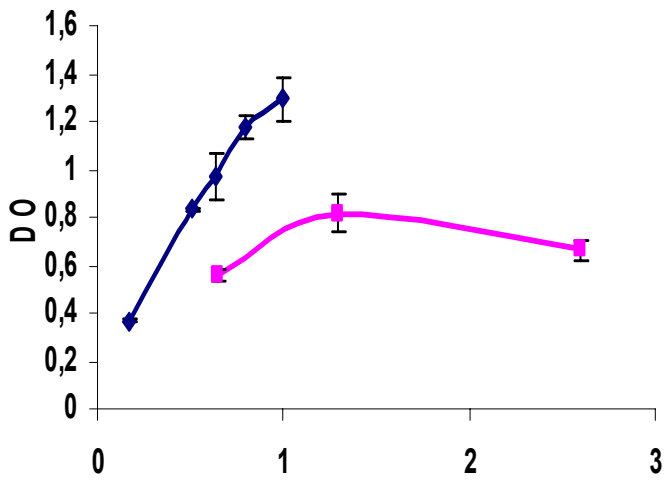

PRL ng/mL

$\neg \mathrm{rPRL}=$ bbPRL caso 17
Caso 16

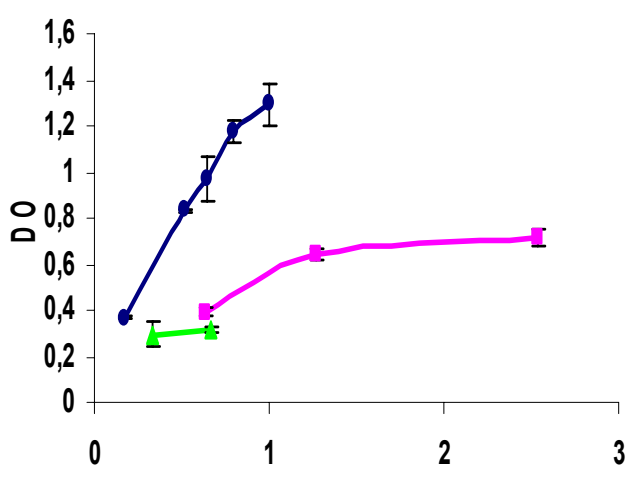

PRLng/mL

\section{Caso 18}

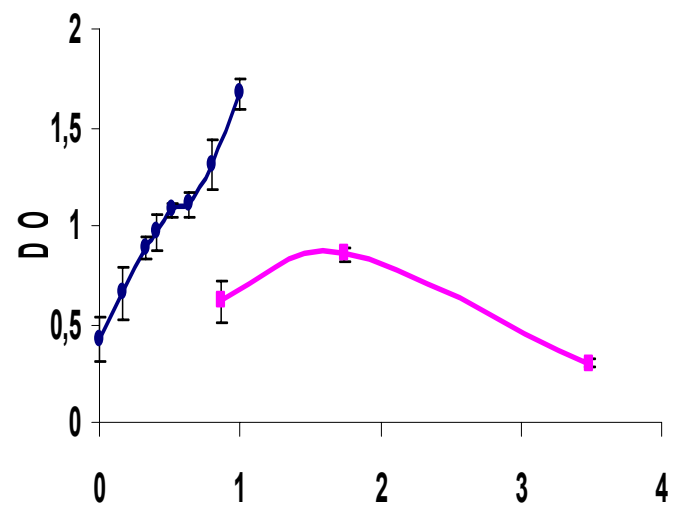

PRL ng/mL 
E2. Gráficos da atividade biológica da mPRL das amostras obtidas por cromatografia dos soros dos indivíduos do Grupo II, sem bbPRL, no ensaio Ba/FLLP.

Caso 19

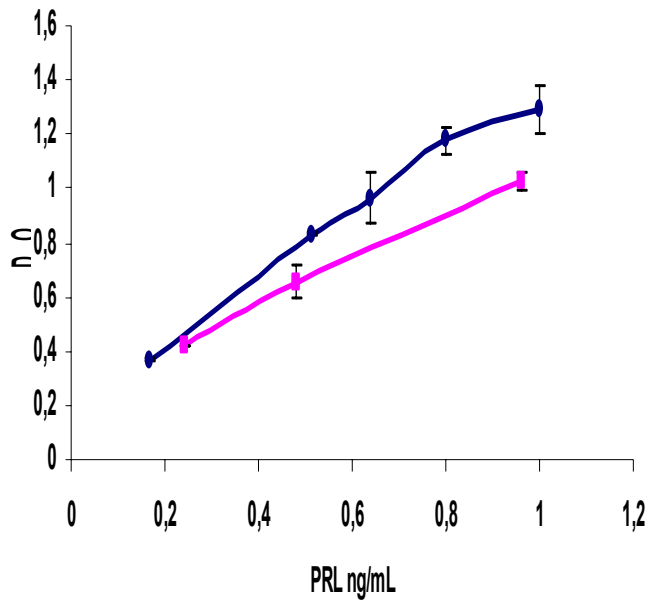

$\rightarrow P P L+m P R L \operatorname{cas} 019$
Caso 20

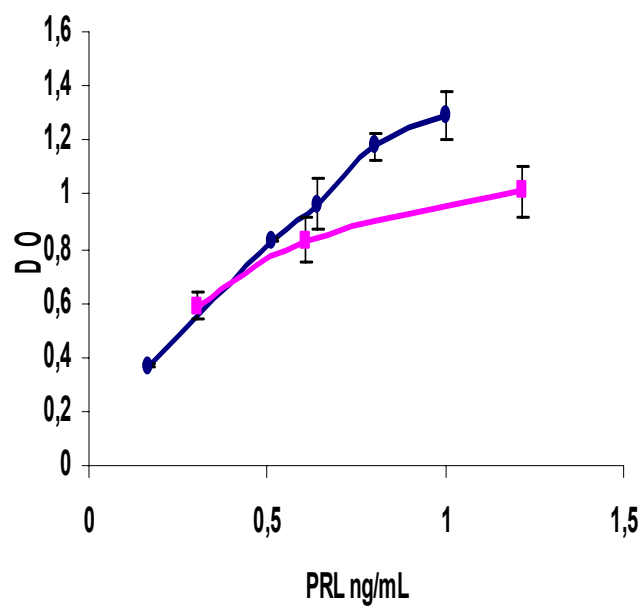

$\rightarrow$ PPRL + -mPRL caso 20 
Caso 21

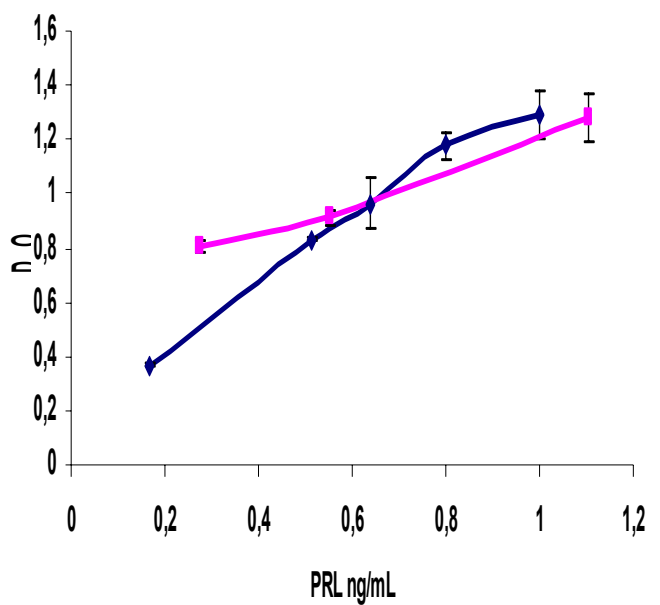

-PPRL + IPPL caso21

\section{Caso 23}

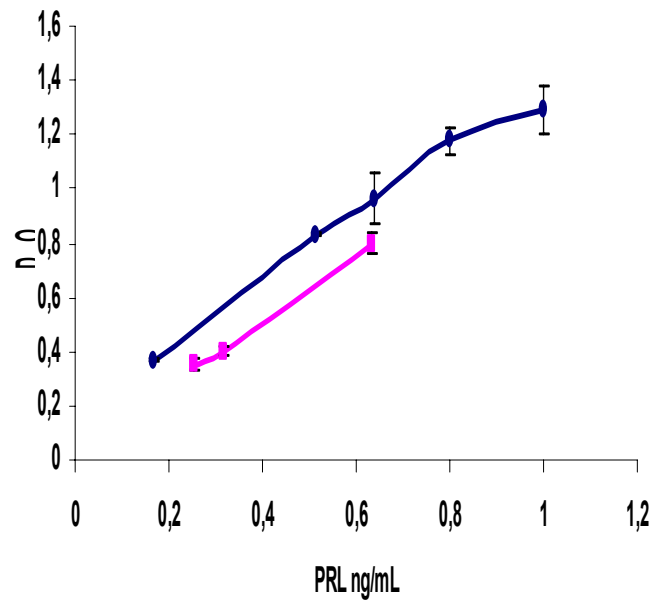

$+P P R L+m P R L$ caso 23

\section{Caso 22}

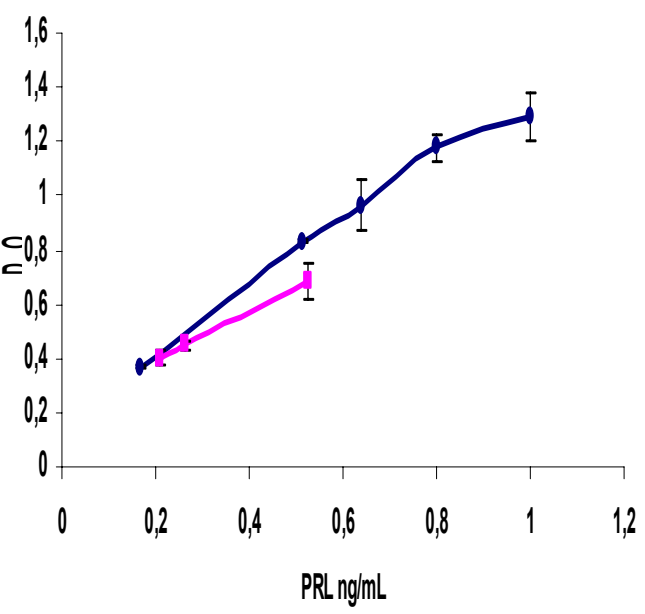

$\rightarrow$ PPRL $+m P R L$ caso 22 
8. Referências 
1 Bole-Feysot C, Goffin V, Edery M, Binart N, Kelly P. Prolactin (PRL) and its receptor: actions, signal transduction, pathways and phenotypes observed in PRL receptor knockout mice. Endocr Rev. 1998;19:225-68.

2 Riddle O, Bates RW, Dykshorn SW. The preparation, identification and assay of prolactin- a hormone of anterior pituitary. Am J Physiol. 1933;105:191-216.

3 Goffin V, Bernichtein S, Touraine P, Kelly P.A. Development and potential clinical uses of human prolactin receptor antagonists. Endocr Rev. 2005;26:400-22.

4 Hwang P, Guyda H, Friesen H. A radioimunnoassay for human prolactin. Proc Natl Acad Sci.USA. 1971;68:1902-6.

5 Lewis UJ, Singh RN, Seavey BK. Human prolactin: isolation and some properties. Biochem Biophys Res Commun. 1971;44:1169-76.

6 Barsh GS, Seeburg PH, Gelinas RE. The human growth hormone family: structure and evolution of the chromosomal locus. Nucleic Acid Res. 1983;11:3939-58.

7 Truong AT, Duez C, Belayew A, Renard A, Pictet R, Bell GI, Martial JA. Isolation and characterization of the human PRL gene. EMBO J. 1984;3:429-37. 
8 Boutin JM, Jolicoeur C, Okamura H, Gagnon J, Edery M, Shirota M, Banville D, Dusanter-Fourt I, Djiane J, Kelly PA. Cloning and expression of the rat prolactin receptor, a member of the growth/PRL receptor gene family. Cell. 1988;53:69-77.

9 Ben-Jonathan N, Mershon JL, Allen DL, Steinmetz RW. Extrapituitary prolactin: distribution, regulation, functions and clinical aspects. Endocr Rev. 1996;17:639-69.

10 Berwaer M, Martial JA, Davis JR. Characterization of an upstream promoter directing extrapituitary expression of the human PRL gene. Mol Endocrinol. $1994 ; 8: 635-42$.

11 Keeler C, Dannies PS, Hodsdon ME. The tertiary structure and backbone dynamics of human PRL. J Mol Biol. 2003;328:1105-21.

12 Suh HK and Frantz AG. Size heterogeneity of human prolactin in plasma and pituitary extracts. J Clin Endocrinol Metab. 1974;39: 928-35.

13 Fraser IS, Zhuang GL. Polymers of prolactin and their clinical significance. Obstet Gynecol Surv 1990;45:515-20.

14 Carlson HE, Markoff E, Lee DW. On the nature of serum prolactin in two patients with macroprolactinemia. Fertil Steril. 1992;58:78-87.

15 Sinha YN. Structural variants of prolactin: occurrence and physiological significance. Endocr Rev. 1995;16:354-69. 
16 Nagy E, Berczi I. Hypophysectomized rats depends on residual prolactin for survival. Endocrinology. 1991;128:2776-84.

17 Ormandy CJ, Camus A, Barra J, Damotte D, Lucas B, Buteau H, Edery M, Brousse N, Babinet C, Binart N, Kelly PA. Null mutation of the prolactin receptor gene produces multiple reproductive defects in the mouse. Genes Dev. 1997;1:167-78.

18 Freeman ME, Kanyicska B. Lerant A, Nagy G. Prolactin: structure, function and regulation of secretion. Physiol Rev. 2000;80:1523-631.

19 Serri O, Chik CL, Ur E, Ezzat S. Diagnosis and management of hyperprolactinemia. CMAJ. 2003;169:575-81.

20 Miyai K, Ichihara K, Kondo K, Mori S.Asymptomatic hyperprolactinemia and prolactinoma in the general population- mass screening by paired assays of serum prolactin. Clin Endocrinol. 1986;25:549-54.

21 Josimovich JB, Lavenhar MA, Devanesan MM, Sesta HJ, Wilchins SA Smith AC. Heterogeneous distribution of serum prolactin values in apparently healthy young women, and effects of oral contraceptive medication. Fertil Steril. 1987;47:785-91.

22 Bronstein MD. Disorders of Prolactin Secretion and Prolactinomas. In: Jameson \& DeGroot, editors. Textbook of Endocrinology. $11^{\text {th }}$ ed. Missouri: Elsevier.2005, p. 485-510. 
23 Buvat J. Hyperprolactinemia and sexual dysfunction in men: a short review. Int J Impot Res. 2003;15:373-7.

24 Kleinberg DL, Noel GL, Frantz AG. Galactorrhea: a study of 235 cases, including 48 with pituitary tumors. $N$ Eng $J$ Med.1977;296:589-600

25 Batrinos ML, Panitsa-Faflia C., Tsiganou E., Pitoulis G., Liapi C. Contribution to the problem of hyperprolactinemia: experienced with 4199 prolactin assays and 117 prolactinomas. Int J Fertil Menopausal Stud. 1994;39:120-7.

26 Whittaker PG, Wilcox T, Lind T. Maintained fertility in a patient with hyperprolactinemia due to big, big prolactin. J Clin Endocrinol Metab. 1981;53: 863-6.

27 Jackson RD, Wortsman J, Malarkey W. Characterization of a large molecular weight prolactin in women with idiopatic hyperprolactinemia and normal menses. $J$ Clin Endocrinol Metab. 1985;61:258-64.

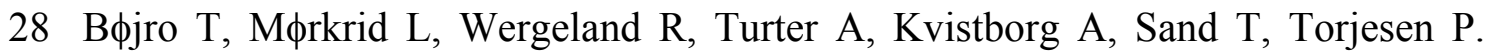
Frequency of hyperprolactinemia due to large molecular weight prolactin (150-170 kD PRL). Scand J Clin Lab Invest. 1995;55:139-47.

29 Hattori N, Ikekubo K Ishihara T, Moridera K, Hino M, Kurahachi H. Correlation of the antibody titers with serum prolactin levels and their clinical course in patients with anti-prolactin autoantibody. Eur J Endocrinol. 1994;130:438-45. 
30 Olukoga AO, Kane JW. Macroprolactinaemia: validation and application of the polyethylene glycol precipitation test and clinical characterization of the condition. Clin Endocrinol. 1999;51:119-26.

31 Hauache OM, Rocha AJ, Maia Jr ACM, Maciel RMB, Vieira JGH. Screening for macroprolactinemia and pituitary imaging studies. Clin Endocrinol. 2002;57:327-31.

32 Fahie-Wilson MN, Soule SG. Macroprolactinaemia: contribution to hyperprolactinaemia in a district general hospital and evaluation of a screening test based on precipitation with polyethylene glycol. Ann Clin Biochem. 1997;34:252-58.

33 Vieira JGH, Tachibana TT, Obara LH, Maciel RMB. Extensive experience and validation of polyethylene glycol precipitation as a screening method for macroprolactinemia. Clin Chem. 1998;44:1758-9.

34 Leslie H, Courtney CH, Bell PM, Hadden DR, McCance DR, Ellis PK, Sheridan B, Atkinson AB. Laboratory and clinical experience in 55 patients with macroprolactinemia identified by a simple polyethylene glycol precipitation method. J Clin Endocrinol Metab. 2001;86:2743-6.

35 Vallete-Kasic S, Morange-Ramos I, Selim A, Gunz G, Morange S, Enjalbert A, Martin P-M, Jaquet P, Brue T. Macroprolactinemia revisited: a study on 106 patients. J Clin Endocrinol Metab. 2002;87:581-8. 
36 Toldy E, Locsei Z, Szabolcs I, Goth MI, Kneffel P, Szoke D, Kovacs GL. Macroprolactinemia: the consequences of a laboratory pitfall. Endocrine. $2003 ; 22: 267-73$

37 Strachan MW, Teoh WL, Don-Wauchope AC, Seth J, Stoddart M, Beckett GJ. Clinical and radiological features of patients with macroprolactinemia. Clin Endocrinol. 2003;59:339-46.

38 Gibney J, Smith TP, McKenna TJ. The Impact on Clinical Practice of Routine Screening for Macroprolactin. J Clin Endocrinol Metab. 2005;90:3927-32.

39 Smith TP, Suliman AM, Fahie-Wilson MN, McKenna TJ. Gross variability in the detection of prolactin in sera containing big big prolactin (macroprolactin) by commercial immunoassays. J Clin Endocrinol Metab. 2002;87: 5410-5.

40 Glezer A, d' Alva CB, Salgado LR, Musolino NR, Serafini P, Vieira JG, Bronstein MD. Pitfalls in pituitary diagnosis: peculiarities of three cases. Clin Endocrinol. 2002;57:135-9.

41 Larrea F, Escorza A, Valero A, Hernandez L, Cravioto MC, Diaz-Sanchez V. Heterogeneity of serum prolactin throughout the menstrual cycle and pregnancy in hyperprolactinemic women with normal ovarian function. J Clin Endocrinol Metab. $1989 ; 68: 982-7$. 
42 Fraser IS, Lun ZG, Zhou JP, Herington AC, McCarron G, Caterson I, Tan K, Markham R. Detailed assessment of big big prolactin in women with hyperprolactinemia and normal ovarian function. $J$ Clin Endocrinol Metab 1989;69:585-92.

43 Suliman AM, Smith TP, Gibney J, McKenna TJ. Frequent misdiagnosis and mismanagement of hyperprolactinemic patients before the introduction of macroprolactinemia screening: application of a new strict laboratory definition of macroprolactinemia. Clin Chem. 2003;49:1504-9.

44 Sapin R, Kertesz G. Macroprolactin detection by precipitation with protein Asepharose: a rapid screening method compared with polyethylene glycol precipitation. Clin Chem. 2003;49:502-5.

45 Leite V, Cosby H, Sobrinho LG, Fresnoza A, Santos MA, Friesen HG. Characterization of big, big prolactin in patients with hyperprolactinemia. Clin Endocrinol. 1992;37:365-72.

46 Vanbesien J, Schiettecatte J, Anckaert E, Smitz J, Velkeniers B, De Schepper J. Circulating anti-prolactin auto-antibodies must be considered in the differential diagnosis of hyperprolactinemia in adolescents. Eur J Pediatr. 2002.161:373-6.

47 De Schepper J, Schiettecatte J, Velkeniers B, Blumenfeld Z, Shteinberg M, Devroey P, Anckaert E, Smitz J, Verdood P, Hooghe R, Hooghe-Peters E. Clinical and biological characterization of macroprolactinemia with and without prolactinIgG complexes. Euro J Endocrinol. 2003;149:201-7. 
48 Guitelman M, Colombani-Vidal ME, Zylbersztein CC, Fiszlejder, Zeller M, Levalle O, Scaglia HE. Hyperprolactinemia in asymptomatic patients is related to high molecular weight posttranslational variants or glycosylated forms. Pituitary. $2002 ; 5: 255-60$.

49 Andersen, AN, Pedersen H, Djursing H, Andersen BN, Friesen HG. Bioactivity of prolactin in a woman with an excess of large molecular size prolactin, persistent hyperprolactinemia and spontaneous conception. Fertil Steril. 1982;38:625-8.

50 Cavaco B, Prazeres S, Santos MA, Sobrinho LG, Leite V. Hyperprolactinemia due to big big prolactin is differently detected by commercially available immunoassays. J Endocrinol Invest. 1999;22:203-8.

51 Leaños-Miranda A, Chavez-Rueda KA, Blanco-Favela F. Biologic activity and plasma clearance of prolactin - $\operatorname{IgG}$ complex in patients with systemic lupus erythematosus. Arthritis Rheum. 2001;44:866-75.

52 Soong YK, Ferguson KM, McGarrick G, Jeffcoate SL. Size heterogeneity of immunoreactive prolactin in hyperprolactinaemic serum. Clin Endocrinol. $1982 ; 16: 259-65$.

53 Andino NA, Bidot C, Valdes M, Machado AJ. Chromatographic pattern of circulating prolactin in ovulatory hyperprolactinemia. Fertil Steril. 1985;44:600-5. 
54 Pansini F, Bergamini CM, Malfaccini M, Cocilovo G, Linciano M, Jacobs M, Bagni B. Multiple molecular forms of prolactin during pregnancy in women. J Clin Endocrinol Metab. 1985;106:81-5.

55 Jackson RD, Wortsman J, Malarkey WB. Macroprolactinemia presenting like a pituitary tumor. Am J Med. 1985;78:346-50.

56 Malarkey WB, Jackson R, Wortsman J. Long-term assessment of patients with macroprolactinemia. Fertil Steril. 1988;50:413-8.

57 Wortsman J, Carlson HE, Malarkey WB. Macroprolactinemia as the cause of elevated serum prolactin in men. Am J Med. 1989;86:704-6.

58 Weill J, Petit S, Stuckens C, Descamps Y, Racadot A, Boersma A, Ponte C. Macroprolactinemia in a child. Arch Fr Pediatr.1990;47:595-6.

59 Corenblum B. Asymptomatic hyperprolactinemia resulting from macroprolactinemia. Fertil Steril. 1990;53:165-7.

60 Blacker C, Feinstein M.C, Avoine D, Gervasi G. Hétérogénéité de la prolactine: conséquences pratiques. Gynécologie. 1994;2:352-7.

61 Guay AT, Sabharwal P, Varma S, Malarkey W.B. Delayed diagnosis of psychological erectile dysfunction because of the presence of macroprolactinemia. J Clin Endocrinol Metab. 1996;81:2512-4. 
62 Fabre-Brue C, Roth E, Simonin G, Palix C, Martin P, Brue T. Macroprolactinemia: a cause of hyperprolactinemia in childhood.J Pediatr Endocrinol Metab. $1997 ; 10: 411-7$

63 Al-Shammari S, Yago S, Schneider W, Chavalier S, Marcovitz S. Macroprolactinemia does not always obviate the need for further investigations for hyperprolactinemia. In: Proceedings of $82^{\text {th }}$ Annual Meeting of the Endocrine Society; Toronto; 2000. p.2194.

64 Guitelman M, Oneto A, Schonfeld A, Zeller M, Fiszlejder L, Vazquez M., Aranda C. macroprolactinemia detection by polyethylele glycol precipitation (PEG): comparison of two assays In: Proceedings of $82^{\text {th }}$ Annual Meeting of the Endocrine Society; Toronto; 2000. p.2198.

65 Fideleff HL, Ruibal G, Boquete H, Pujol A, Sequera A, Sobrado P. Macroprolactinemia in childhood and adolescence: a cause of asymptomatic hyperprolactinemia. Horm Res. 2000;53:16-9.

66 Cattaneo F, Kappeler D, Müller B. Macroprolactinemia, the major unknown in the differential diagnosis of hyperprolactinemia. Swiss Med Wkly. 2001;131:122-6.

67 Diver MJ, Ewins DL, Worth RC, Bowles S, Ahlquist JA, Fahie-Wilson MN. An unusual form of big, big (macro) prolactin in a pregnant woman. Clin Chem. 2001;47:346-8. 
68 Pinto LP, Hanna FW, Evans LM, Davies JS, John R, Scanlon MF. The TSH response to domperidone reflects the biological activity of prolactin in macroprolactinaemia and hyperprolactinaemia. Clin Endocrinol. 2003;59:580-4.

69 Mounier C, Trouillas J, Claustrat B, Duthel R, Estour B. Macroprolactinemia associated with prolactin adenoma. Hum Reprod. 2003,18:853-7.

70 Yuen YP, Lai JP, Au KM, Chan AY, Mak TW. Macroprolactin- a cause of pseudohyperprolactinemia. Hong Kong Med J. 2003;9:119-21.

71 Hattori N, Ikekubo K, Nakaya Y, Kitagawa K, Inagaki C. Immunoglobulin G subclasses and prolactin (PRL) isoforms in macroprolactinemia due to anti-PRL autoantibodies. J Clin Endocrinol Metab. 2005;90:3036-44.

72 Molitch ME, Russel EJ. The pituitary "incidentaloma". Ann Intern Med. $1990 ; 112: 925-31$.

73 Reincke M, Allolio B, Saeger W, Menzel J, Winkelmann W. The 'incidentaloma' of the pituitary gland. Is neurosurgery required? JAMA. 1990;263:2772-6.

74 Aron DC, Howllet TA. Pituitary incidentalomas. Endocrinol Metab Clin North Am. 2000;29:205-21

75 Falaschi P, del Pozo E, Rocco A, Toscano V, Petrangeli E, Pompei P, Frajese G. Prolactin release in polycystic ovary. Obstet Gynecol. 1980;55:579-82. 
76 Hattori N. The frequency of macroprolactinemia in pregnant women and the heterogeneity of its etiologies. J Clin Endocrinol Metab. 1996;81:586-90.

77 Pascoe-Lira D, Duran-Reyes G, Contreras-Hernandez I, Manuel-Apolinar L, Blanco-Favela F and Leaños-Miranda A. Frequency of macroprolactinemia due to autoantibodies against prolactin in pregnant women. $J$ Clin Endocrinol Metab. 2001;86:924-9.

78 Fahie-Wilson MN. Polyethylene Glycol Precipitation as a Screening Method for Macroprolactinemia Clin Chem. 1999;45:436-7.

79 Suliman AM, Smith TP, Gibney J, McKenna TJ. Frequent misdiagnosis and mismanagement of hyperprolactinemic patients before the introduction of macroprolactinemia screening: application of a new strict laboratory definition of macroprolactinemia. Clin Chem. 2003;49:1504-9.

80 Prazeres S, Santos MA, Ferreira HG, Sobrinho LG. A practical method for the detection of macroprolactinemia using ultrafiltration. Clin Endocrinol. 2003;58:686-90.

81 Schiettecatte J, De Schepper J, Velkeniers B, Smitz J, Steirteghem AV. Rapid detection of macroprolactin in the form of prolactin-immunoglobulin $\mathrm{G}$ complexes by immunoprecipitation with anti-human IgG-agarose. Clin Chem Lab Med. 2001;39:1244-8. 
82 Amadori P, Dilberis C, Marcolla A, Pinamonti M, Menapace P, Valentini A. Identification of IgG-immunocomplex macroprolactin with an immunometric "sandwich" system: technical and clinical considerations. J Endocrinol Invest. $2004 ; 27: 1022-8$

83 Hattori N, Ikekubo K, Ishihara T, Moridera K, Hino M, Kurahachi H.. A normal ovulatory woman with hyperprolactinemia: presence of anti-prolactin autoantibody and the regulation of prolactin secretion. Acta Endocrinol. 1992;126:497-500.

84 Lee DW and Markoff E. Immunoglobulin binds prolactin in human serum. In: Proceedings of $74^{\text {th }}$ Annual Meeting of the Endocrine Society; San Antonio, Texas; 1992; p. 382.

85 Cavaco B, Leite V, Amparo Santos M, Arranhado E, Sobrinho LG. Some forms of big big prolactin behave as a complex of monomeric prolactin with an immunoglobulin $\mathrm{G}$ in patients with macroprolactinemia or prolactinoma. $\mathrm{J}$ Clin Endocrinol Metab. 1995;80:2342-6.

86 Hattori, N. and Inagaki, C. Anti-prolactin (PRL) autoantibodies cause asymptomatic hyperprolactinemia: bioassay and clearance studies of PRLimmunoglobulin G complex. J Clin Endocrinol Metab. 1997;82:3107-10.

87 Hattori N, Ishihara T, Ikekubo K, Moridera K, Hino M, Kurahachi H. Autoantibody to human prolactin in patients with idiopatic hyperprolactinemia. $J$ Clin Endocrinol Metab. 1992;75:1226-9. 
88 Hattori N, Ikekubo K Ishihara T, Moridera K, Hino M, Kurahachi H. Effects of anti-prolactin autoantibodies on serum prolactin measurements. Eur J Endocrinol. $1994 ; 130: 434-7$.

89 Tanaka T, Yano H, Umezawa S, ShishibaY, Okada K, SaitoT, Hibi I. Heterogeneity of big-big hPRL in hyperprolactinemia. Horm Metab Res. $1989 ; 21: 84-8$.

90 Heffner LJ, Gramates LS, Yuan RW. A glycosylated prolactin species is covalently bound to immunoglobulin in human amniotic fluid. Biochem Biophys Res Commun. 1989;165:299-305.

91 Farkouh NH, Packer MG, Frantz, AG. Large molecular size prolactin with reduced receptor activity in human serum: high proportion in basal state and reduction after thyrotropin-releasing hormone. J Clin Endocrinol Metab. 1979;48:1026-32.

92 Tanaka T, Shiu RP, Gout PW, Beer CT, Noble RL, Friesen HG. A new sensitive and specific bioassay for lactogenic hormones: measurement of prolactin and growth hormone in human serum. J Clin Endocrinol Metab. 1980;51:1058-63.

93 Tritos NA, Guay AT, Malarkey WB. Case report: asymptomatic 'big' hyperprolactinemia in two men with pituitary adenomas. Eur $J$ Endocrinol. 1998;138:82-5. 
94 Glezer A, Vieira, JG, Giannella-Neto D, Bronstein MD. Hyperprolactinemia and big prolactin (bPRL): clinical manifestations are related to the absolute value of monomeric prolactin (mPRL) in serum. In: Proceedings of $86^{\text {th }}$ Annual Meeting of the Endocrine Society; New Orleans; 2004; poster P2.447.

95 Garnier PE, Aubert ML, Kaplan SL, Grumbach MM. Heterogeneity of pituitary and plasma prolactin in man: decreased affinity of "Big" prolactin in a radioreceptor assay and evidence for its secretion. J Clin Endocrinol Metab.1978;47:1273-81.

96 Smirnova OV, Bogorad RL. Short forms of membrane receptors: generation and role in hormonal signal transduction. Biochemistry (Moscow). 2004;69:351-63.

97 Ali S, Pellegrini I, Kelly PA. A prolactin-dependent immune cell line (Nb2) expresses a mutant form of prolactin receptor. J Biol Chem. 1991;266:20110-7.

98 Llovera M, Pichard C, Bernichtein S, Jeay S, Touraine P, Kelly PA, Goffin V. Human prolactin (hPRL) antagonists inhibit hPRL-activated signaling pathways involved in breast cancer cell proliferation. Oncogene. 2000;19:4695-705.

99 Gambino GM, Beck-Peccoz P, Borgato S, Faglia G, Spada A, Persani L. Bioactivity and glycosylation of circulating prolactin in various physiological and pathological conditions. Pituitary. 1999;2:225-31. 
100 Rennie PS, Prior JC, Bruchovsky N and Gout PW. Bioactive forms of serum lactogens: effects of treatment of prolactinoma patients with bromocriptine. Clin Endocrinol. 1985;22:65-73.

101 Bonhoff A, Vuille JC, Gomez F, Gellersen B. Identification of macroprolactin in a patient with asymptomatic hyperprolactinemia as a stable PRL-IgG complex. Exp Clin Endocrinol Diabetes. 1995;103:252-5.

102 Clevenger CV, Furth PA, Hankinson SE, Schuler LA. The role of prolactin in mammary carcinoma. Endocr Rev. 2003;24:1-27.

103 Bernichtein S, Jeay S, Vaudry R, Kelly PA, Goffin V. New Homologous bioassays for human lactogens show that agonism or antagonism of various analogs is a function of assay sensitivity. Endocrine. 2003;20:177-90.

104 Goffin V, Kinet S, Ferrag F, Binart N, Martial JA, Kelly PA. Antagonistic properties of human prolactin analogs that show paradoxical agonistic activity in Nb2 bioasay. J Biol Chem. 1996;271:16573-79.

105 Wilson JD, Foster DW, Kronenberg HM, Larsen PR. Williams Textbook of Endocrinology. $9^{\text {th }}$ ed Philadelphia: Saunders; 1998: 419-420.

106 Feldt-Rasmussen U, Hoier-Madsen M, Bech K, Blichert-Toft M, Bliddal H, Date J, Danneskiold-Samsoe B, Hegedus L, Hippe E, Hornnes PJ, et al. Anti-thyroid peroxidase antibodies in thyroid disorders and non-thyroid autoimmune diseases. Autoimmunity. 1991;9:245-54. 
107 II Consenso Brasileiro de Fator Antinuclear em Células HEp-2. Rev Bras Reumatol. 2003;43:129-40.

108 European Society of Paediatric Gastroenterology and Nutrition. Revised criteria for diagnosis of coeliac disease. Arch Dis Child. 1990;65:2205-160.

109 Lerner A, Kumar V, Iancu TC. Immunological diagnosis of childhood coeliac disease: comparison between antigliadin, antireticulin and antiendomysial antibodies. Clin Exp Immunol. 1994;95:78-82.

110 Vitoria JC, Arrieta A, Ortiz L, Ayesta A. Antibodies to human tissue transglutaminase for the diagnosis of celiac disease. J Pediatr Gastroenterol Nutr. 2001;33:349-50.

111 Alaedini A, Green PH. Narrative review: celiac disease: understanding a complex autoimmune disorder. Ann Intern Med. 2005;142:289-98.

112 Wilson JD, Foster DW, Kronenberg HM, Larsen PR. Williams textbook of Endocrinology. $9^{\text {th }}$ ed Philadelphia: Saunders; 1998: 982-3.

113 Takeda H, Kawasaki E, Shimizu I, Konoue E, Fujiyama M, Murao S, Tanaka K, Mori $\mathrm{K}$ et al. Clinical, autoimmune, and genetic characteristics of adult-onset diabetic patients with GAD autoantibodies in Japan (Ehime Study). Diabetes Care. 2002;25:995-1001. 
114 Talwalkar JA, Lindor KD. Primary biliary cirrhosis. Lancet. 2003;362:53-61.

115 Shibata M, Onozuka Y, Morizane T, Koizumi H, Kawaguchi N, Miyakawa H, Kako M, Mitamura K. Prevalence of antimitochondrial antibody in Japanese corporate workers in Kanagawa prefecture. J Gastroenterol. 2004;39:255-9.

116 Dorman JS, Steenkiste AR, Foley TP, Strotmeyer ES, Burke JP, Kuller LH, Kwoh CK. Menopause in Type 1 Diabetic Women: Is it Premature? Diabetes. 2001;50:1857-62.

117 Hoek A, Schoemaker J, Drexhage HA. Premature ovarian failure and ovarian autoimmunity. Endocr Rev. 1997;18:107-34.

118 Forges T, Monnier-Barbarino P, Faure GC, Bene MC. Autoimmunity and antigenic targets in ovarian pathology. Hum Reprod Update. 2004;10:163-75.

119 Damewood MD, Zacur HA, Hoffman GJ, Rock JA. Circulating antiovarian antibodies in premature ovarian failure. Obstet Gynecol. 1986;68:850-4.

120 Cameron IT, O'Shea FC, Rolland JM, Hughes EG, de Kretser DM, Healy DL. Occult ovarian failure: a syndrome of infertility, regular menses, and elevated follicule-stimulating hormone concentrations. $J$ Clin Endocrinol Metab. $1988 ; 67: 1190-4$

121 Neter J, Kutner MH, Nachtsheim CJ, Wasserman W. Applied linear statistical models. 4th ed. Chicago, Illinois: Irwin; 1996. 
122 Suzuki M, Takashima T, Kadoya M et al. Height of normal pituitary gland on MNR imaging: age and sex differentiation. J Comput Assist Tomogr.1990;14:369.

123 Elster AD, Chen MY, Williams DWD, Key LL. Pituitary gland: MNR imaging of physiologic hypertrophy in adolescence. Radiology.1990;174:681-5.

124 Tsunoda A, Okuda O, Sato K. MNR height of the pituitary gland as a function of age and sex: especially physiological hypertrophy in adolescence and in climaterium. Am J Neuroradiol.1997;18:551-4.

125 Chanson P, Daujat F, Young J, Bellucci A, Kujas M, Doyon D, Schaison G. Normal pituitary hypertrophy as a frequent cause of pituitary incidentaloma: a follow-up study. J Clin Endocrinol Metab. 2001;86:3009-15.

126 Doraiswamy, P.M., Potts, J.M., Axelson, D.A. et al. MNR assessment of pituitary gland morphology in healthy volunteers: age- and gender-related differences. $\mathrm{Am}$ J Neuroradiol.1992;13:1295-9.

127 De Marinis L, Bonadonna S, Bianchi A, Maira G, Giustina A. Primary empty sella. J Clin Endocrinol Metab. 2005;90:5471-7.

128 Gertler A, Djiane J. Mechanism of ruminant placental lactogen action: molecular and in vivo studies. Mol Genet Metab. 2002;75:189-201. 